\title{
Blast Furnace Granulated Coal Injection System Demonstration Project \\ Public Design Report
}

\section{Topical Report}

March 1995

Work Performed Under Cooperative Agreement No.: DE-FC21-91MC27362

For

U.S. Department of Energy Office of Fossil Energy

Morgantown Energy Technology Center

Morgantown, West Virginia

By

Bethleham Steel Corporation Bethlehem, Pennsylvania 


\section{DISCLAIMER}

This report was prepared as an account of work sponsored by an agency of the United States Government. Neither the United States Government nor any agency thereof, nor any of their employees, makes any warranty, express or implied, or assumes any legal liability or responsibility for the accuracy, completeness, or usefulness of any information, apparatus, product, or process disclosed, or represents that its use would not infringe privately owned rights. Reference herein to any specific commercial product, process, or service by trade name, trademark, manufacturer, or otherwise does not necessarily constitute or imply its endorsement, recommendation, or favoring by the United States Government or any agency thereof. The views and opinions of authors expressed herein do not necessarily state or reflect those of the United States Government or any agency thereof.

This report has been reproduced directly from the best available copy.

Available to DOE and DOE contractors from the Office of Scientific and Technical Information, 175 Oak Ridge Turnpike, Oak Ridge, TN 37831; prices available at (615) 576-8401.

Available to the public from the National Technical Information Service, U.S. Department of Commerce, 5285 Port Royal Road, Springfield, VA 22161; phone orders accepted at (703) 487-4650. 


\section{DISCLAIMER}

Portions of this document may be illegible in electronic image products. Images are produced from the best available original document. 


\title{
Blast Furnace Granulated Coal Injection System Demonstration Project Public Design Report
}

\author{
Topical Report
}

Work Performed Under Cooperative Agreement No.: DE-FC21-91MC27362

\author{
For \\ U.S. Department of Energy \\ Office of Fossil Energy \\ Morgantown Energy Technology Center \\ P.O. Box 880 \\ Morgantown, West Virginia 26507-0880
}

\author{
By \\ Bethlehem Steel Corporation \\ Bethlehem, Pennsylvania 18016
}




\section{TABLE OF CONTENTS}

Page

No.

$1.0 \quad$ INTRODUCTION

2.0 BLAST FURNACE PROCESS DESCRIPTION

5

3.0 GRANULATED COAL INJECTION TECHNOLOGY

9

4.0 DEMONSTRATION PROJECT GOALS

5.0 BLAST FURNACE ENERGY BALANCE

6.0 SCOPE OF WORK

7.0 MAJOR EQUIPMENT LISTING

25

8.0 REFERENCES 


\section{LIST OF FIGURES}

Figure 1

Figure 2

Figure 3

Figure 4

Figure 5

Figure 6

Figure 7

Figure 8

Figure 9

Figure 10

Figure 11

Figure 12

Figure 13

Figure 14

Figure 15

Figure 16

Figure 17

Figure 18

Figure 19

Figure 20

Figure 21
The Steelmaking Process $\ldots \ldots \ldots \ldots \ldots \ldots$

The Blast Furnace Complex . . . . . . . . . . . . . . . 28

Zones In The Blast Furnace . . . . . . . . . . . . . . . . . 29

Coal Injection Test Program Parameters . . . . . . . . . . 30

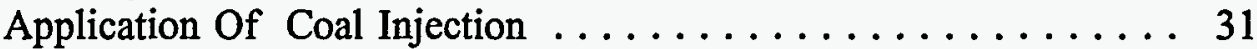

Coal Injection Test Site/Facilities $\ldots \ldots \ldots \ldots \ldots \ldots \ldots \ldots$

Coal Injection - Burns Harbor Plant . . . . . . . . . . . 33

Facility Design Parameters . . . . . . . . . . . . . 34, 35

Project Schedule . . . . . . . . . . . . . . . . 36

Management Summary Schedule . . . . . . . . . . . . . . 37-41

Bethlehem Steel BFGCI Project . . . . . . . . . . . . . . 42

Phase I \& II Organization . . . . . . . . . . . . . . . . 43

Project Construction Organization ............... 44

Phase III Organization . . . . . . . . . . . . . . . 45

Site Photograph Before Coal Injection . . . . . . . . . . . . 46

Site Photograph Before Coal Injection . . . . . . . . . . 47

Site Photograph Before Coal Injection . . . . . . . . . . 48

Plot Plan/Exterior Photograph Key . . . . . . . . . . . . . . . 49

William Mill Description . . . . . . . . . . . 50, 51

Illustration of Injection Lance at the Tuyere . . . . . . . . . . 52

Coal Injection Lance on "D" Furnace Tuyere . . . . . . . . . 53 


\section{LIST OF DRAWINGS}

Drawing No.

221959

261665

261678

$11-0928 \mathrm{~A}$

$100-51 \mathrm{~T}-01$

P21824X-00

$\mathrm{C} 2266302$

P22370X-00

$\mathrm{C} 2266300$

C2266301

200/300-59J-01

$100-25 \mathrm{Q}-00$

400/500-51V-05

130-20L-01

1320000121

21002026
Description

"D" Furnace Lines, General Arrangement

"C" Furnace Lines, General Arrangement

"C" Furnace Plate Cooler Pattern, Developed Outside View

"C" Furnace Tuyere Stock, General Arrangement

Site Plot Plan

Coal Injector Model 12/8/6-6/8, General Arrangement

Plan View Layout Of Lance \& Tuyere

Coal Injection Lance Assembly, General Arrangement

Re-Assembly Of Transit Components To Main Injector Assembly

Injection Piping Cast Elbow \& Straight Arrangement

Process Flow Diagram, Coal Storage \& Reclaim

Process Flow Diagram, Coal Preparation \& Injection

Coal Preparation \& Injection, Equipment Arrangement

Process \& Utility Building, Orientation Plan

Atlas Copco Air Compressor, General Arrangement

Under Burden Probe, General Arrangement 


\subsection{INTRODUCTION}

The public design report describes the Blast Furnace Granulated Coal Injection (BFGCI) project under construction at Bethlehem Steel Corporation's (BSC) Burns Harbor, Indiana, plant (see Figure 11). The project is receiving cost-sharing from the U.S. Department of Energy (DOE), and is being administrated by the Morgantown Energy Technology Center in accordance with the DOE Cooperative Agreement No. DE-FC21-91MC27362.

The project is the first installation in the United States for the British Steel technology using granular coal in blast furnaces. The objective is to demonstrate that granular coal is an economic and reliable fuel which can successfully be applied to large North American blast furnaces. These include: coal grind size, coal injection rate, coal source (type) and blast furnace conversion method. To achieve the program objectives, the demonstration project is divided into the following three Phases:

$\begin{array}{lll}\text { Phase I } & - & \text { Design } \\ \text { Phase II } & - & \text { Procurement \& Construction } \\ \text { Phase III } & - & \text { Operation }\end{array}$

Preliminary design (Phase I) began in 1991 with detailed design commencing in April 1993. Construction at Burns Harbor (Phase II) began August 1993. Construction is expected to be complete in the first quarter of 1995 which will be followed by a demonstration test program (Phase III).

\subsection{Program Background}

It was recognized over a hundred years ago that injecting hydrocarbons through the furnace tuyeres would decrease coke requirements. Hydrocarbon injection does alter the heat balance of the lower section of the furnace. The combustion of fuels injected at temperatures less than $200^{\circ} \mathrm{F}$ produces reducing gasses with a lower heat content than what is achieved by burning coke that has been preheated to over $2000^{\circ} \mathrm{F}$. Additionally, when the injected fuel has a high hydrogen to carbon atomic ratio, less heat is evolved in the combustion of that fuel to $\mathrm{CO}$ and $\mathrm{H}_{2}$. Natural gas has a hydrogen to carbon ratio of 4 to 1 ; the comparative values for fuel oil and bituminous coal are 1.5 to 1 and 0.75 to 1 , respectively. In order to balance the endothermic effect of tuyere injection and maintain a preset tuyere raceway adiabatic flame temperature, either the blast temperature or oxygen content can be increased or the blast humidity reduced.

The selection of coal in preference to other injectants is based on the fact that the endothermic effect of coal on the high temperature heat supply to the lower furnace is the smallest of all the injected fuels 
Coal injection into blast furnaces was the earliest form of tuyere injection with experiments beginning in France between 1840 and 1845. Paddles or primitive screw feeders were used to introduce coal into the air blast close to the tuyeres. The practice continued for several years. Besides some unsuccessful attempts at pneumatic injection of coal between 1910 and 1920 and experiments in the USSR in the early 1950's, it was not until 1959 and the early 1960's that coal injection was successfully practiced. Trials at Buffalo in the USA, Louvroil in France and Stanton in England proved that the technology was available for pneumatic injection of coal, but the economics were such that oil and natural gas became the most popular tuyere injectant fuel world-wide. The exceptions were at the Armco Steel Company in the USA and Shoudu Iron and Steel Company in China, where coal injection has been practiced from the mid1960 's until the present day.

The 1960 trials in the United Kingdom proved that the technology existed for pneumatic injection of granular coal. The trials used coal with a size consist of $100 \%$ less than $1 / 8$ inch $(3.2 \mathrm{~mm})$ and approximately $11 \%$ less than 74 micron. This size coal is easier and less expensive to produce, using a hammer mill, than is finer, pulverized coal with equipment such as a ball or roller mill pulverizers. The trials also showed that the granular coal would flow well using pneumatic conveying techniques. Injection rates of up to 360 pounds per net ton of hot metal (NTHM) were achieved using a wide variety of coals. The coal was found to reduce the need for coke on an equivalent weight basis. Coal injection was discontinued, however, because of lower oil prices.

The facility being installed by BSC will use BFGCI technology developed jointly by British Steel and Simon Macawber. ${ }^{(12)}$ The BFGCI technology was first used in 1982 on British Steel's Queen Mary blast furnace at the Scunthorpe Works. Based on the Queen Mary's performance, coal injection systems were installed on Scunthorpe's Queen Victoria, Queen Anne, and Queen Bess (operational standby) blast furnaces and on Blast Furnaces 1 and 2 at the Ravenscraig Works. Queen Victoria's system was brought on line in November 1984 and Queen Anne's in January 1985. The Ravenscraig systems were started up in 1988.

More recently, British Steel has operated BFGCI systems at both its Scunthorpe and Ravenscraig Works. Although British Steel discontinued the operation of its Ravenscraig blast furnaces in early 1993 in response to a contraction of the British steel market, BFGCI is still employed on Scunthorpe's four blast furnaces. 


\section{$1.2 \quad$ Project Schedule}

1.2.1 Project schedule milestones for coal handling. preparation and injection are as follows:

Begin Detailed Construction Engineering . . . . . . . . April 1, 1993

Begin Procurement . . . . . . . . . . . . . . . . July 1, 1993

Received State Environmental Construction Permit ... August 4, 1993

Start Construction .................... August 31, 1993

$90 \%$ Design Review . . . . . . . . . . . . . . . . January 12, 1994

$50 \%$ Construction Review ................ June 14, 1994

Begin Start Up and Commissioning Activities . . . . . . August 1994

Mechanical Completion . . . . . . . . . . . . . . . . December 1994

100\% Construction Review . . . . . . . . . . . . . . . . December 1994

Performance Testing Completion ... . . . . . . . . . . March 1995

Begin Coal Testing Demonstration Phase . . . . . . . . . May 1995

Complete Coal Testing Demonstration Phase . . . . . . J January 1998

A more detailed project management time line schedule showing engineering, procurement and construction activities for the major areas is shown in Figures $9 \& 10$.

1.2.2 Project schedule construction milestones for " $\mathrm{C}$ " blast furnace reline including furnace cooling improvements, installation of furnace instrumentation (in-burden probe, tuyere pressure, and bustle pipe temperature), and stockhouse modifications:

Begin Construction .................... August 1, 1994

Compete Construction . . . . . . . . . . . . November 2, 1994

\subsection{Project Cost}

The estimated project cost is summarized into Phases as follows:

Phase I (Design) . . . . . . . . \$5,190,000

Phase II (Procure \& Construct) . . \$ \$133,850,000

Phase III (Operation) $\ldots \ldots \ldots \ldots \$ 51,610,000$

Total Project Cost . . . . . . . \$190,650,000

The total project cost is shared between Bethlehem Steel and the DOE as follows:

DOE Share $(16.4 \%) \ldots \ldots \ldots \ldots \$ 31,259,530$

Bethlehem Steel Share (83.6\%) .. \$159,390,470 


\section{$1.4 \quad$ Organization}

\subsubsection{Phase I \& II}

BSC is the owner and operator of the facility and the program manager as defined under the cooperative agreement with the DOE. As the program manager, BSC, placed a turnkey contract with Fluor Daniel, Inc., Greenville, SC, for engineering, procurement, construction, training, commissioning, and performance testing of the raw coal handling, coal preparation and coal injection systems. Fluor Daniel placed a subcontract with ATSI/Simon Macawber, Amherst, NY, for the design and supply of equipment associated with the injection system. See Figures 12 and 13 for a schematic organization chart.

The injection facility involves the storage and handling of dry, granular coal after it leaves the coal preparation facility until it is injected into the blast furnace. The injection facility technology involving the handling and control of granular coal through the injection facility is provided by a joint venture company, ATSI - Simon Macawber (ATSI/SM), in Amherst, NY. ATSI/SM has the license to market the technology in North America. ATSI/SM obtained the North American license from Simon Macawber, United Kingdom, who has the license to market the injection technology world-wide. The injection technology (presented in Section 3.0) includes the design of the injection facility components and supply of the proprietary injector hardware from Simon Macawber, Doncaster, United Kingdom. ATSI/SM will also furnish training and start up services as part of their supply.

BSC has contracted with British Steel, PLC, for the supply of blast furnace operation "know how" and start up technical assistance. This includes operational, maintenance and safety instruction manuals, prestart up training for BSC operators and maintenance personnel at British Steel's Scunthorpe Works, facility site start up services at Burns Harbor, and consulting services for a two year period after commissioning.

Furnace improvement projects (discussed in Section 6.0) necessary to support coal injection were subcontracted by BSC to various design firms. Construction of these facilities was done either by Fluor Daniel or by Davy Songer, the contractor hired to perform the " $\mathrm{C}$ " blast furnace reline in 1994. 


\subsubsection{Phase III}

The organization associated with the testing and demonstration phase of the project is shown in Figure 14.

\subsection{Site Selection}

The key factor influencing the location of the process equipment is to minimize the distance between the injectors and the blast furnace. The total energy required to generate compressed air to transport the coal to the furnaces and the constant operating and maintenance problems associated with wearing and plugging of the injection lines dictate that the injection lines be as short as possible. The closest point of equal distance to both blast furnaces was the site occupied by an old warehouse and maintenance building (see Figures $15 \& 16$ ). The site selected for the coal storage pile was the south end of the ore storage yard which is located between the existing railroad car unloading station and the new process building (see Figure 17). This location minimized the length of new conveyors required.

\subsection{BLAST FURNACE PROCESS DESCRIPTION}

\section{$2.1 \quad$ General}

Blast furnaces produce hot metal, which is used in the basic oxygen furnaces for refinement into various grades of steel. Major ingredients in the production of hot metal are iron ore, coke and limestone. As shown in Figure 1, the iron making blast furnace is at the heart of the integrated steelmaking process.

The principal purpose of a blast furnace is to smelt iron ores to produce pig iron. Other raw materials consumed in the smelting process are (1) coke, which is the principal fuel and reducing agent; (2) limestone and dolomite, which act to flux the earthy constituents in the iron-bearing materials and coke ash to form a slag; and (3) hot air and oxygen, which are needed to support combustion of the coke (Figure 2). Supplemental fuels such as heavy oils and tar have been used in the past to replace some of the coke. Currently natural gas is being used. Residence time for the solid materials in the blast furnace is typically 6-8 hours.

The blast furnace produces a slag which is skimmed from the molten pig iron. The slag contains most of the impurities associated with the iron-making process. A normal composition of the slag is 38 percent calcium oxide ( $\mathrm{CaO})$, 12 percent magnesium oxide $(\mathrm{MgO}), 37$ percent silica $\left(\mathrm{SiO}_{2}\right), 10$ percent alumina $\left(\mathrm{Al}_{2} \mathrm{O}_{3}\right)$, a few percent manganous oxide $(\mathrm{MnO})$, and 1 to 2 percent 
sulfur (S). The slag can be utilized as road fill, as a cement additive, or in other commercial applications. Thus, sulfur introduced by the direct injection of coal becomes a constituent of a useful by-product.

A large volume of low-grade gas is produced during the smelting process. This gas has a heating value in the range of 80 to 90 Btu per cubic foot. On leaving the furnace, this gas is cleaned of dust particles using conventional gas cleaning equipment. It is then used elsewhere in the plant for such purposes as preheating combustion air or for facility heating.

The design of a modern blast furnace contour (Figure 3) can be described as follows. From the top, or throat section, where the solid materials are placed on the bed to form the furnace stockline, the furnace widens at a very low angle to allow the bed to expand slightly as it descends. There is a cylindrical section, or belly, approximately two-thirds of the distance down the furnace, which joins the upper tapered section to the lower tapered section, or bosh. The bosh is a short, tapered section which restricts the cross-section to compensate for the sintering and fusion of the bed as its temperature rises. The barrel-shaped section below the bosh contains the tuyeres and the hearth area.

Preheated combustion air, which may be enriched with oxygen, is blown into the blast furnace through the tuyeres. The zone within the furnace that is swept by the hot blast is called the raceway, The size of the raceway is dependent upon the hot blast temperature and pressure, the properties of the feedstock that has descended from the top of the furnace, and the physical characteristics of the blast furnace. Lowering of the raceway temperature, which can occur when large quantities of natural gas are used as an injected supplemental fuel, reduces blast furnace production rates. In the case of Burns Harbor, the hot air blast is enriched with expensive oxygen to restore the raceway temperature. As previously mentioned coal has a lower hydrogen content than gas or oil. Therefore, when coal is injected as a supplemental fuel it will not cause as severe a reduction in raceway temperatures.

\subsection{The Burns Harbor Blast Furnaces}

The Burns Harbor " $\mathrm{C}$ " and " $\mathrm{D}$ " blast furnaces are considered to be large high production furnaces rated at 7000 tons per day of hot metal (see drawings 221959, 261665 and Figure 6). Each furnace is constructed of a steel shell with internal refractory lining. The furnace weight is supported by a concrete foundation pad beneath the hearth and by 8 columns which tie into the steel shell at the intersection of the bosh and stack about $1 / 3$ the distance up the furnace. The furnace has two tap holes in the hearth which are used alternately to remove hot metal and slag from the furnace, and 28 tuyeres which supply pre-heated $\left(2000^{\circ} \mathrm{F}\right)$ combustion air through the furnace shell and refractory 
lining into the furnace interior (raceway). Raw materials are charged into the furnace in batches through a two-bell charging system at the top of the furnace. Blast furnace gas generated during the smelting operation is vented though offtake pipes at the top of the furnace. The interior refractory lining used to contain the high temperature process (in excess of $3000^{\circ} \mathrm{F}$ in the raceway zone) is a combination of fireclay, high alumina, and silicon carbide in the stack section, carbon and silicon carbide in the bosh section, and carbon in the hearth area. Water and air are used to cool the refractory and prolong its life. The stack section of " $D$ " furnace contains about 24 rows of water cooled plates, each row with 32 to 40 cooling plates, a total of about 776 cooler plates for the furnace. The bosh normally cooled by spraying water on the outside of the steel shell plate will not be sufficient for the additional heat generated by coal injection. In 1991 the "D" furnace bosh was converted to stave cooling (a water cooled member between the steel shell and refractory lining). " $\mathrm{C}$ " furnace was also converted to stave cooling during its reline in 1994. " $\mathrm{C}$ " furnace, being the demonstration furnace and subjected to higher levels of coal injection than " $\mathrm{D}$ " furnace, will require additional plate cooling in the stack area which will include 40 rows of coolers for a total of about 1316 cooler plates. The increased cooling plate design, commonly referred to as high density cooling (see drawing 261678), was also installed during the reline of "C" blast furnace completed November 2, 1994. The hearth bottom is cooled with a forced air system and the hearth sides are cooled with water cooling members on the outside of the steel shell plate. The additional cooling members on the bosh and stack areas of " $C$ " furnace necessitated improvements to the cooling water supply and drain systems and include facilities to monitor the thermodynamics of the improved cooling system.

Both furnaces have been using natural gas as a supplemental fuel to offset coke. A natural gas circle pipe is located beneath the bustle pipe. A pipe connection and valve off of the circle pipe is located in the vicinity of each tuyere. A section of hard pipe is run from the valve followed by a flexible hose which connects to the gas injection lance (see drawing 11-0928A). The gas injection lance is installed through a hole and threaded connection on the lower section of the tuyere stock (blow pipe) such that the injection lance tip is precisely located within the tuyere. To convert the furnace from gas to coal, the gas injection lance is removed, an adapter fitting in screwed into the threaded lance connection in the blow pipe, the coal injection lance assembly is connected to the adapter and the lance inserted into the blow pipe. The natural gas circle pipe is left in place so that natural gas could be used on the furnace if for some reason coal would not be available for an extended period of time. Conversion of the furnace from coal back to natural gas is a relatively easy matter and can be done while the furnace is operating. This is accomplished by closing the valve on the end of the lance and replacing the coal flexible hose with the gas flexible hose and re-opening the valve. See Figures 20 and 21. 
"C" and "D" blast furnaces are fed raw materials by a conveyor belt system from a stockhouse dedicated to each furnace (see plot plan 100-51T-01). The stockhouses contain storage bins. feeders, screens, weigh hoppers, etc. for iron ore (pellets), sinter (iron fines and flux materials), and coke. The "C" furnace stockhouse is controlled to fill the conveyor belt feeding the furnace so the furnace receives the raw materials in the proper proportion and sequence. Coal injection will replace natural gas in its entirety and coke in varying amounts depending on the level of coal injection. As coke is replaced with injected coal the ratio of iron to coke charged into the furnace increases. This equates to a larger batch of ore for each batch of coke.

On "D" furnace the level on coal injection will be equal to or slightly higher than the equivalent amount of natural gas injection resulting in minimal impact on the operation of the "D" stockhouse. However, on "C" furnace, the demonstration furnace, the stockhouse did not have enough capacity to increase the ore batch to the size to accommodate coal injection levels up to 400\#. Stockhouse modifications necessary to support coal injection levels required during the demonstration phase were completed during the " $\mathrm{C}$ " blast furnace reline. The stockhouse work is described in more detail in Section 6.5.

\subsection{Blast Furnace Reline}

Blast furnace refractory needs to be replaced on a regular basis as normal wear gradually reduces the refractory thickness to the point where continued operation becomes risky. A furnace outage is required to accomplish the reline activities which will last anywhere from 30 to 100 days depending on the scope of work. The operating time between outages is typically years but can vary greatly depending on the quality of refractory, the amount and type of refractory cooling in use and the operating characteristics of the furnace during its campaign. With improvements in refractory quality and cooling, furnace campaign life has tended to increase in recent years. "D" furnace which was relined in 1991 is scheduled for its next reline in 1998 (a 7 year campaign), while " $C$ " furnace which was relined in 1994 is scheduled for another reline in 2006 (a 12 year campaign), with a bosh and lower stack repair in year 8 or 9 depending on the impact of coal injection.

Repair to peripheral facilities are also done during furnace relines since these facilities cannot be taken out of service unless the furnace is shut down. These areas include: the gas cleaning system, stoves, hot blast system, cold blast system, stockhouse, cooling water systems and furnace top changing equipment. 


\subsection{GRANULATED COAL INJECTION TECHNOLOGY}

The BFG̣CI technology involves the use of ordinary bituminous coals that are typically used by the power generation industry as opposed to premium cost metallurgical coals typically used by the steel industry to produce coke. The preparation of the coal (grinding and drying) can be done with a wide variety of commercially supplied mill systems that are also typically used by the power generation industry. In fact, a very simple, low cost hammer mill design would be sufficient to produce the granular coal specification developed by British Steel. However, the need to demonstrate both granular and pulverized coal sizes prevented a hammer mill from being used for this facility.

The granular coal injection technology (storage, metering and transporting the granular coal into the furnace) was supplied by ATSI/ SM. The granular technology surrounds the design of the injection system which includes the product coal silos, weigh bins, distribution bins, injectors, injection lines, injection lances and control system. The technology also includes the supply of injectors, injection piping system components, and injection lances by Simon Macawber.

The 56 injectors, 28 per furnace, model 12/8/6-6/8, are shown on drawings P21824X00 and $\mathrm{C} 2266300$. The primary function of the injector is to precisely control the amount of coal injected into each tuyere of the furnace. This is accomplished by the major components of the injector assembly which include from top to bottom - the lock hopper, the injector vessel, the motor and screw feeder, and the conveying pipe connection. The lockhopper is necessary to convey the coal from the distribution bin above the injector at atmospheric pressure to the injector vessel at a pressure in excess of $100 \mathrm{psig}$. The upper dome valve above the lockhopper opens allowing coal from the distribution bin to gravity flow into the lockhopper. The upper dome valve closes allowing the lockhopper to be brought up to high pressure. The dome valve beneath the lockhopper opens allowing the coal to gravity flow into the high pressure injection hopper. When the lockhopper is empty the lower dome valve closes. The high pressure air inside the lockhopper is vented through the lockhopper filter to the atmosphere reducing the pressure inside the lockhopper to atmospheric. The lockhopper is now ready for another cycle. The coal which dropped into the injection vessel falls on a screw feeder which is driven by a variable speed motor. The screw carries the coal to the injection pipe where it combines with a flow of conveying air and is carried through the injection pipe to the furnace. The speed of the screw feeder is precisely controlled to maintain a desired amount of coal into each tuyere of the furnace. The above described sequence of operation is controlled automatically by the computer based on the desired amount of coal to be delivered to the furnace. The injectors can be controlled individually or as a group depending on the desire of the blast furnace operator. The injectors have demonstrated a turn-down ratio in excess of $10: 1$ and availability in excess of $99 \%$ at British Steel facilities. 
A typical injection pipe elbow and following short straight section (shown on drawing C2266301) are cast from a nickel hardened cast iron. The injection pipe is ordinary schedule 80 pipe sized to maintain a velocity of $10-20$ meters/sec. If the velocity is too low, coal will settle out and cause blockages. If the velocity is to high, excess wear will occur.

The coal injection lance assembly is shown on drawings P22370X-00 and C2266302. The unique feature of the lance assembly is its ability to accommodate a change of the lance while the furnace is operating. A lance change can be done in about 15 minutes. The lance is constructed of ordinary steel pipe with an inconnel tip where it is exposed to the hot blast atmosphere. The lance is shown pictorially in Figure 20. A photograph of the injection lance on a " $D$ " furnace tuyere is shown in Figure 21.

Operating the blast furnace with injected granular coal (blast furnace operating knowhow) is supplied by British Steel, PLC. This technology includes: 1) review of existing blast furnace facilities, operating and maintenance practices, 2) written operating, safety and maintenance manuals associated with BFGCI, 3) operator and maintenance training at British Steel's Scunthorpe Works, 4) on-site commissioning assistance, and 5) post commissioning technical assistance for a two year period.

A schematic showing the application of the technology to the blast furnace is given on Figure 5. Some of the advantages of this technology include:

- The injection system has been used overseas with granular coal as well as with pulverized coal. No other system has been used over this range of coal sizes.

- The capital costs for granular coal systems are potentially less than for pulverized.

- Granular coal is easier to handle in pneumatic conveying systems. Granular coals are not as likely to stick to conveying pipes if moisture is not adequately maintained.

- Research tests conducted by British Steel indicate that granular coal is more easily maintained in the blast furnace raceway (combustion zone) and is less likely to pass through the coke bed. Coke requirement ratios obtained by British Steel have not been bettered in any worldwide installation.

- Granular coal's coarseness delays gas evolution and temperature rise associated with coal combustion in the raceway. Consequently, it is less likely to generate high temperatures and gas flows at the furnace walls which result in high heat losses, more rapid refractory wear and poorer utilization of reducing gases.

- System availability has exceeded $99 \%$ during the years of operation at British Steel.

- High injection levels require accurate variable control of injection rates, both for individual tuyeres and the complete system. The unique variable speed, positive displacement Simon Macawber injectors provide superior flow control and measurement over other coal injection systems. 


\subsection{DEMONSTRATION PROJECT GOALS}

\subsection{Coal Particle Size}

Operation of the BFGCI system will be demonstrated on "C" blast furnace for both granular and pulverized coal particle sizes. However, the primary focus of the project will be on the granular coal size where potential advantages include reduced capital cost for grinding facilities and reduced energy consumption for the grinding process. The project will show the effects of coal particle size on blast furnace performance. Results will be of value in the planning of future domestic commercial installations, since there are no other blast furnaces in the U.S. using granular coal injection.

\subsection{Coal Injection Rate}

The plan for the project includes demonstrating and evaluating sustained operation of the technology over a range of coal injection rates up to 400 pounds of coal per NTHM for both granular and pulverized coal sizes on " $C$ " blast furnace.

\subsection{Coal Source}

This project will generate comparative data on coals from four separate mines that provide coal with distinctly different chemical and physical characteristics. The plan includes using an Eastern bituminous coal with low ash and low sulfur content; an Eastern bituminous coal with moderate ash and higher sulfur content; a Midwestern bituminous coal with higher inherent moisture but with low ash and moderate-to-high sulfur content; and a Western subbituminous coal with high inherent moisture but with low ash and sulfur content.

\subsection{Blast Furnace Conversion Method}

The two blast furnaces will be converted to coal injection by the first quarter of 1995. Blast furnace " $C$ " was converted while the furnace was down for its reline during the third and fourth quarter of 1994. Blast furnace " $D$ " was converted while it was operating. This "on-the-fly" conversion of "D" furnace was accomplished during the March to November, 1994, period while the furnace was operating and during scheduled blast furnace maintenance outages which normally occur once a month and last about 8 hours.

See Figure 4 for a summary of the test program parameters. 


\subsection{BLAST FURNACE ENERGY BALANCE}

Granular coal will replace natural gas and a portion of the coke in the blast furnace. Bethlehem Steel utilizes an empirical computer model to analyze the effect this will have on the blast furnace process. The model, code name BALWAX, is a heat and material balance model for the blast furnace and associated processes. Bethlehem utilized the model to determine the economics associated with the granular coal injection project. Based on the model output and project capital cost data, Bethlehem determined that granular coal injection would result in an attractive economic return to the Burns Harbor Division.

For a given case the key inputs to the BALWAX model are:

a. Costs, chemical composition, energy content, moisture level of ores, fluxes, coals and other fuels.

b. The overall hot metal production requirement, coke oven capacity and utilization of purchased coke.

c. The availability of all coals, ores, revert materials, fluxes except for the "swing" material required to achieve specified product demand for each process. Typically these swing materials could be: one coal type for the coke ovens, one sintering ore fines type for the sinter plant, one pellet type, and purchased coke for the blast furnace.

d. For each blast furnace, the production, the blast conditions, slag acid to base ratio, hot metal silicon, sulfur and temperature, burden composition and coke rate. The coke rate assumption is checked in the model via empirical coke rate coefficients. Either the production rate or the wind rate may be specified and the other calculated.

For each case the key outputs from the BALWAX model are:

a. For each blast furnace, a two stage mass and energy balance is produced which indicates the quantities, chemical composition and temperature of the furnace outputs (hot metal, slag and top gas) and completes the specification of required inputs not already specified: ferrous materials, purchased coke, fluxes, and wind rate.

b. Also, for the blast furnace, detailed heat balances and elemental material balances and analysis of coke rate changes based on coke rate coefficients.

c. For the sinter plant, an overall material balance presents the required ore fines and additional flux needed to satisfy sinter production and basicity to acidity ratio requirements.

d. The coke plant balances indicate coal, coke and by product streams.

e. The quantities, unit costs, and total costs and energy requirements for each process and for overall process are presented on a summary sheet. 
The injection of coal into the Burns Harbor plant " $\mathrm{C}$ " and " $\mathrm{D}$ " blast furnaces required the installation of major new facilities and modifications to some existing facilities. The scope of work for this project can be categorized into the following areas -- raw coal supply, raw coal reclaim, coal preparation, coal injection, peripheral facilities and environmental control facilities. The facilities are shown schematically on Figure 7. A plot plan key location is shown on Figure 18 and site plot plan drawing 100-51T-01.

\subsection{RAW COAL SUPPLY}

Raw coal is shipped from the coal mine to the Burns Harbor plant by rail in unit trains of 100 cars, each car carrying $80-100$ tons of coal. The coal is unloaded using the existing car dumper, which is part of the blast furnace material handling system. The car dumper, used to unload coal for the coke ovens and imported coke for the blast furnace, is now required to unload a little over 1 unit train per week for coal injection at planned levels of coal injection of $180 \#$ on " $\mathrm{D}$ " furnace and $280 \#$ on "C" furnace. Adequate time is available on the car dumper for this level of operation and future levels of coal injection of $400 \#$ on both "C" and "D" furnace.

Previously coal from the car dumper conveyed to the south on \#7 conveyor which discharged on to \#68 conveyor directing coal to the coke ovens or coke to the blast furnace stockhouse material handling system. As part of the coal injection project, the tail end of $\# 7$ conveyor has been elevated to permit the installation of a diverter gate to allow coal to flow from \#7 conveyor to either \#68 conveyor or the new transfer conveyor (S8) which supplies raw coal to the blast furnace.

The new 60" wide transfer conveyor (S8) has been installed from a new \#7 conveyor junction tower (620-TX-001) and runs east about 186' and 24' $-40^{\prime}$ above ground to a new junction tower (200-TX-002). In junction tower (200TX-002) coal is transferred to a new $60^{\prime \prime}$ wide stockpile conveyor (S9), running

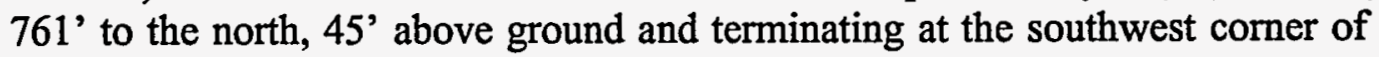
the ore (pellet) storage area.

Approximately $500^{\prime}$ of the south end of the ore storage pile was reclaimed by blast furnace operations prior to the start of construction on August 30, 1993, to make space available for the new raw coal storage pile. The coal pile approximately $120^{\prime}$ wide $\times 350^{\prime}$ long $\times 60^{\prime}$ high is formed by a $200^{\prime}$ long radial belt stacker ( $\mathrm{S} 10$ ) capable of building a 28,000 ton coal storage pile (10 day supply at a $400 \#$ injection rate on each furnace). 
The new material handling system from the existing car dumper to the coal storage pile will be sized at 2,300 tons per hour to match the unloading capacity of the car dumper.

A 5' high sheet pile separation wall has been installed between the ore and coal piles.

\section{Reference Drawing: 200/300-59J-01 Process Flow}

\subsection{RAW COAL RECLAIM}

A raw coal reclaim tunnel has been installed underground beneath the coal storage pile. The inside of the concrete tunnel is about $12^{\prime}$ wide $\times 16^{\prime}$ high and contains four coal reclaim hoppers in the top of tunnel. The reclaim hoppers beneath the coal pile feed a 36 " wide reclaim conveyor ( $\mathrm{C} 100)$ located in the tunnel. The 400' long reclaim conveyor transports the coal at a rate of 400 tons per hour above ground to the south of the coal storage pile. A magnetic separator is located at the tail end of the conveyor to remove tramp ferrous metals. At junction tower (300-TX-001) the conveyor discharges into a grizzly bar screen to separate coal over 2 " size from the main stream of minus $2 "$ coal. The oversize coal passes through an American Pulverizer hammer mill type precrusher discharging minus 2 " coal. The coal from the precrusher joins the coal which passed through the grizzly bar screen and is conveyed from ground level by the 36 " wide plant feed conveyor (C101) to the top of the coal preparation process building.

Reclaiming coal from the storage pile to the reclaim conveyor is done by gravity through four hoppers with slide gates to control flow. It is necessary for periodic operation of a bulldozer on the pile to push coal from the "dead" storage areas to the "live" storage areas above the reclaim hoppers.

Reference Drawing: 200/300-59J-01 Process Flow

\subsection{COAL PREPARATION}

The plant feed conveyor (C101), capable of transporting 400 tons per hour, terminates about 103' above ground level at the top of the coal preparation section of the Process Building. Coal is transferred to a distribution conveyor (C102), which directs into either of two raw coal storage bins (400-BN-001 \& 002). The steel raw coal bins are cylindrical in shape with a conical shaped bottom. They are completely enclosed with a vent filter on top. Each bin holds 240 tons of coal, a four hour capacity at maximum injection levels of 400 pounds of coal per net ton of hot metal (\#/NTHM). Air cannons are located in the conical section to loosen the coal to assure that mass flow is 
attained through the silo. Nitrogen is available at each of the storage bins to maintain an inert atmosphere and automatically flood the bin interior in the event a coal fire is detected.

From the bins coal flows into a feeder (400-CV-007 \& -008), which controls the flow of coal to the Williams DF90 coal preparation mill (400-PV-001 \& 002 ) driven by a $500 \mathrm{HP}$ variable speed motor (see Figure 19). The mill contains 6 - roller journals that rotate about a vertical axis against the inside diameter of the 90 " bowl ring. The faster the journals rotate the greater the crushing force against the bowl ring. Therefore, the coal particle size is largely controlled by the mill rotational speed. Heated air from a natural gas fired burner is mixed with recycled air from the downstream side of the process and is swept through the mill grinding chamber. The air lifts the ground coal from the mill vertically through a classifier where oversized particles are removed and circulated back to the mill for further grinding. It should be noted that a 74 " classifier is required to make granular coal and an $85^{\prime \prime}$ unit is required to produce pulverized coal. The proper sized particles are transported from the classifier in a 52" diameter duct. While in the grinding mill and during the transport phase the coal is being dried to $1 \%-1.5 \%$ surface moisture. The drying gas chemistry is controlled to maintain oxygen levels below combustible levels.

The coal and gas mixture pass through a cyclone separator (400-CY-001 \& 002 ) where about $95 \%$ of the coal fines are separated from the gas. More than half of the gas from the cyclone is circulated back to the coal grinding mill, and the remainder is sent to the mill bag filter (400-BH-001 \& -002) where a portion of the gas is vented to the atmosphere to get rid of the moisture removed from the coal.

There are two Williams Patent Crusher grinding/drying mill systems. Each system produces 30 tons per hour of pulverized coal (70\% minus 200 mesh) or 60 tons per hour of granular coal (100\% minus 4 mesh). It will be possible to install a third grinding mill system in the future to enable higher injection rates to be more reliably achieved.

The coal fines removed in the cyclone flow by gravity to the product coal screens (400-CF-001 \& -002). The product coal screens remove debris (plastic, fiberglass, straw, rubber, etc.) which has passed through the grinding mill before the coal enters the injection plant. Coal passing through the screens is conveyed by screw feeders into a four-way splitter hopper. Each of the four legs discharges into a screw feeder that sends coal to one of four product coal silos. Each product coal silo holds 180 tons.

Coal fines removed in the mill bag filter are dense phase, air conveyed directly 
to the four-way splitter.

\author{
Reference Drawing: 100-25Q-00 Process Flow \\ 400/500-51V-05 General Arrangement/Sections
}

\title{
$6.4 \quad$ COAL INJECTION
}

The coal injection facility consists of four parallel in-line series of equipment, two for each blast furnace. Each series of equipment begins with the screw feeder to the product coal silo and ends with the coal injection lance at the blast furnace tuyere.

Coal from the two product coal screens is directed to four screw feeders (400CV-001 through 004), each feeds a product coal storage silo (500-SL-001 through 004). The steel silo is cylindrically shaped with a conical bottom and is sized to store 180 tons. This amount is sufficient to maintain coal injection for six hours at $400 \#$ injection rate without an in-flow of coal from the coal preparation plant. The silo is totally enclosed and has a vent filter on top. Nitrogen is fed into various levels of the silo to help fluidize the coal to insure mass flow and to maintain an internal atmosphere free of oxygen. This type of system is referred to as an "oxygen exclusion" design. Coal flows by gravity from the silo to the enclosed weigh bin (500-BN-001 through 004) in two ton batches. The flow is controlled by a rotary valve. The two ton batches are dumped from the weigh hopper to the distribution bin (500-BN-005 through 008).

The circular shaped, totally enclosed steel distribution bin serves as a coal holding area for the individual two ton batches. A vent filter is located at the top of the distribution bin. The distribution bin contains 14 conical shaped pant legs which are fluidized with nitrogen to insure continuous flow. Each pant leg feeds an injector (630-FE-009 through 064). The injector contains a lockhopper, which automatically allows small batches of coal to sequentially pass from the near atmospheric pressure of the distribution bin to the $100 \mathrm{psi}$ environment of the injector vessel. A screw feeder at the bottom of the injector meters coal from the injector vessel to the injection line. At this point the coal is mixed with high pressure air and is carried through approximately $600^{\prime}$ of 1-1/4" and 1-1/2" pipe to an injection lance mounted on each of the blast furnace 28 tuyere blow pipes. At the injection lance tip coal is mixed with hot blast air and is carried into the blast furnace raceway as a combustible fuel. The fourteen injectors at the bottom of the distribution bin feed alternate furnace tuyeres.

As previously noted, two parallel series of equipment each containing one product coal silo, one weigh bin, one distribution bin, 14 injectors, 14 injection 
lines and 14 injection lances are required to inject coal into each furnace.

$\begin{array}{lll}\text { Reference Drawing: } & 100-25 Q-00 & \text { Process Flow } \\ 400 / 500-51 \text { V-05 } & \text { General Arrangement/Sections }\end{array}$

\subsection{PERIPHERAL FACILITIES}

\subsubsection{Process Building}

The above mentioned coal preparation system (grinding/drying mill) and injection plant system equipment is housed in a Process Building located to the west of 12th Street on a site occupied by an old warehouse and maintenance building.

The coal preparation section occupies a footprint of $56^{\prime} \times 76^{\prime}(4,256$ $\mathrm{ft}^{2}$ ) and has two roof levels at about 45' and 105' above grade. The lower exterior walls are precast concrete panels and the upper portion is steel sided. This section of the building is heated and ventilated.

The injection section occupies a footprint of $66^{\prime} \times 78^{\prime}\left(5,148 \mathrm{ft}^{2}\right)$ and is about 156' high. The lower exterior walls are precast concrete panels and the upper level is steel sided with the east side having stainless steel siding to resist the corrosive gases emitted from the nearby blast furnace slag pits. This portion of the building is heated and ventilated.

The Process Building contains a central vacuum system for use in cleaning up coal dust that will accumulate on equipment and access platforms. The above grade work platforms in the Process Building are serviced by an elevator and stair tower.

\section{Reference Drawing: 130-20L-01 Orientation Plan}

\subsubsection{Utilities Building}

The Utilities Building occupies a footprint of $120^{\prime} \times 120^{\prime}\left(14,400 \mathrm{ft}^{2}\right)$ is about $18^{\prime}$ high. It has precast concrete exterior walls and is partitioned to provide space for: motor controls, electrical switchgear, injection air compressors, HVAC, spare parts, control room, and office. The entire space is heated and ventilated. Air conditioning is provided for the control room and office.

Reference Drawing: 130-20L-01 Orientation Plan 


\subsubsection{Air Compressors}

Compressed air is generated at approximately 140 psi and 9500 SCFM is required to transport coal through injection lines to " $\mathrm{C}$ " and "D" blast furnaces and for miscellaneous uses. Approximately $96 \%$ of the air is required by the injection lines. Two $3500 \mathrm{HP}$ air compressors are required for this purpose (one of the two is a standby unit) The compressors are located in the Utilities Building. Each of the two air compressor systems consists of: three-stage centrifugal compressor, intercoolers, aftercooler, air receiver, prefilter, dryer, afterfilter.

Reference Drawing: 1320000121 General Arrangement

\subsubsection{Process Control}

The control system is designed to provide a steady, accurate, and reliable supply of coal to the blast furnaces. The level of automation will permit: 1) raw coal supply (car dumper to coal pile) to be controlled from the existing material handling system control station in J-5 Junction House, 2) raw coal reclaim and coal preparation to be controlled from the control room in the Utility Building, and 3) coal injection rate to be controlled by the blast furnace operator in the existing " $\mathrm{C}$ " and "D" furnace control room.

The automation is accomplished through the use of appropriate Level 0 devices (instruments, transmitters, switches, etc.) that provide input and output for PLC's (programmable logic controllers), Level 1 devices to control equipment functions, and Level 1.5 devices-MMI's (man machine interfaces) to provide operator access to the control system.

All Level 0, Level 1, and Level 1.5 devices are interconnected through the use of hard wires, data highways and fiber optics to provide an integrated control system. The control system for coal supply, coal reclaim, coal preparation and coal injection is linked to the blast furnace Level 2 control system (described in Section 6.5.10) to provide data for operation of the blast furnaces and for data retrieval and archival purposes.

\subsubsection{Warehouse/Maintenance Building}

The old Blast Furnace Warehouse and Maintenance Building was removed to make space for the coal preparation and injection facility. A new 9,000 $\mathrm{ft}^{2}\left(50^{\prime} \times 180^{\prime} \times 16^{\prime}\right.$ high) pre-engineered steel sided warehouse and a new 7,000 $\mathrm{ft}^{2}\left(50^{\prime} \times 140^{\prime} \times 20^{\prime}\right.$ high) pre-engineered 
steel sided maintenance building was installed about 1,000 feet to the south of the Process Building and a few hundred feet to the west of the blast furnace office. The warehouse has two truck access doors and is used primarily to store refractories used on the blast furnace cast floor. The maintenance building has two truck access doors and a 10 ton overhead crane and is used to perform equipment repair and maintenance activities. Both buildings are heated and ventilated.

\subsubsection{Dust Control}

Two small buildings have been erected, one near the car dumper, the other near the coal precrusher, to house a chemical tank, mixing facilities, transfer pumps and transfer pipe lines to supply a liquid coal dust suppressant to appropriate coal conveying transfer points to minimize fugitive coal dust emissions.

\subsubsection{Fire Protection}

Fire prevention methods employed in coal preparation and coal injection facilities utilize nitrogen blankets and maintain oxygen content below levels necessary to support combustion.

Equipment handling coal and occupied areas near coal handling facilities are protected with suitable fire protection controls. The existing plant fire water system pressure is inadequate to reach the upper levels of the Process Building. A small building was installed to house a diesel engine operated fire pump to serve the facilities being installed on this project. Fire water pipelines have been installed from the pump house to all of the conveyors and the Process Building. Automatic fire detection equipment was installed to activate the system in the event of a fire. The fire protection system is connected to the plant fire alarm system so that plant fire personnel can quickly respond to fire.

\subsubsection{Utilities}

\subsubsection{Electrical}

$13.8 \mathrm{KV}$ power was supplied from the K-6 electrical tower, east of J-5 Junction House, to operate the approximately $6,500 \mathrm{KW}$ required by the new facilities. The injection air compressor motors are supplied with $13.8 \mathrm{KV}$ power, while other motors required for building services, coal preparation, coal injection and peripheral facilities are supplied with reduced voltage power 
as appropriate.

$480 \mathrm{~V}$ power required for facilities in the raw coal supply area is supplied from the existing J-8 electrical substation.

\subsubsection{Nitrogen}

Approximately 9,000 SCFM of 40 PSI low pressure nitrogen and 500 SCFM of 200 PSI high pressure nitrogen is required to provide: an inert gas atmosphere in the injection plant, purge gas for the vessel vent filters, an emergency gas blanket for components in the coal preparation plant, and a sufficient cooling atmosphere to minimize system shut down time. A 3" pipe line has been run from the existing 18" high pressure nitrogen line on the plant main pipe bridge to the northeast of the blast furnace office and an 8 " pipe line has been run from the existing $10^{\prime \prime}$ low pressure nitrogen pipe on the main plant pipe bridge. A portion of the high pressure nitrogen is used to maintain the 40 psi pressure of the low pressure nitrogen.

\subsubsection{Natural Gas}

Approximately 670 SCFM of natural gas at $60 \mathrm{psi}$ is required for the heater in the coal grinding/drying mill circuit. A 4" pipe line has been run from the existing 24 "line on the pipe bridge northeast of the blast furnace office. This pipe runs parallel to the 3" and 8" nitrogen lines described above.

\subsubsection{Lake Water}

Approximately 1,450 GPM of lake water is required for air compressor and HVAC cooling. A 12" pipe line has been run underground to the Utility Building from the existing 60 " main beneath 12th Street.

\subsubsection{Furnace Instrumentation}

\subsubsection{1. "C" Furnace In-Burden Probe}

Coal injection will result in significant changes to the blast furnace process. To determine and analyze the nature of the effects, an in-burden probe has been installed on "C" blast furnace. The installation of a probe on " $D$ " furnace will be delayed until higher levels of coal injection are implemented 
after the next reline of "D" furnace in year 1998.

A British Steel design retractable probe was installed near the top of " $C$ " furnace. When actuated it enters through the furnace shell and penetrates the furnace burden below the stockline. The tip of the probe reaches the center of the furnace to measure gas temperature and take a gas sample. The probe indexes outward at preset positions taking a gas temperature and gas sample at each location. The gas sample is analyzed by an existing mass spectrometer. After completing a cycle, a profile of the furnace gas temperature and chemistry is available for analysis. This information provides the basis for understanding the dynamics of coal injection, making it possible to make process changes to maximize production, minimize fuel rate, and decrease wear of the blast furnace refractory lining.

Reference Drawing: 21002026 General Arrangement

\subsubsection{Blow Pipe Pressure}

A pressure sensor has been installed on each of the 28 hot blast blow pipes on " $\mathrm{C}$ " and " $\mathrm{D}$ " furnace. The individual blow pipe pressure is compared with a pressure in the upstream hot blast main. The pressure differential serves as an indicator of hot blast flow through each tuyere. If the pressure transmitter senses a lowering of the normal hot blast pressure loss through a blow pipe, which indicates a plugged tuyere, the system will automatically shut down the injector feeding that tuyere. This will prevent coal from backing up the blow pipe into the bustle pipe if a tuyere becomes plugged.

\subsubsection{Bustle Pipe Temperature Sensors}

Six, equally-spaced, thermocouples have been installed near the bottom of the bustle pipe on each furnace to detect abnormally high temperatures which would harm the refractory lining. If the blow pipe pressure sensor malfunctions and fails to shut off the coal injector, coal will quickly fill the entire tuyere stock assembly, eventually backing up into the bustle pipe. When coal reaches the bustle pipe it will begin to burn creating a thermal condition which will exceed the design limitations of the bustle pipe refractory lining. The temperature sensing thermocouples will detect the high temperature condition and automatically shut down all of the injectors. 


\subsubsection{Level II Process Control}

The coal handling, coal preparation and coal injection Level I programmable logic controllers (PLC) transfer data to the blast furnace Level II process control system. The Level II system performs calculations regarding the operation and performance of the furnace based on the level of injected coal. The Level II system is also used to perform trending of the various functional data being gathered by the Level I PLC's. All development work will be done on the Level II system. The Level II system sends data to the Level III Great Lakes Regional Data Center for archiving.

- The old blast furnace Level II system was fully utilized and unable to handle the additional work load imposed by coal injection and the new facilities installed on the " $C$ " blast furnace reline. The old Level II system has been replaced with a new system using two - DEC VAX processors (to be cost shared with the " $\mathrm{C}$ " reline project). The new processors handle existing " $\mathrm{C}$ " and " $\mathrm{D}$ " blast furnace functions, additional requirements of the " $\mathrm{C}$ " reline, coal injection, and development work.

\subsubsection{1. "C" Stockhouse Modifications}

Modifications were required to the " $\mathrm{C}$ " Furnace Stockhouse to accommodate the high levels of coal injection on the " $\mathrm{C}$ " Blast Furnace which are possible after high density cooling is installed during the " $\mathrm{C}$ " reline. Coal injection levels of $280 \#$ on "C" furnace and $180 \#$ on "D" furnace are planned. To satisfy the requirements of the DOE cooperative agreement, coal injection levels up to $400 \#$ will be tested on "C" furnace.

Injection of coal into the furnace reduces the amount of coke required to produce liquid iron, resulting in an increase in the ore to coke ratio charged into the furnace. British Steel Consultants have recommended the coke batch size, currently about 17 tons, remain the same and the amount of ferrous fines in the pellet and sinter charge be reduced from approximately $15 \%$ to $5 \%$ or less. This results in increasing the ferrous charge from approximately 70 tons to 93 tons for coal injection rates up to $400 \#$.

The previous stockhouse configuration limited the ferrous charge (pellets and sinter) and modifications were required to reach the required batch size and reduction in ferrous fines. The sinter was 
moved from the three previously used bins to the bins previously used for nut coke. The old sinter bins are being used for pellets increasing the pellets storage bins from five to eight. The nut coke bins were modified to accommodate the sinter. The new sinter system also includes new feeders, conveyor modifications, new screens, new fines handling system and new weigh hopper feeders.

\subsubsection{Gas Scrubber Water Treatment}

Chlorine is contained in varying amounts in the coal to be injected into " $\mathrm{C}$ " and "D" Blast Furnaces. After combustion in the blast furnace, hydrogen chloride (HCL) gas is formed. The HCL gas passes through the furnace burden and becomes a component of the furnace exhaust gasses. Upon coming in contact with the blast furnace gas wash water in the scrubber, the HCL gas is absorbed into the gas wash water decreasing the $\mathrm{pH}$ of the recirculated water system. It is necessary to neutralize the acidic condition to keep the water system equipment free from corrosion.

A caustic soda solution $(50 \% \mathrm{NaOH})$ will be added to the water system at a rate controlled by a $\mathrm{pH}$ control system to neutralize the acid. The recirculated scrubber water system $\mathrm{pH}$ will be maintained at about the same level as previously experienced (7.4 average). A caustic soda tank has been installed along with metering pumps for the addition of $\mathrm{NaOH}$ to the water system.

\subsection{ENVIRONMENTAL CONTROL FACILITIES}

The proposed facility will comply with the State of Indiana environmental regulations which will require the control of air borne particles with a size less than 10 microns $\left(\mathrm{PM}_{10}\right)$ as approved for this project in August 1993. ${ }^{(5)}$ Also, a project environmental assessment was approved by the DOE in May 1993. ${ }^{(4)}$

\subsubsection{Raw Coal Handling}

To limit the fugitive dust emitted from the handling of raw coal between the car dumper and the coal preparation plant the following has been installed:

a. covers for the conveyors.

b. dust suppression spray at the conveyor transfer points.

c. building enclosures on the conveyor transfer towers. 


\subsubsection{Coal Preparation}

The raw coal to the coal preparation mill is stored in bins (one for each of the two mills) before entering the preparation mill for sizing and drying. The bins are totally enclosed and vented to the atmosphere through a filter to control particulate emissions. Dust captured in the filter is discharged into the bin.

The preparation of coal involves using a combination of combusted natural gas and recycle gas to dry and convey the coal from the mill. A cyclone is used to separate about $95 \%$ of the coal from the gas before recycling the gas back to the mill. About $50 \%$ of the total gas flow containing about $5 \%$ of the coal is sent through a mill bag filter. About $50 \%$ of the bag filter flow is discharged to atmosphere to vent off moisture removed from the coal and the remaining bag filter flow is recirculated through the mill. The mill bag filter is designed to keep particulate discharge below 0.005 grains per dry standard cubic feet of air flow which within the limits imposed by environmental regulations. Dust captured by the bag filter is sent to the product coal bins and injected into the furnace.

\subsubsection{Coal Injection}

Prepared coal is stored in four product coal silos which are fluidized with nitrogen to maintain a constant coal flow to the weigh hoppers. The excess nitrogen is vented to the atmosphere through a filter connected to the top of each silo vessel. The captured dust is discharged back into the silo.

Each of the four distribution bins are fluidized with nitrogen to maintain coal flow to the injectors. The excess nitrogen is vented to the atmosphere through a filter connected to the top of each bin. The captured dust is discharged back into the bin.

Fourteen injectors take coal from each of the four distribution bins. The coal enters the injector lockhopper where the pressure is raised from atmospheric to about 100 psig. The lockhopper high pressure gas is vented to the atmosphere through a filter which serves 7 injectors. The captured dust is discharged back into the distribution bin.

\subsection{FACILITY DESIGN PARAMETERS}

The raw coal handling, coal preparation and coal injection facilities described above have been installed to meet the design parameters shown in Figure 8. 


\section{EOUIPMENT}

\section{SUPPLIER}

ATSI/SM

Injectors and Injection Lances $\ldots \ldots \ldots \ldots \ldots \ldots \ldots \ldots \ldots \ldots \ldots \ldots \ldots \ldots \ldots \ldots \ldots \ldots$ Simon Macawber, UK Coal Grinding/Drying Mill System $\ldots \ldots \ldots \ldots \ldots \ldots$ Williams Patent Crusher Williams Mill Drive Motors $\ldots \ldots \ldots \ldots \ldots \ldots \ldots \ldots$ Westinghouse Williams Mill Power Transmission Equipment $\ldots \ldots \ldots \ldots \ldots \ldots \ldots \ldots$ Falk Mill System Bag Filter . . . . . . . . . . . . . . . . . . MAC Injection Air Compressors $\ldots \ldots \ldots \ldots \ldots \ldots \ldots \ldots \ldots \ldots \ldots \ldots \ldots \ldots \ldots \ldots \ldots$ Atlas Copco Injection Air Compressor Motor $\ldots \ldots \ldots \ldots \ldots \ldots \ldots \ldots \ldots$ Siemens

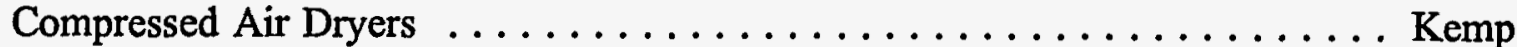
Raw Coal Conveyor Systems $\ldots \ldots \ldots \ldots \ldots \ldots \ldots \ldots$ Long Airdox Screw Feeders . . . . . . . . . . . . . . . . . . Thomas Conveyors Process Building Structural Steel ............. AFCO Steel Fabricators Dense Phase Conveyor System ................. Simon Air Systems

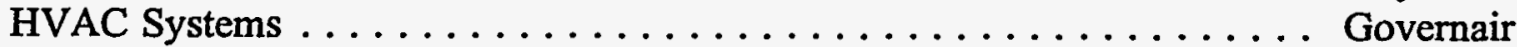

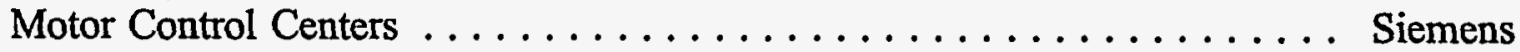
High Voltage Power Distribution ................ Asea Brown Boveri Programmable Logic Controllers .................. Allen Bradley Coal Precrusher ....................... American Pulverizer Main I.D. and Exhaust Fan . .................. Chicago Blower Recycle Gas Heater Burner System . . . . . . . . . . . . . North American Product Coal Screens . . . . . . . . . . . . . . . . . . . . . . Rotex

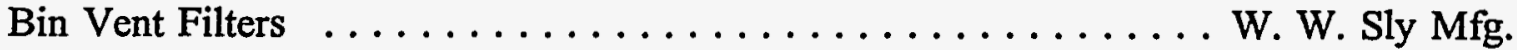
Dust Suppression System $\ldots \ldots \ldots \ldots \ldots \ldots \ldots \ldots \ldots \ldots \ldots$ Betz

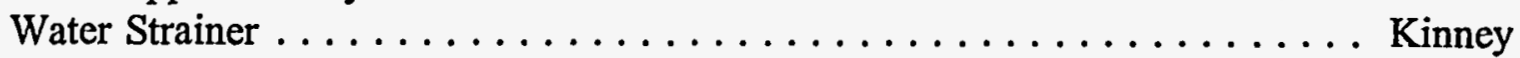

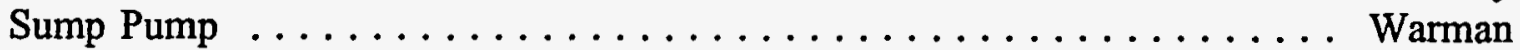
Oxygen Analyzer System $\ldots \ldots \ldots \ldots \ldots \ldots \ldots \ldots \ldots$ Neutronics In-Burden Probe $\ldots \ldots \ldots \ldots \ldots \ldots \ldots \ldots \ldots \ldots \ldots \ldots$ British Steel Injection System Rotary Valves $\ldots \ldots \ldots \ldots \ldots \ldots \ldots \ldots \ldots$ Smoot Conveyor Power Transmission Equipment $\ldots \ldots \ldots \ldots \ldots \ldots \ldots \ldots$ Rex Product Coal Sampler . . . . . . . . . . . . . . InterSystem Sampler Process Building Environmental Monitoring $\ldots \ldots \ldots \ldots \ldots \ldots \ldots$ MSA Explosion Suppression System $\ldots \ldots \ldots \ldots \ldots \ldots \ldots \ldots \ldots \ldots$ Fike Process Building Central Vacuum Cleaning System ............. Lamson Fire Water Pump ...................... Fairbanks Morse Diesel Engine For Fire Pump $\ldots \ldots \ldots \ldots \ldots \ldots \ldots \ldots \ldots$ Cummins 


\subsection{REFERENCES}

1. D. S. Gathergood, "Coal Injection Into The Blast Furnace", International Iron \& Steel Institute Committee on Technology, April 26, 1988.

2. D. S. Gathergood and G. Cooper, "Blast Furnace Injection - Why Granular Coal? Steel Technology International, 1988.

3. D. Kwasnoski and L. L. Walter, "Blast Furnace Granular Coal Injection", Second Annual Clean Coal Technology Conference, Atlanta, GA, September 8, 1993.

4. J. S. Siegel, Environmental Assessment Approval, May 6, 1993.

5. P. Dubenetzky, "Construction Permit, Office of Air Management, Indiana Department of Environmental Management", issued August 4, 1993.

6. D. Kwasnoski and L. L. Walter, "Blast Furnace Granular Coal Injection", Third Annual Clean Coal Technology Conference, Chicago, IL, September 6, 1994. 


\section{FIGURE 1}

\section{THE STEELMAKING PROCESS}

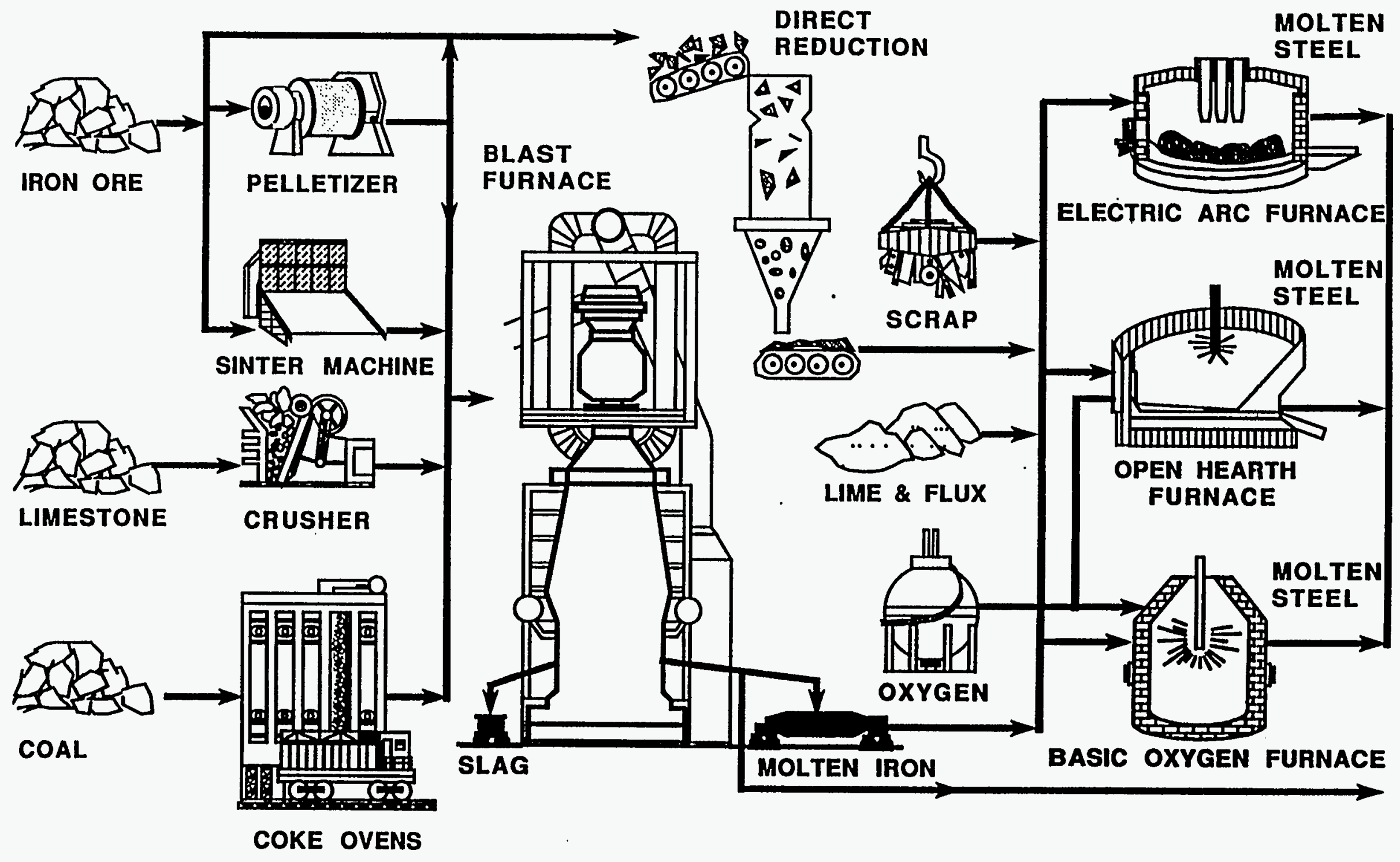


FIGURE 2

THE BLAST FURNACE COMPLEX

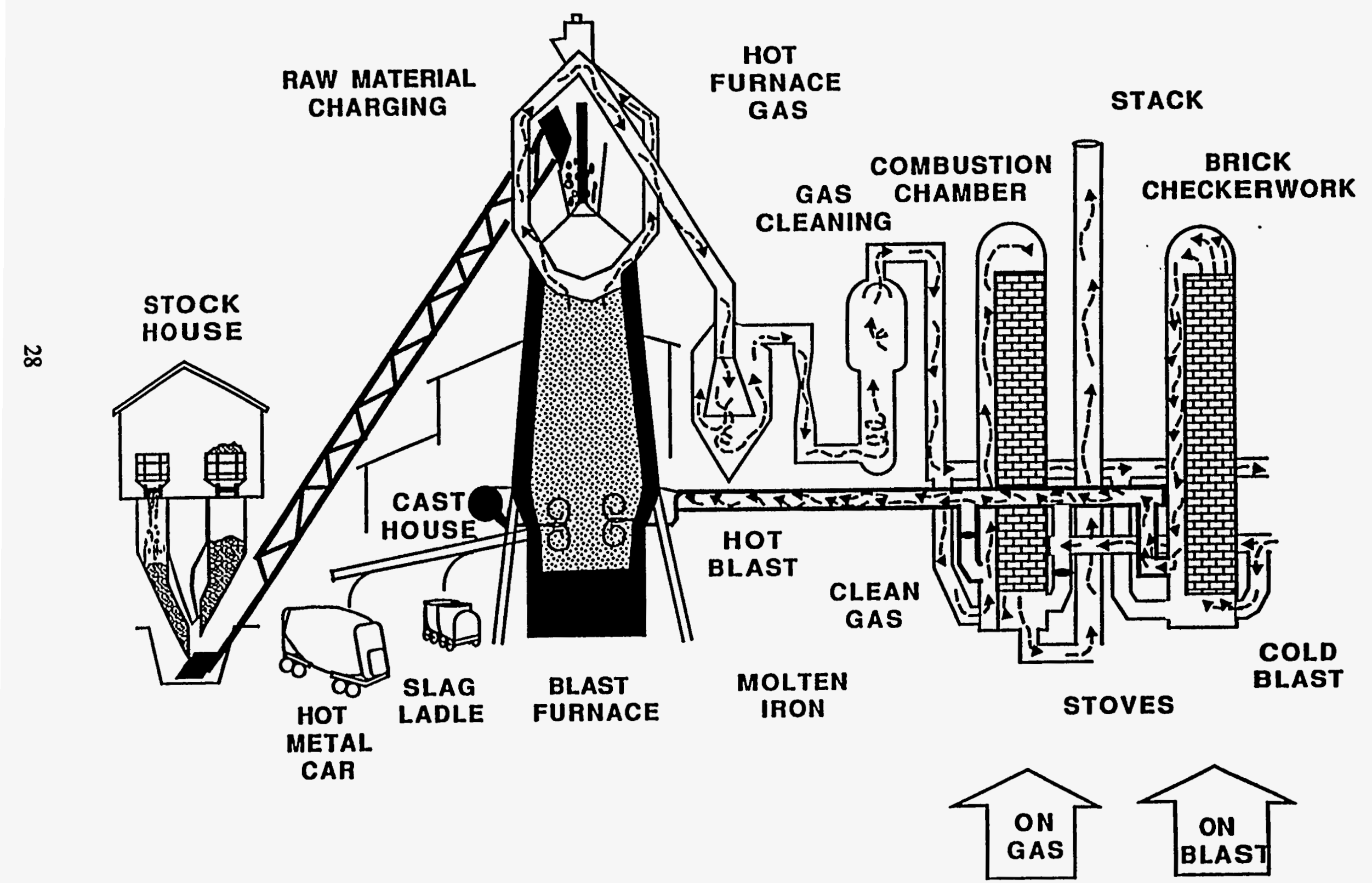




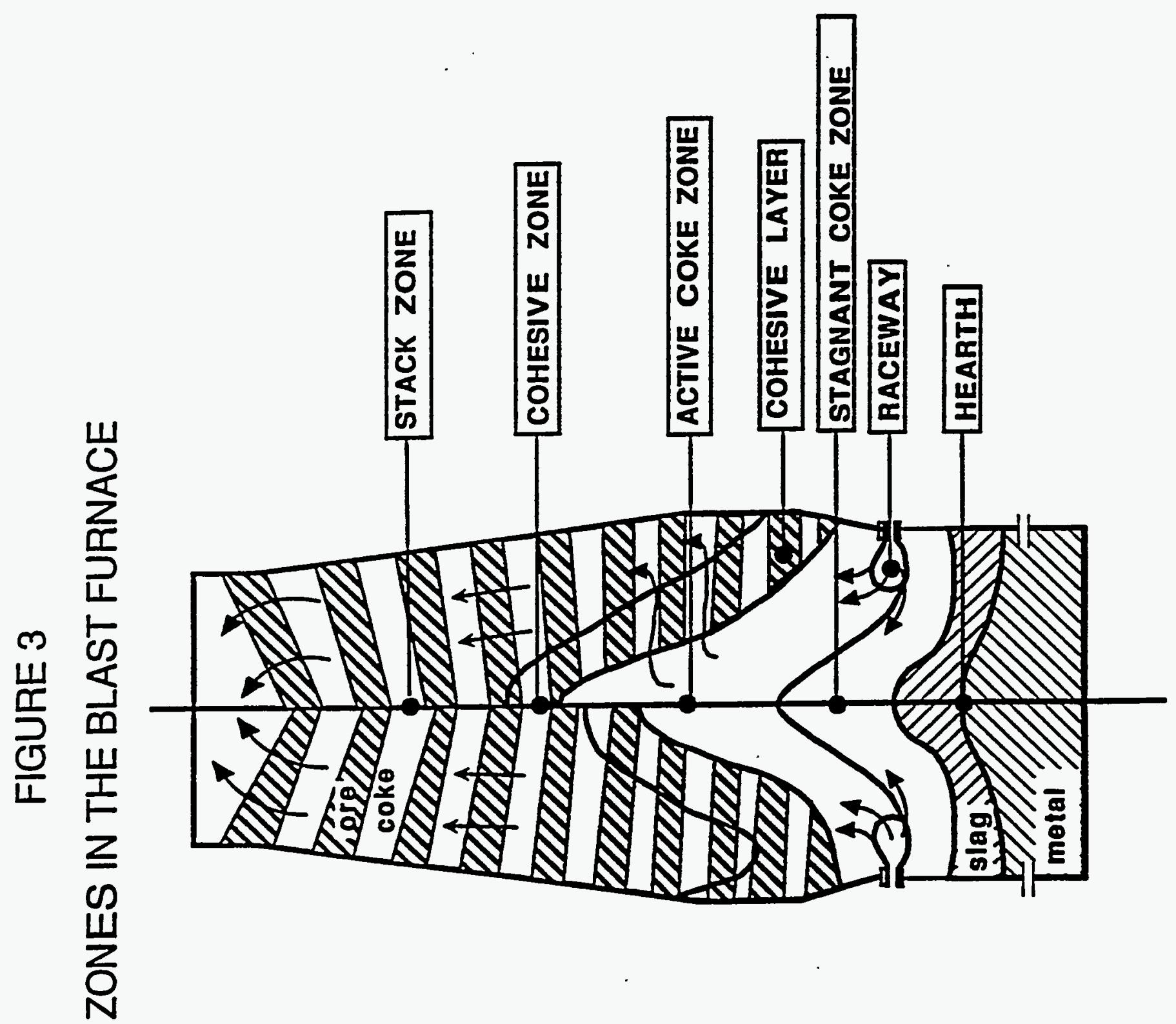




\section{FIGURE 4 \\ Coal Injection Test Program Parameters}

Coal Grind Size

Injection Level

Coal Types

System Installation

Reduced Coke

Requirement
- Granular (100\% -4 mesh) to Pulverized (75\% -200 mesh)

- Up to 400 lbs per NTHM

- East, Midwest and West (Differing Chemical and Physical Characteristics)

- During Furnace Reline and "On-the-Fly"

- Less Reliance on Foreign Coke and/or Environmental Problems Associated with Domestic Coke Production

Bethlehem Steel Corp. 
FIGURE 5

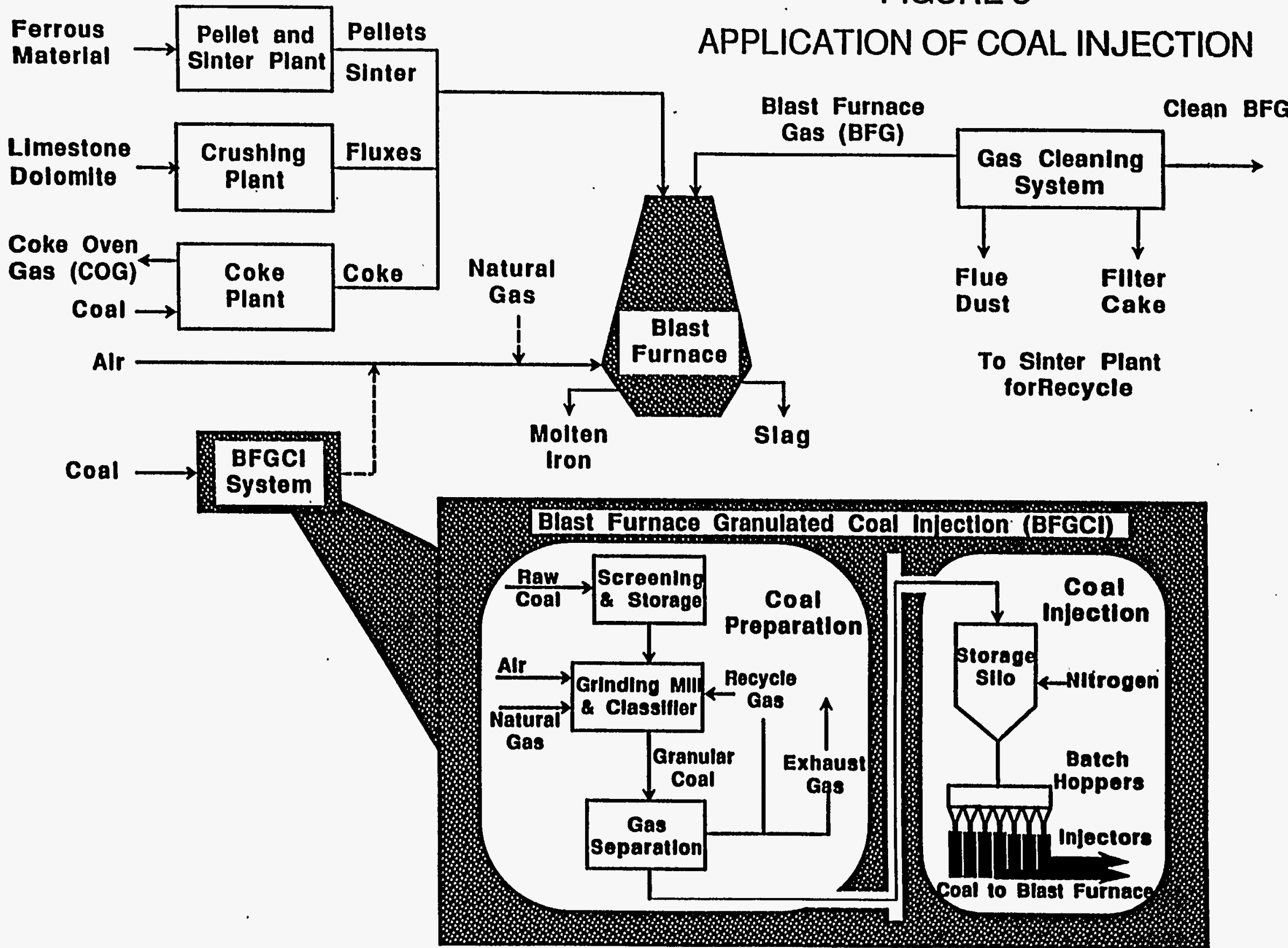




\section{FIGURE 6 Coal Injection Test Site/Facilities}

Location

Blast Furnaces

- Number

- Size

- Production Rate

- Fuel Injection
- Bethlehem Steel Burns Harbor Plant, Porter County, Northern Indiana

$-2$

- $\quad 35 \& 38 \mathrm{ft}$. Hearth Diameter

- Approximately 7,000 tons/Day Pig Iron/Furnace (8 TPD per 100 cu.ft. Working Volume)

- Natural Gas, Oil, Tar 
FIGURE 7

COAL INJECTION - BURNS HARBOR PLANT

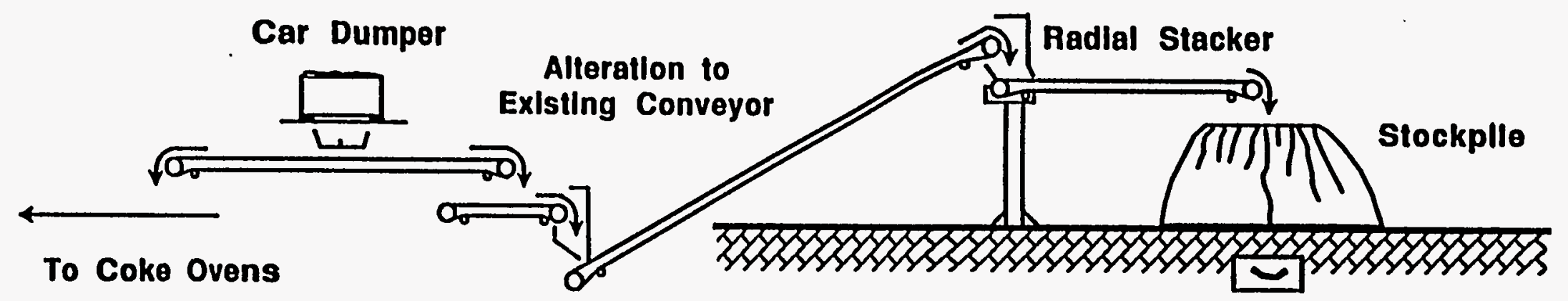

$\stackrel{\omega}{\omega}$

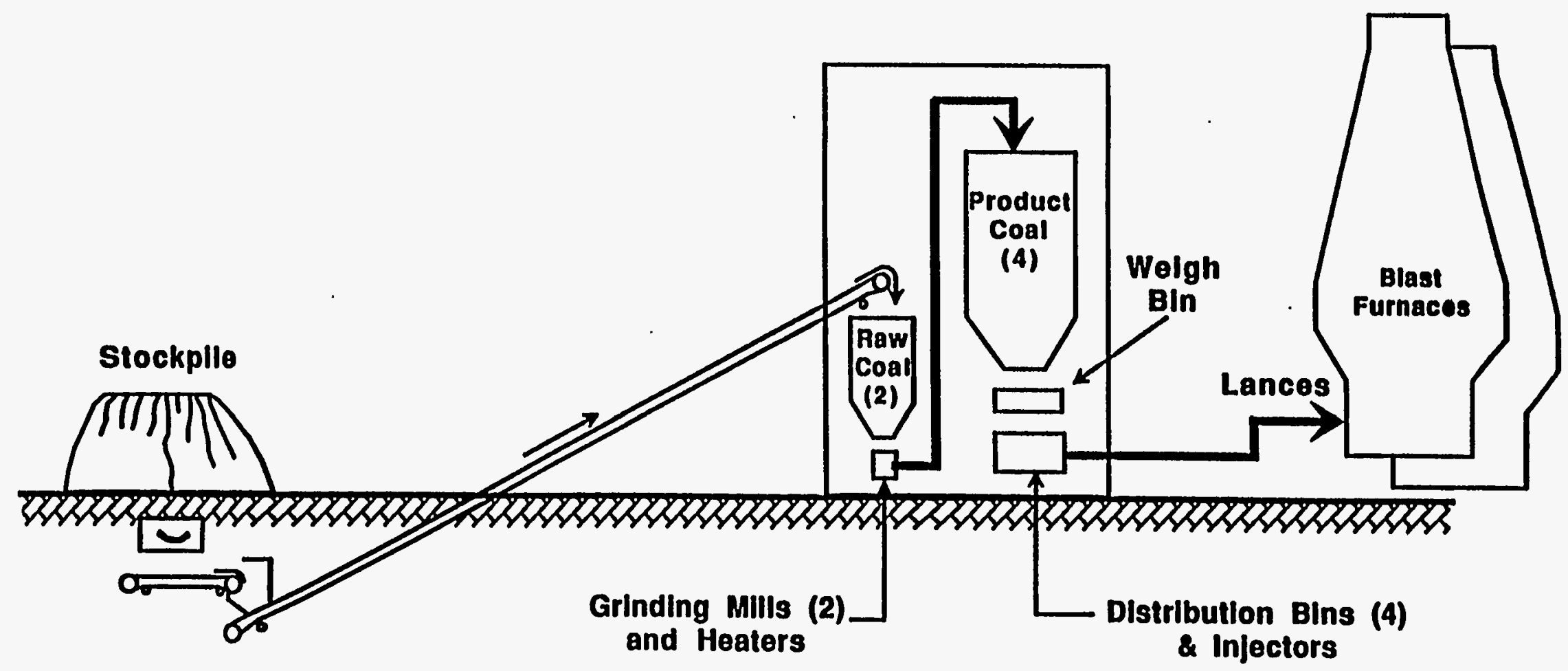




\section{FACILITY DESIGN PARAMETERS}

1. Raw Coal Delivery - $2300 \mathrm{~T} / \mathrm{Hr}$

2. Raw Coal Stockpile - 28,000 Tons

3. Raw Coal Reclaim - $400 \mathrm{~T} / \mathrm{Hr}$.

4. Coal Preparation

Two separate and identical mill systems, each system consisting of the following major pieces:

Raw Coal Silo - 240 Tons capacity

Dryer Mill System -

Granular Capacity - 60 T/Hr. (99.9\% minus 4 mesh)

Pulverized Capacity - 30 T/Hr. (70\% minus 200 mesh)

Drying Capacity $-10.6 \%$ incoming surface moisture dried to max. $1.5 \%$ at granular or pulverized grind size.

5. Injection System

Two separate and identical injection systems - one system feeding each blast furnace.

Each system consisting of the following major pieces:

Product Coal Storage Silo - $2 @ 180$ Tons capacity each

Weigh Hopper - 2 @ 2 Tons capacity each

Distribution Bin - 2, each feeding 14 injectors

Injectors - 28 model 12/8/6 injectors per furnace, each with a rated capacity of 77\#/Min and a combined capacity of 431.2\#Dry Coal/NTHM @ an individual blast furnace production level of 7,200 THM/Day and coal density of $45 \# / \mathrm{Ft}^{3}$. 


\section{FACILITY DESIGN PARAMETERS (cont.)}

6. Utilities

Injection Air Compressor - 2, each with a capacity to support an injection rate of $400 \#$ on both furnaces simultaneously.

Other Utilities - designed to support the simultaneous maximum level of operation for both Coal Preparation Dryer Mill Systems and both Injection Systems.

7. Comments

7a. The combined capacity of the Injection Systems exceeds the combined capacity of the Coal Preparation Systems as follows:

Coal Preparation Maximum Capacity

\begin{tabular}{ll}
\hline Mill Systems & Equiv. Injection \\
\hline Granular $=120 \mathrm{~T} / \mathrm{Hr}$ & $400 \# / \mathrm{NTHM} / \mathrm{Fce}$ \\
Pulverized $=60 \mathrm{~T} / \mathrm{Hr}$ & $200 \# / \mathrm{NTHM} / \mathrm{Fce}$
\end{tabular}

Injector Capacity Compressor Capacity

431.2\#/NTHM/Fce 400\#/NTHM/Fce**

*equivalent to $71.4 \# / \mathrm{Min} / \mathrm{Injector}$

**one of two air compressors operating

7b. For sustained levels of operation above $280 \# / N T H M / F c e$ it will be necessary to install a third coal preparation mill system to provide the spare capacity necessary to ensure a reliable and uninterrupted operation.

7c. Anticipated level of operation

Period 1995 through 1998

DOE Testing

- up to 400\#/NTHM on "C" Furnace for both granular and pulverized. Excess capacity if available would be directed to "D" Furnace.

Normal Operation $\quad-180 \# / N T H M$ on "D" Furnace

- 280 \#/NTHM on "C" Furnace

Beyond 1999

Normal Operation - 280\#/NTHM on "C" Furnace

- 280\#/NTHM on "D" Furnace 


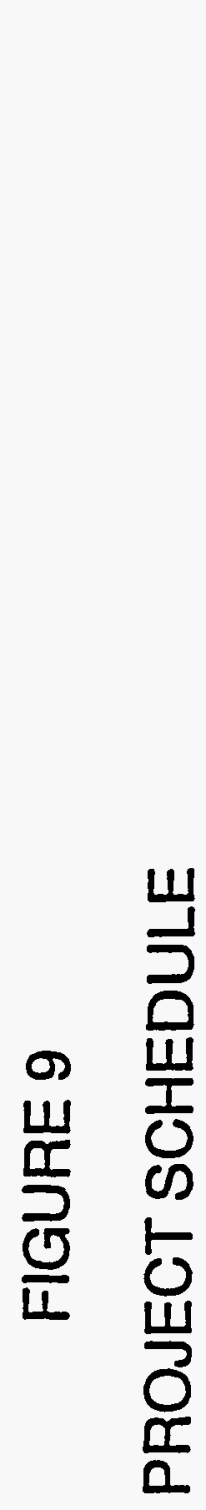

$\boldsymbol{\theta}$

10

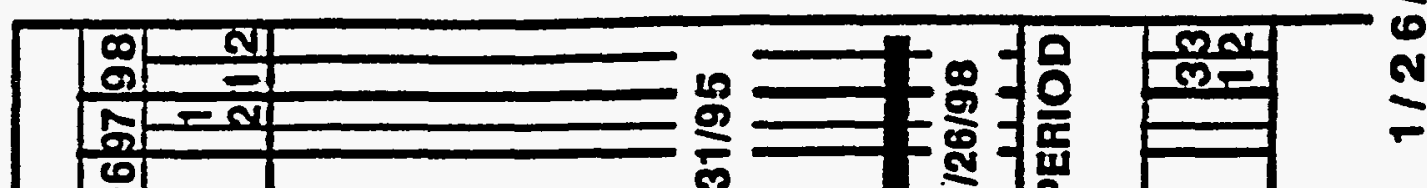

क्

EN

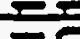

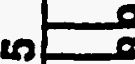

o 1

क 10

$-5$

s

지

=a

=

$+\frac{m}{\infty}$

के

$\infty$

12

$\rightarrow$ nt

7 10 $\frac{2}{0}$

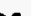

-

2
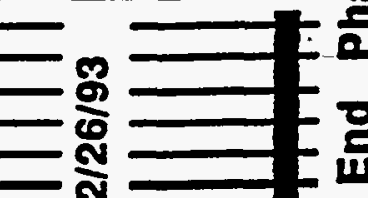

E。

II

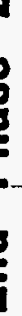

ง
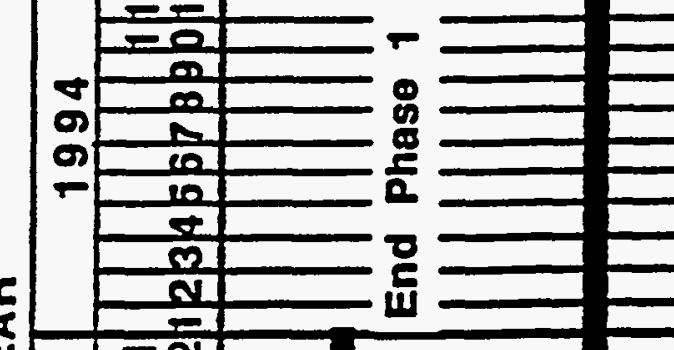

iu

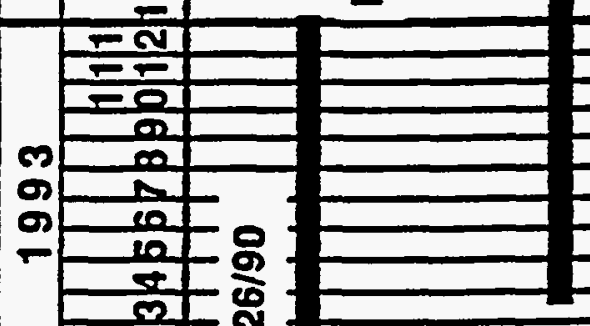

$\frac{\pi}{20}$

s $=0$

क)

FF

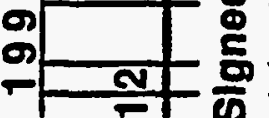

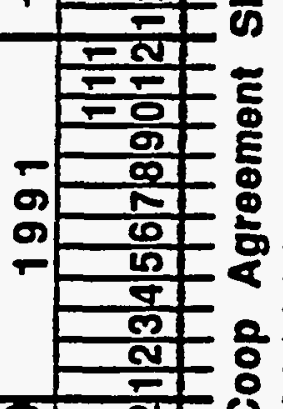

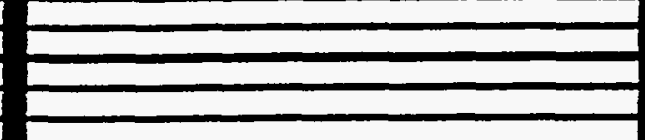

410

혀이

$-\frac{0}{9}$

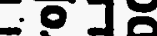

동

E

6

70

$\infty$

N

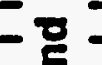

$$
f
$$

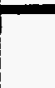

(

की

us

o

$\frac{10}{10}$

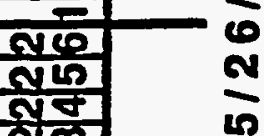

oानती

or

$9=0$

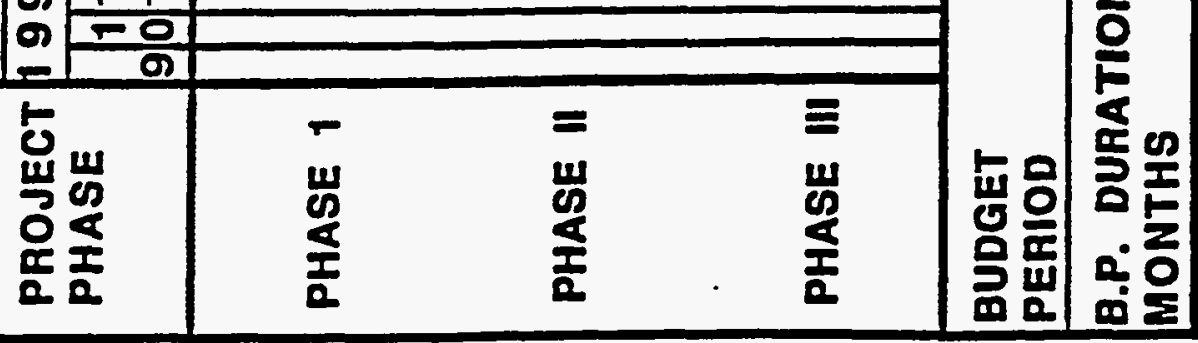




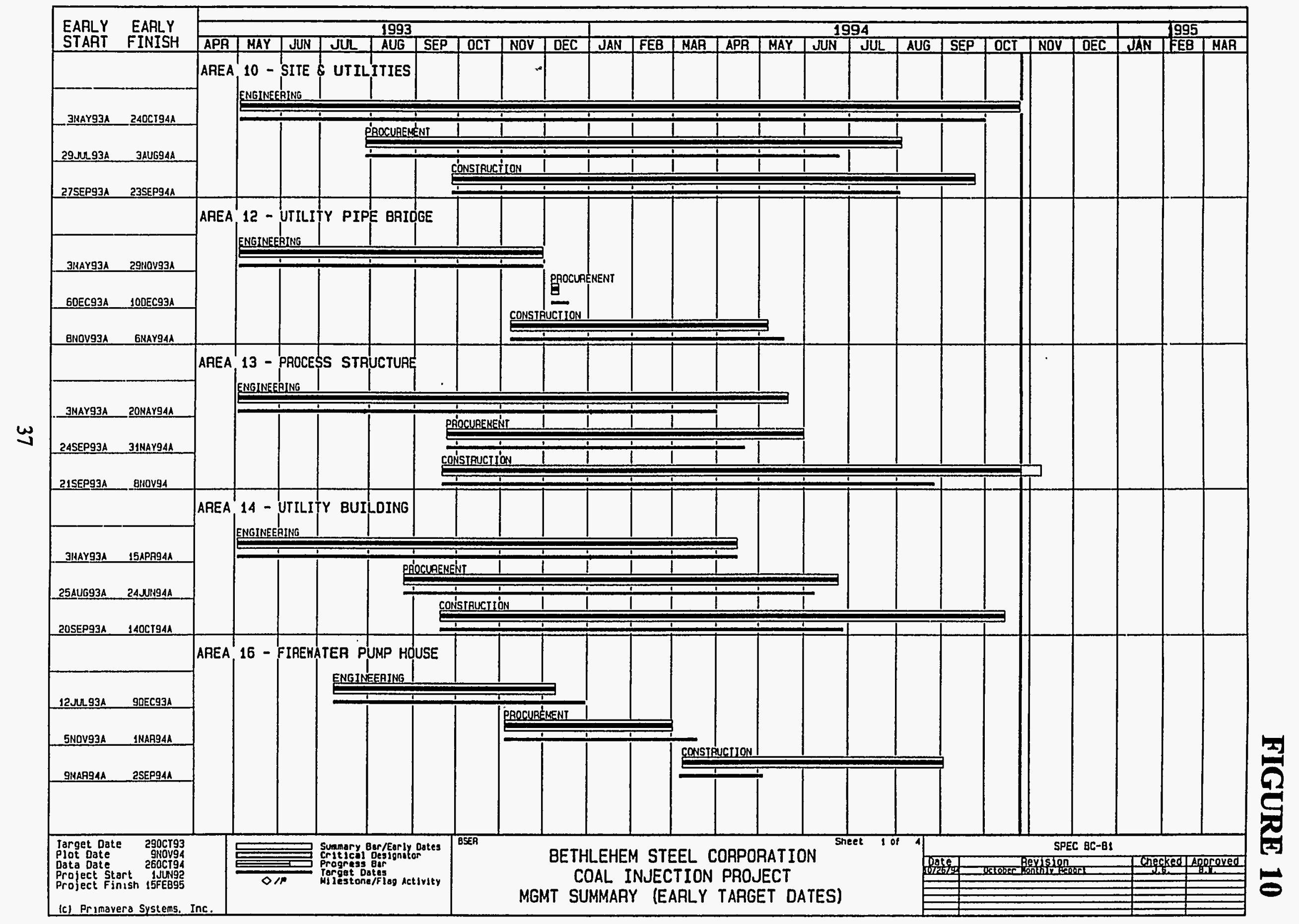




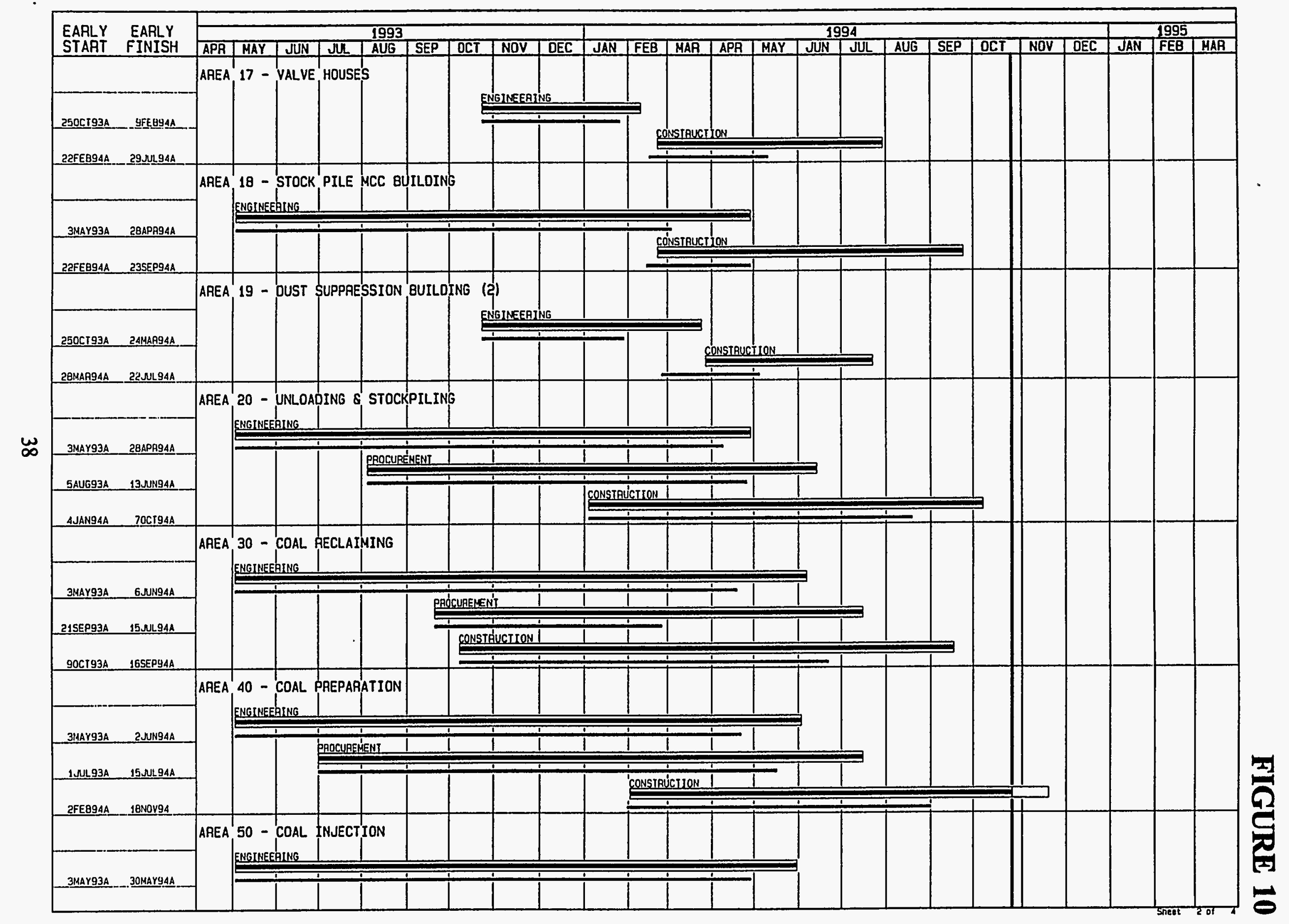




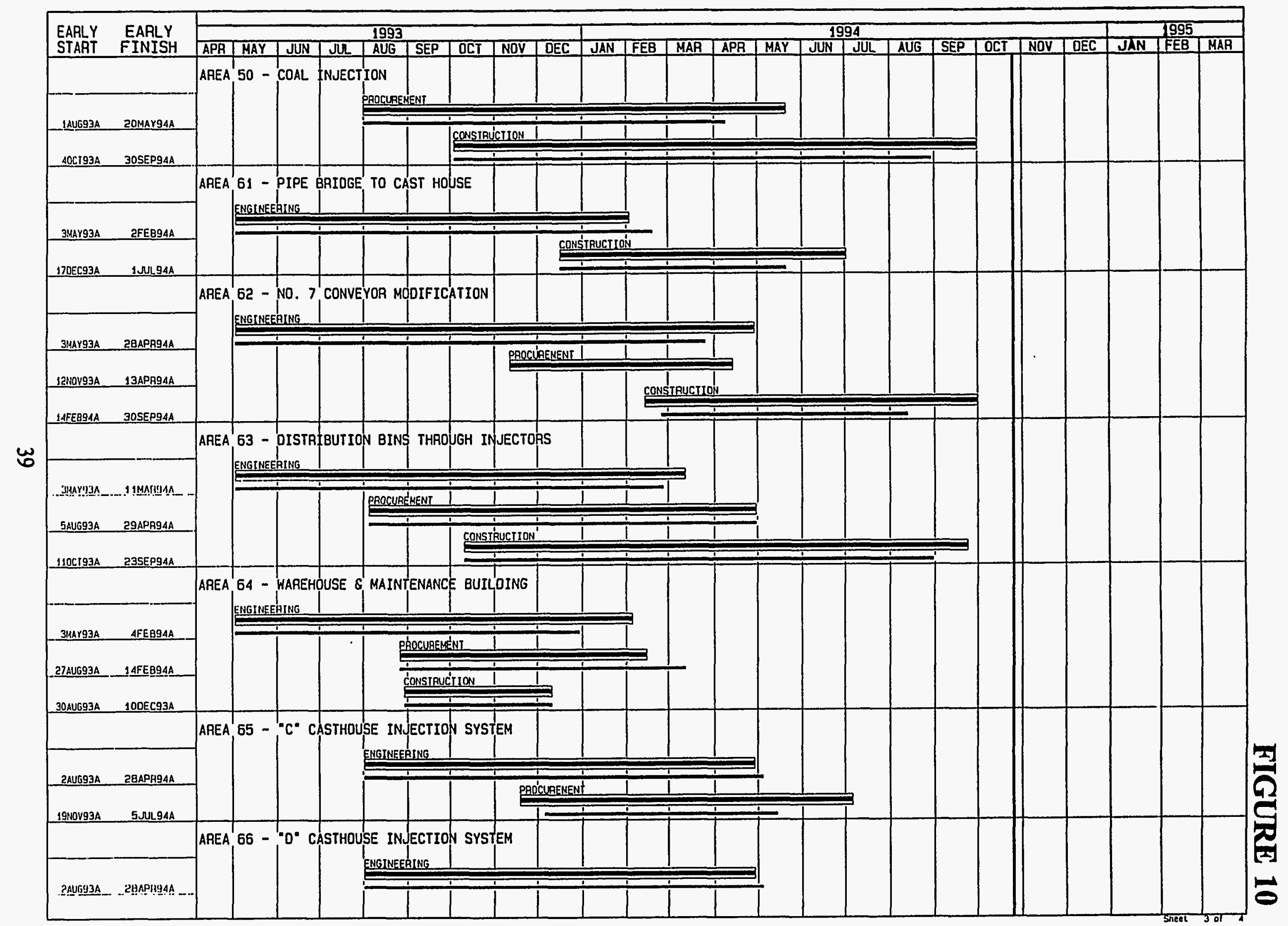


$\therefore-1$

FIGURE 10

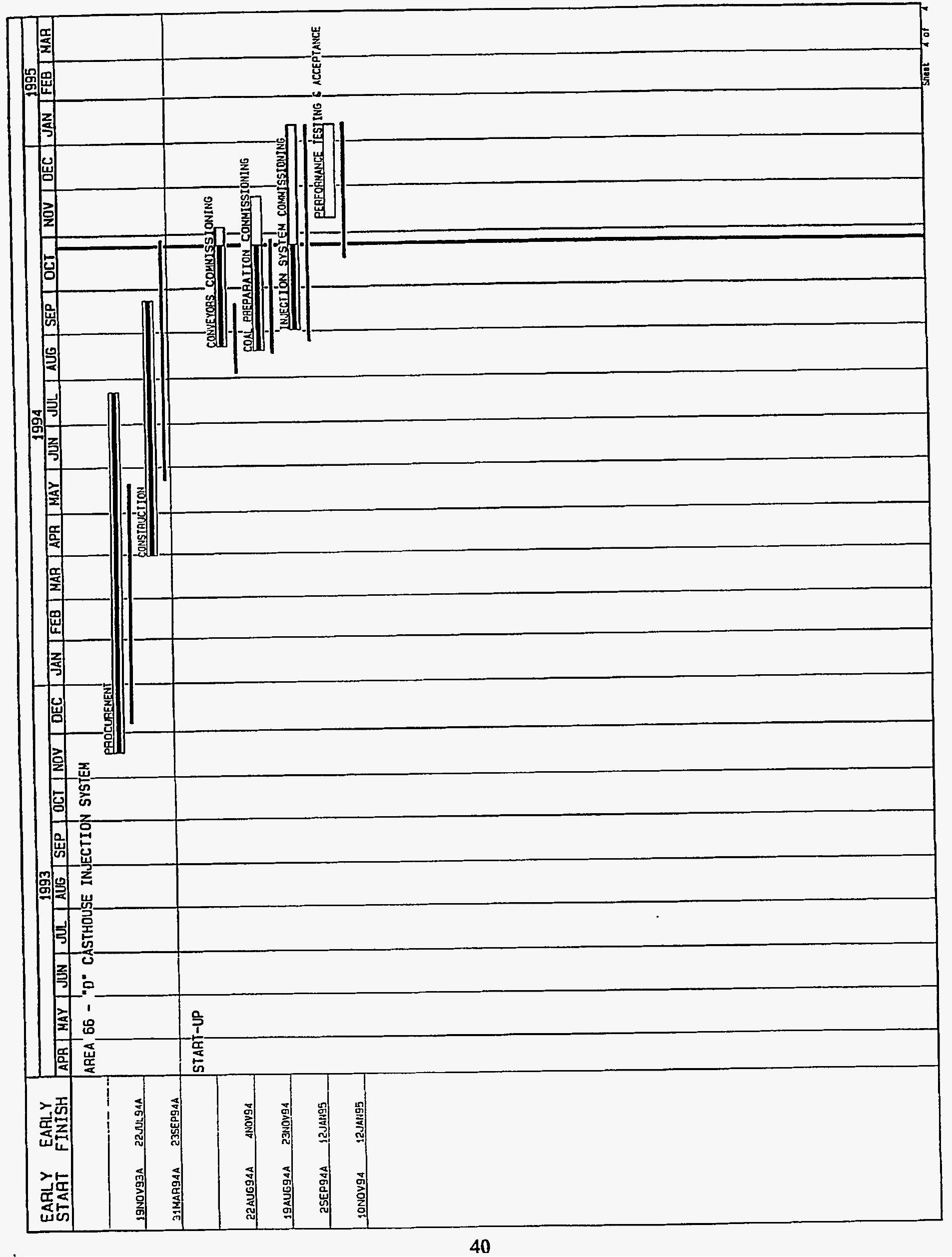




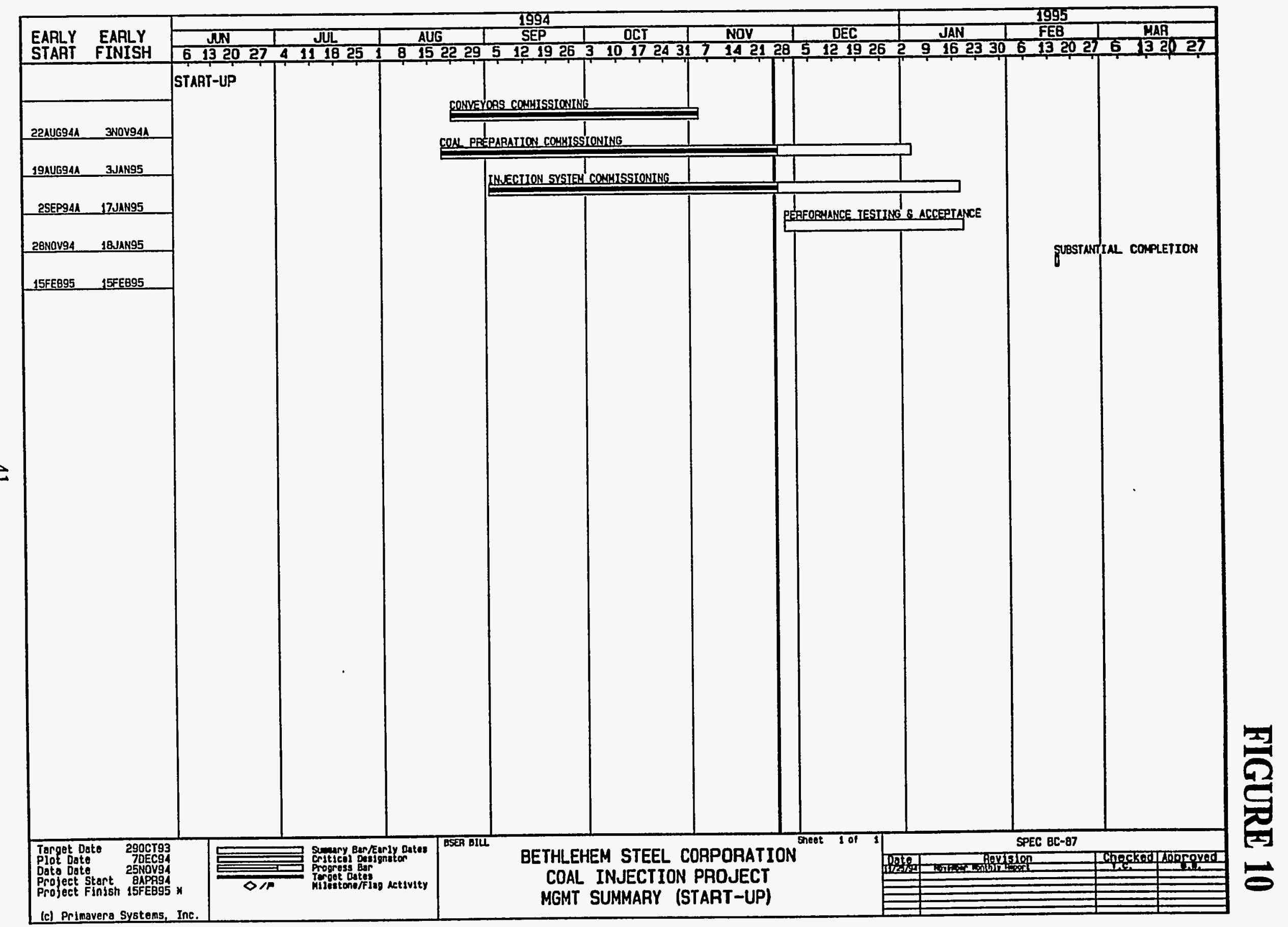




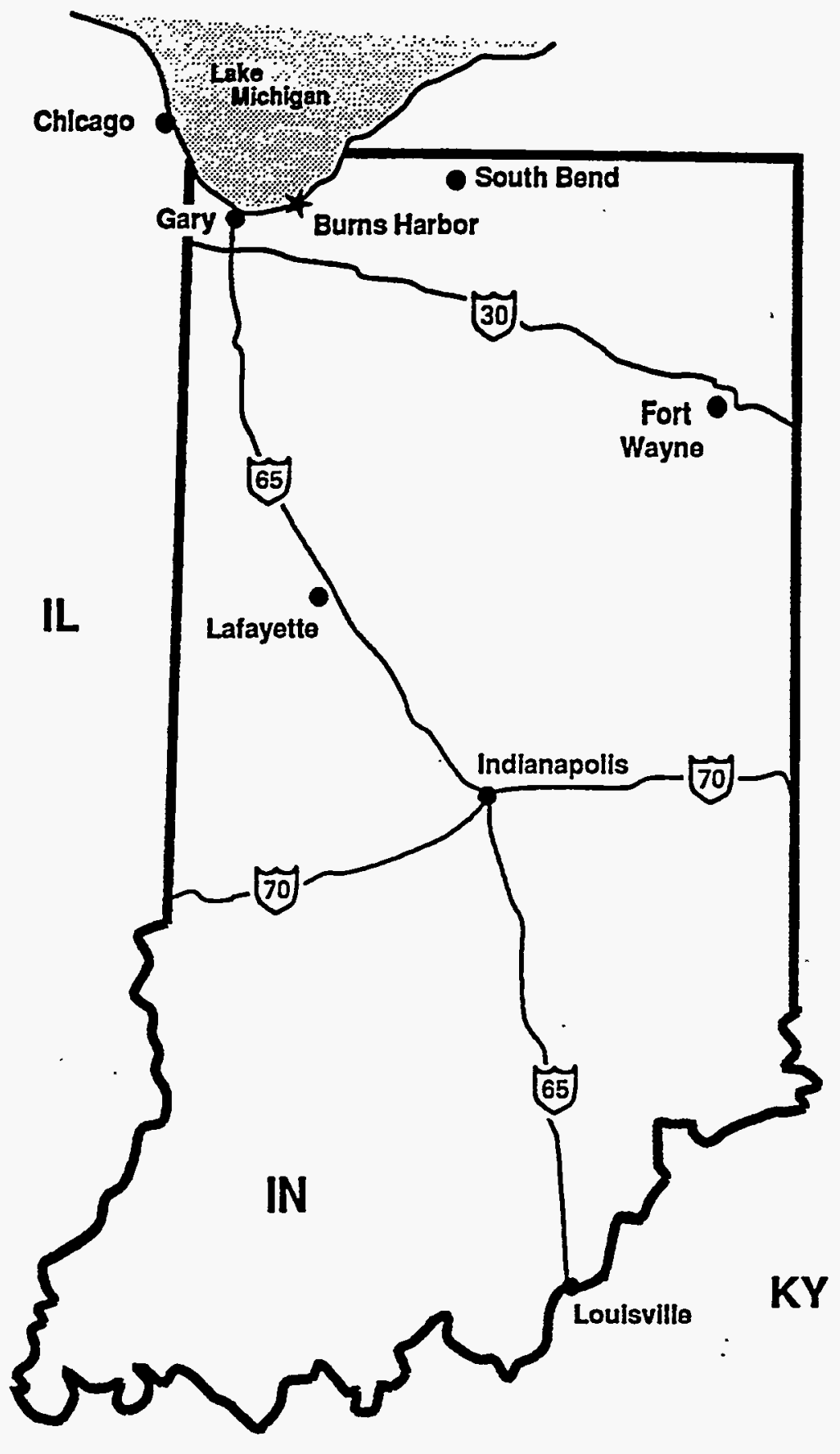

Bethlehem Steel BFGCI Project

FIGURE 11 
BETHLEHEM STEEL CORPORATION

BURNS HARBOR PLANT

BLAST FURNACE GRANULATED COAL INJECTION

\section{PHASE I \& II ORGANIZATION}

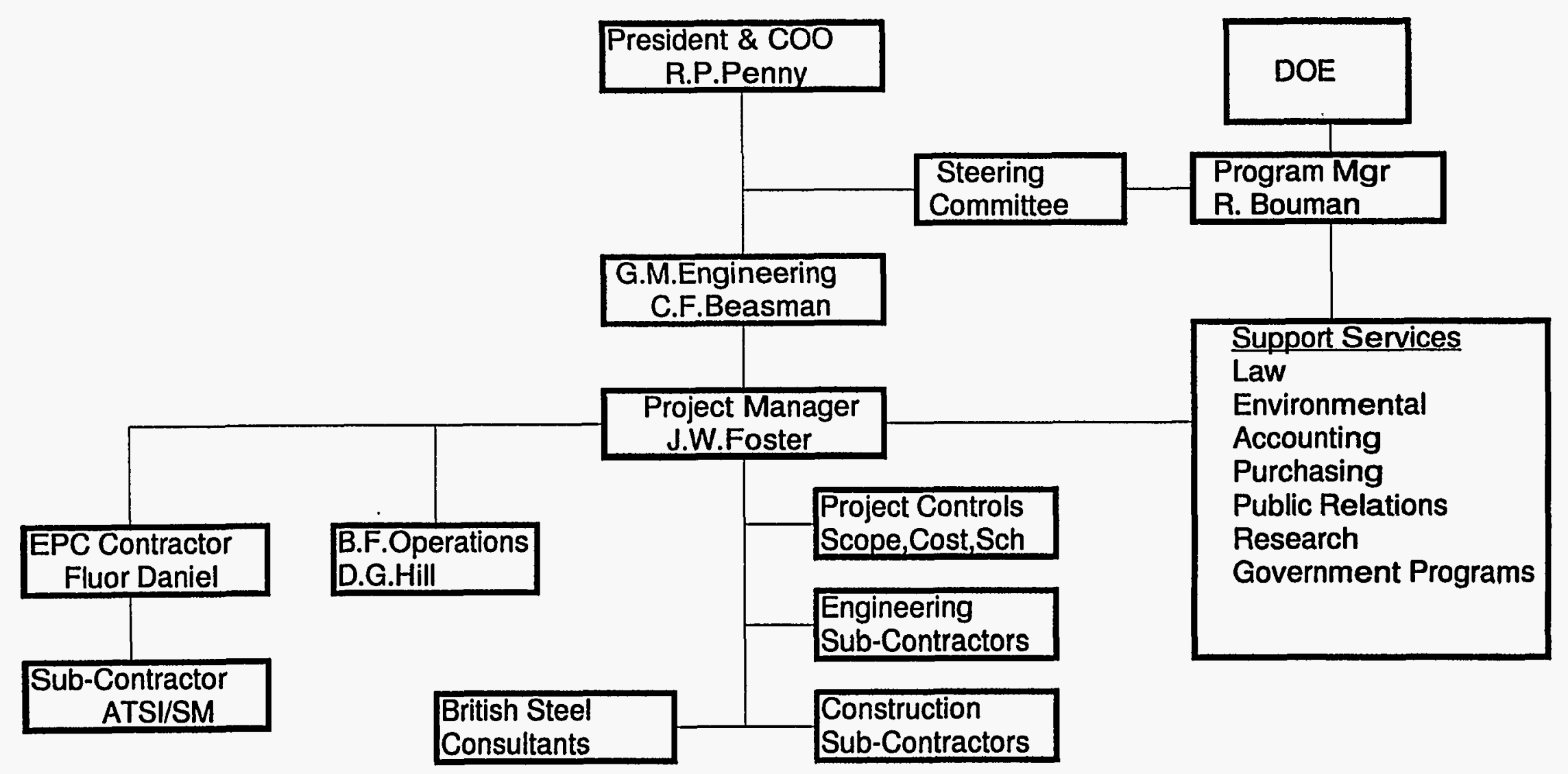




\section{PROJECT CONSTRUCTION ORGANIZATION}

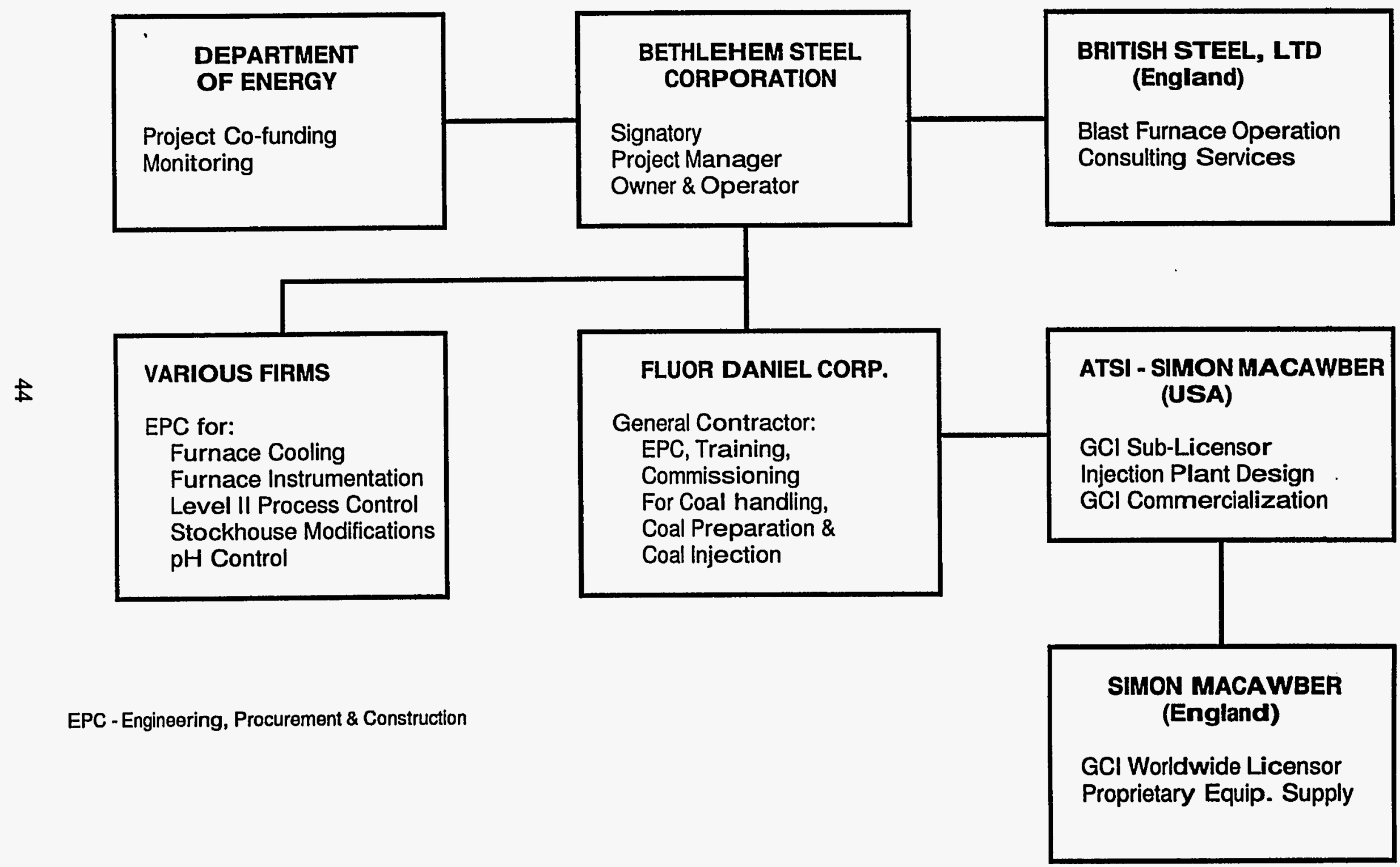

FIGURE 13 
BETHLEHEM STEEL CORPORATION

BURNS HARBOR PLANT

BLAST FURNACE GRANULATED COAL INJECTION

\section{PHASE III ORGANIZATION}

\section{BLAST FURNACE TESTING \\ DOE CONTRACT ADMINISTRATION}

㝕

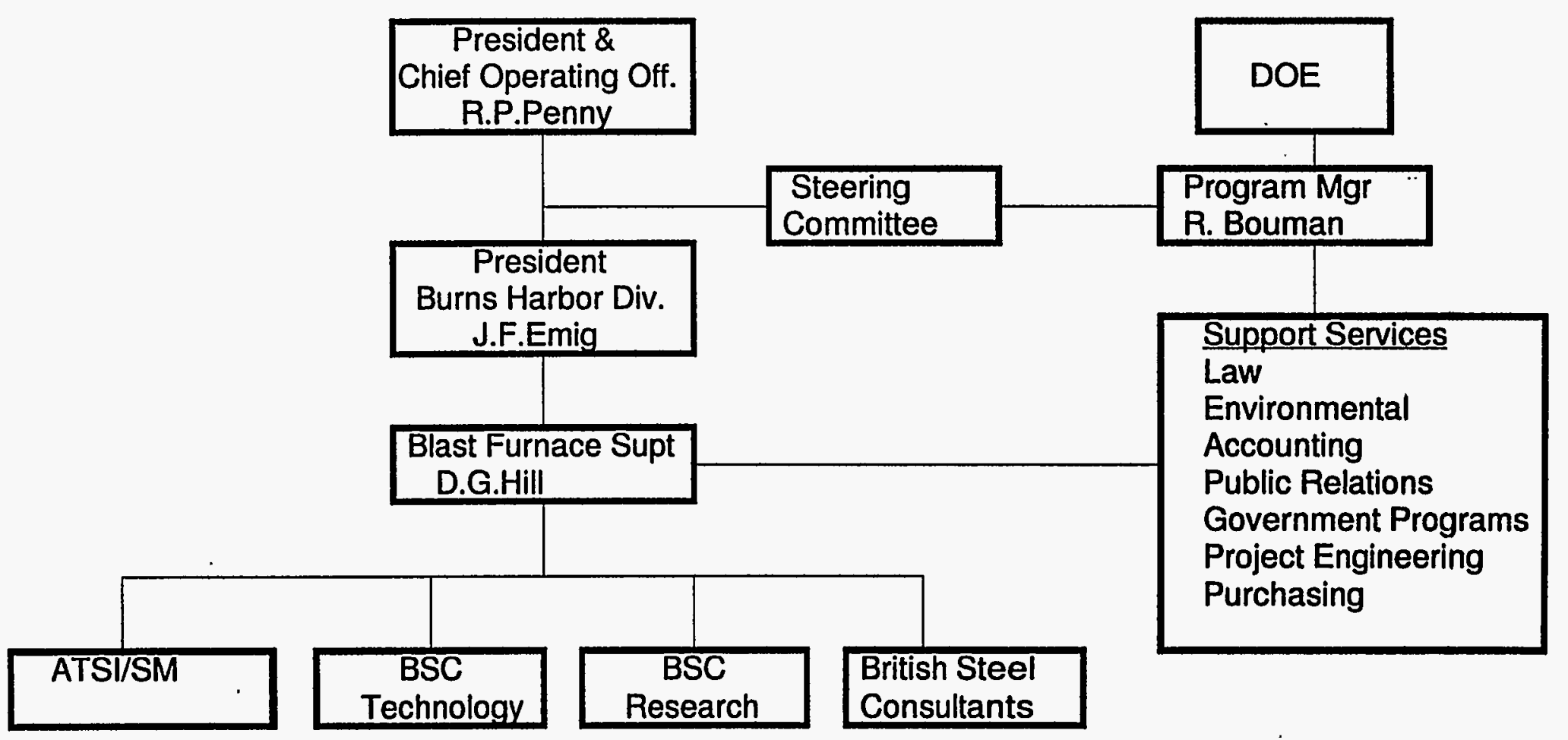

Phase III - Demonstration \& Testing

FIGURE 14 


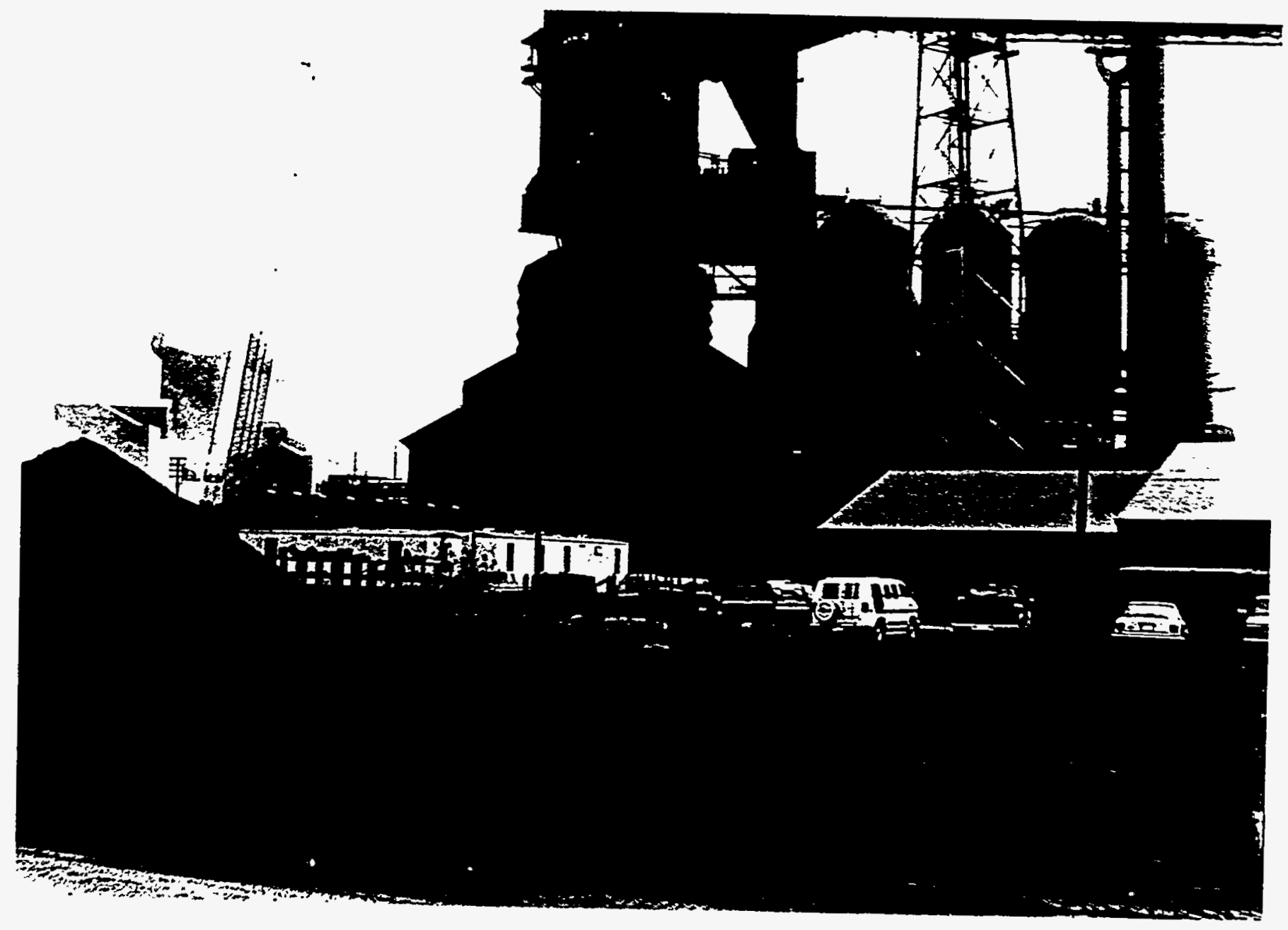

Photograph looking to the east. "D" blast furnace and stoves are in the background. The old warehouse and maintenance building, demolished to make room for the Process Building, is shown in the right foreground. Photograph taken July 1991. 


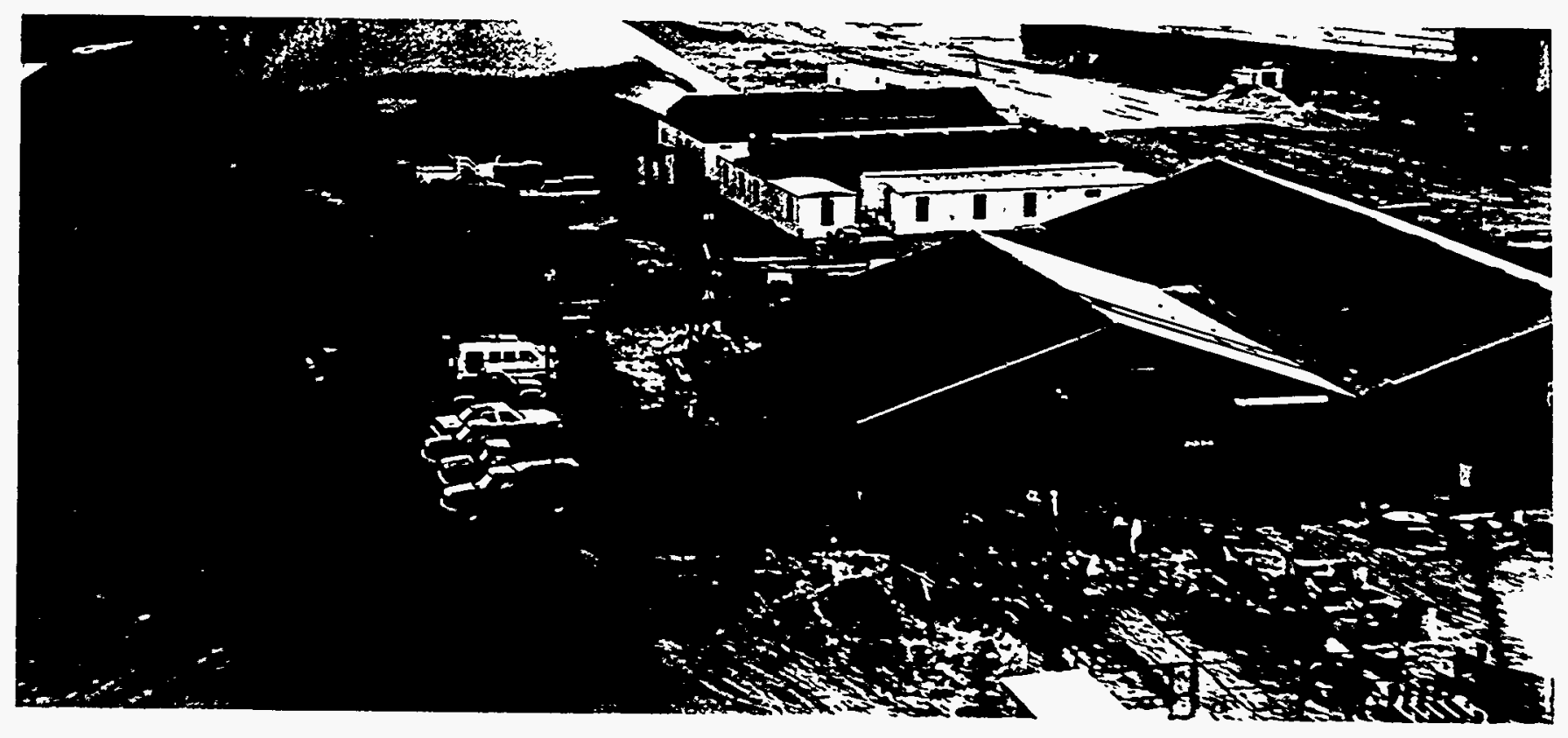

Photograph looking to the north. The old warehouse and maintenance building are shown in the right foreground. The warehouse and maintenance building were demolished to make room for the Coal Injection Process Building. Photograph taken July 1991. 


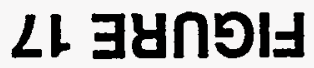

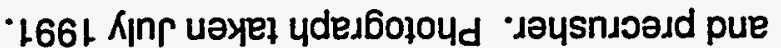

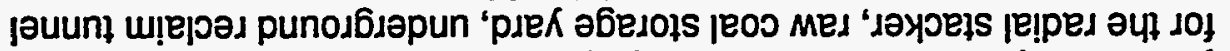

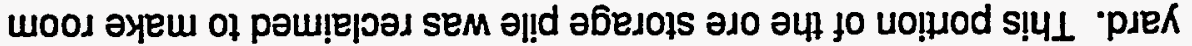

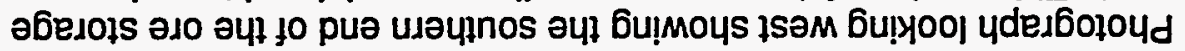

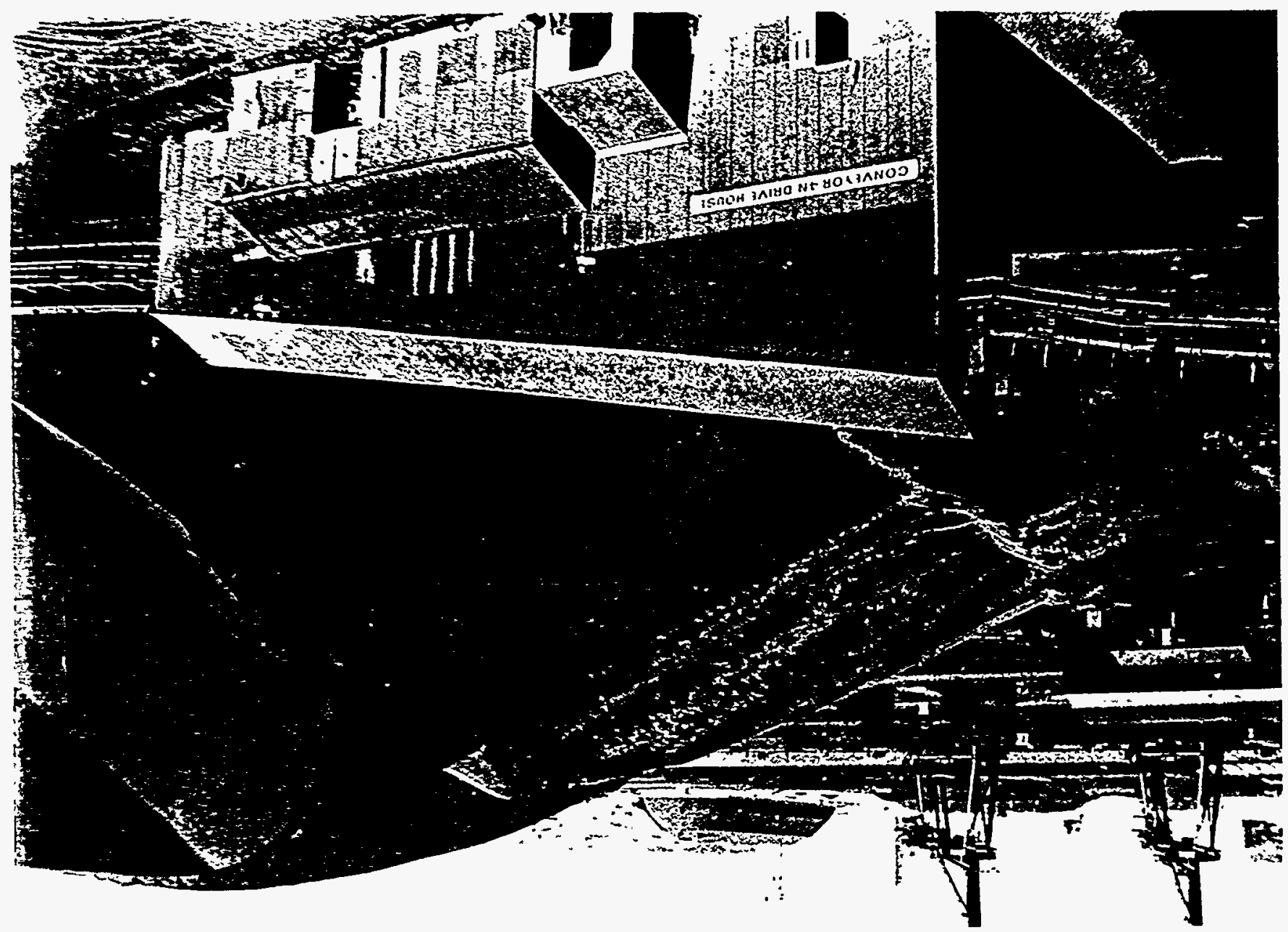




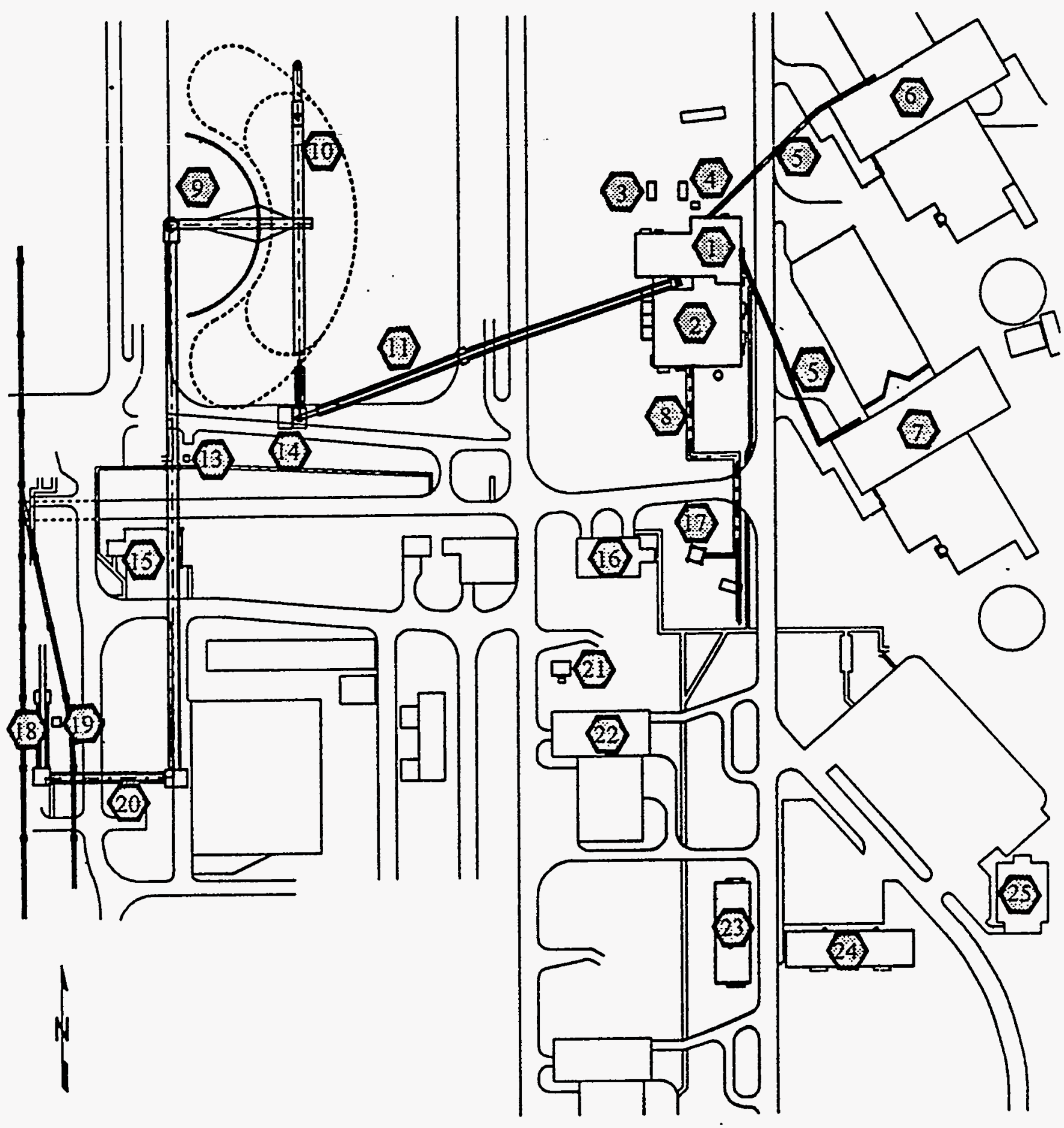

1. Process Structure

2. Utility Building

3. Bag Filters

4. Valve House $C$

5. Coal Injection Pipe Bridge

6. Blast Furnace D

7. Blast Furnace $C$

8. Utility Pipe Bridge

9. Radial Stacker
10. Reclaim Conveyor

11. Plant Feed Conveyor

12. Stock Pile Conveyor

13. Valve House A

14. MCC, Dust Suppression, Valve House Building

15. Junction House J3

16. Junction House J5

17. Tower $\mathrm{K} 6$
18. Conveyor \#7

19. Dust Suppression

20. Transfer Conveyor

21. Fire Pump House

22. Stock House D

23. Maintenance

24. Warehouse

25. Blast Furnace Computer Room 


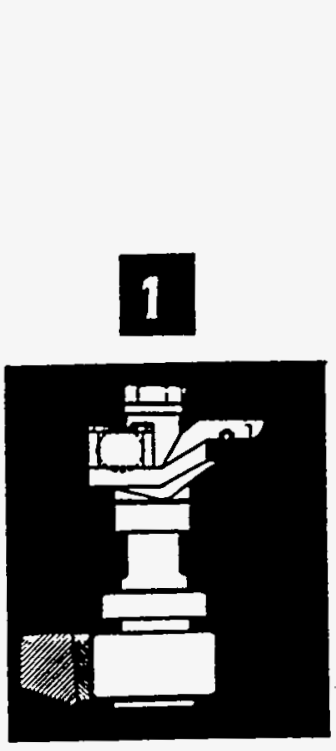

Crushing Force varies as (RPM)

Crushing pressure increases as the square of the Roller Mill speed. By selecting the proper speed. Williams can meet any capacity requirement.

All joumals easily remored through large access door. (2-4 Hrs.)

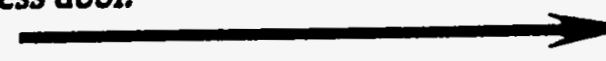

\section{FEEDER}
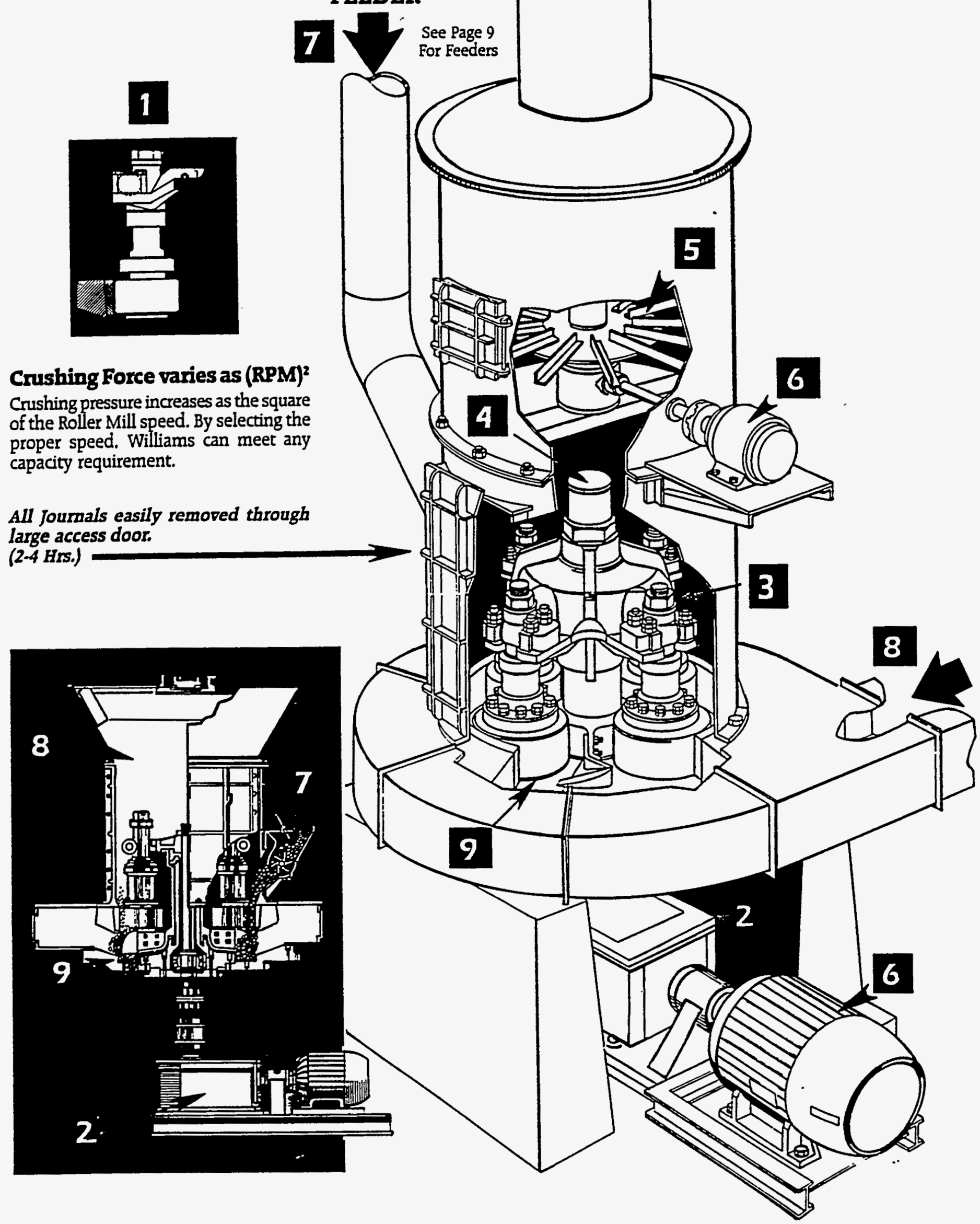

FIGURE 19 


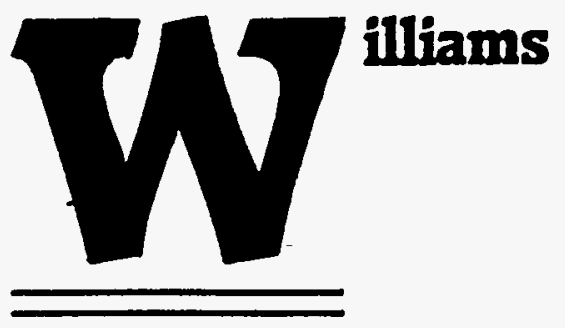

\section{TURN DOWN RATIO}

Infinite turn down while maintaining product size. Williams adjusts the mill grinding rate as a direct function of control system demand. The mill capacity is modulated by varying mill speed.

\section{EXTERTAL GEAR BOX}

Extemal right angle gear box-eliminates contamination of product into gear box. Removal of gear box from skid allows change out of mill main vertical shaft.

\section{NO SPRINGS}

No springs or roll control adjustments are required for product size change or roll wear. Centrifugal force is utilized to do the grinding. This force is adjusted thru instantaneous response of the mill speed.

\section{MILL SPEED}

Mill speed modulation varies the centrifugal forceproduct capacity ranges from $100 \%$ to $0 \%$ utilizing an optional variable frequency A.C. drive.

\section{PRODUCT CONTROL}

Micrometer control of finished product. Product size (regardless of turn down or grinding element wear) is controlled by utilizing the Williams Spinner Separator equipped with a variable speed drive. Drive adjustment is controlled automatically from centralized control panel.

\section{MOTORS}

All drive motors are standard TEFC. squirrel cage induction motors. All drives are direct thru standard flexible coupling. or if desired. by V.belt drive.

\section{FEEDER}

Williams provides a standard rotary pocket feeder that is automatically modulated to maintain mill load. This feeder is equipped with pivotable gate to allow oversize or frozen material to enter the crushing chamber. Weigh belt feeders. live bottom bin feeders, or vibratory feeders can also be incorporated. See page 7.

\section{FLUIDIESD BED DRYTNE}

Hot gasses entering the grinding chamber below the grinding rolls-fluidize the entire grinding chamber and promote rapid efficient drying of all material typesincluding Lignite and sorbent. Large open area thru grinding chamber allows particle terminal velocities to be maintained while fluidized by heated gasses.

\section{PLOW CLEARANCE}

Adequate clearance between the plows and the mill base provides a "Stone box" effect eliminating the need for liners in this area. This clearance is an added margin or protection against tramp metal. 


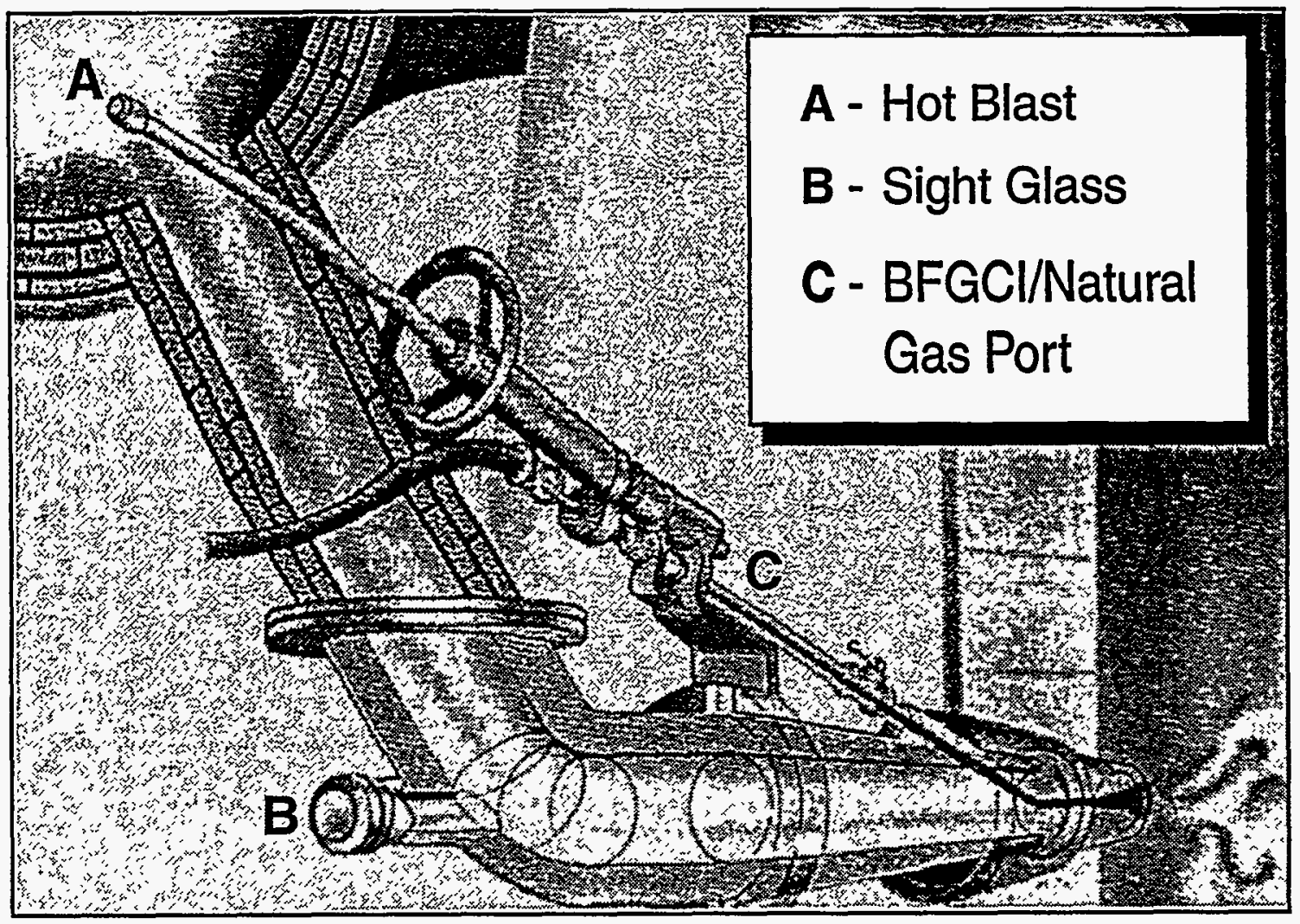

Illustration details the position of the coal injection lance relative to the blast furnace tuyere and hot blast main. Each furnace has 28 tuyeres through which the preheated combustion air is directed into the blast furnace. An injection lance is installed into the pipe supplying hot blast to each tuyere. This lance will supply granular coal to the hot blast air at the tuyere. The granular coal will combust as it enters the blast furnace raceway. The lance also has the capability of accepting natural gas if for some reason the supply of coal is interrupted. 


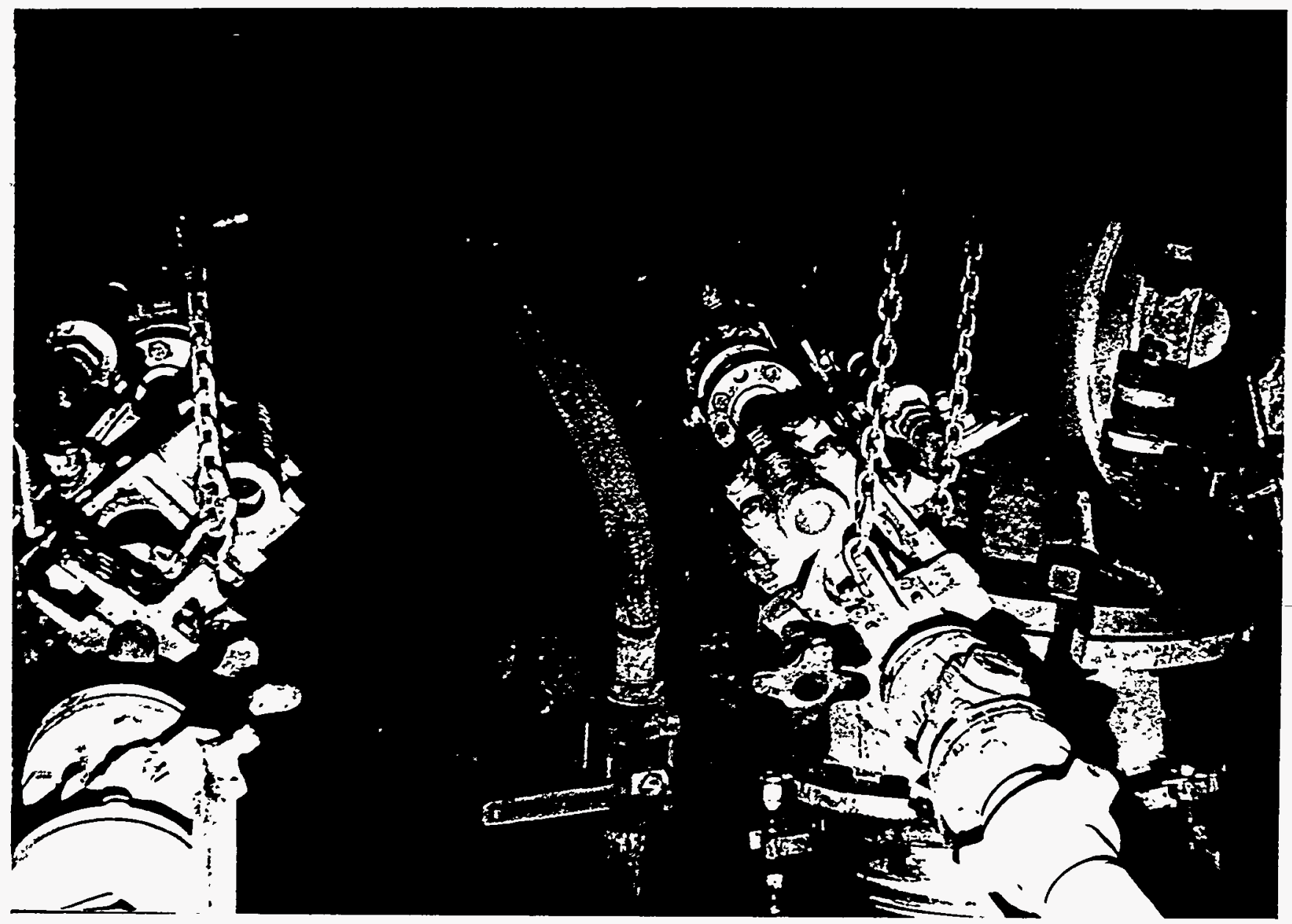

Photograph showing an injection lance connected to a tuyere on "D" blast furnace. The lance is connected to the coal supply line which enters the lance at the upper left hand corner of the photograph. The natural gas supply pipe, shut off valve and hose can be seen in the center of the photograph. The end of the natural gas hose is resting on the tuyere platform just off of the bottom edge of the photograph. The natural gas supply hose can be connected to the the injection lance if the supply of coal is not available. 


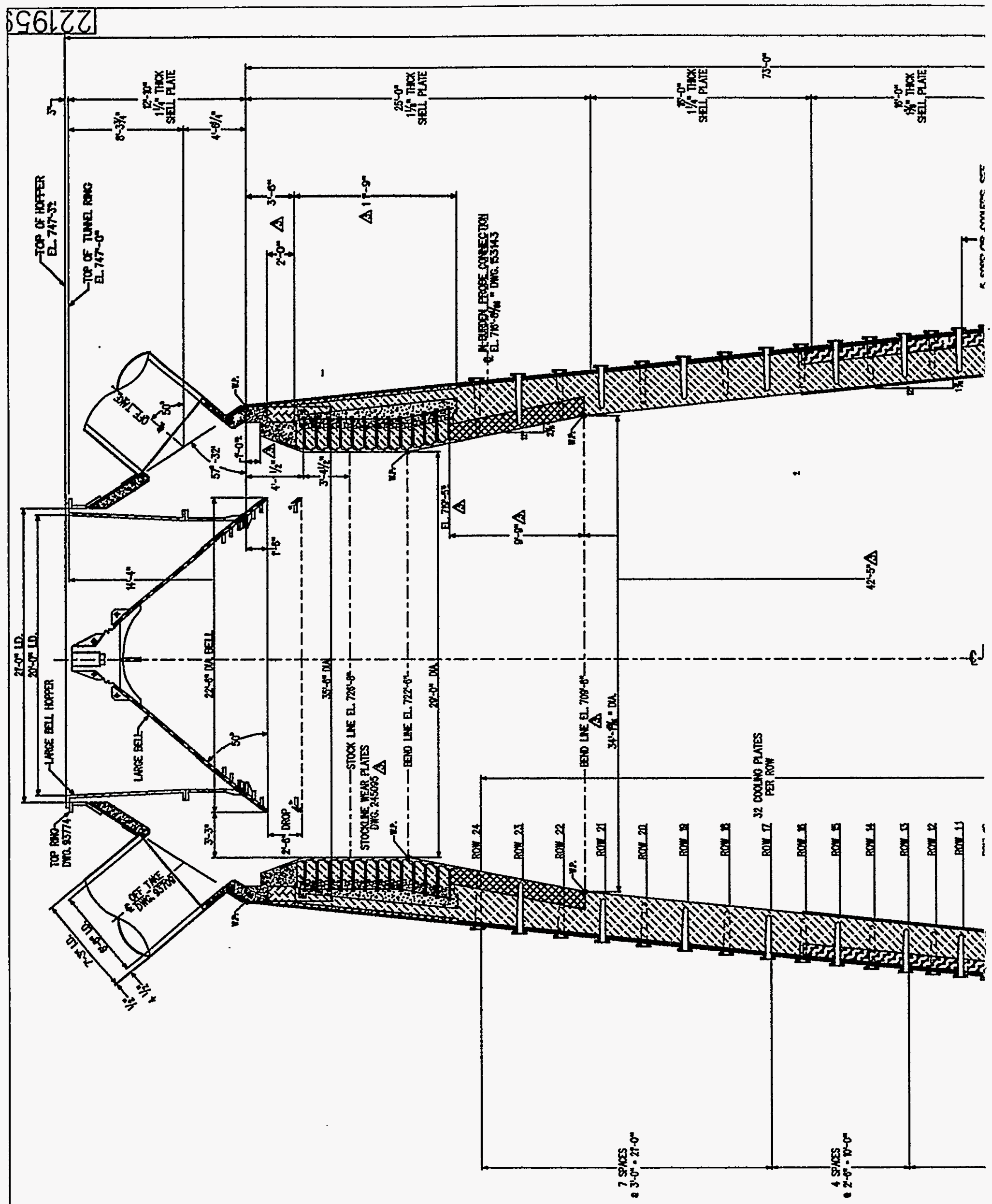




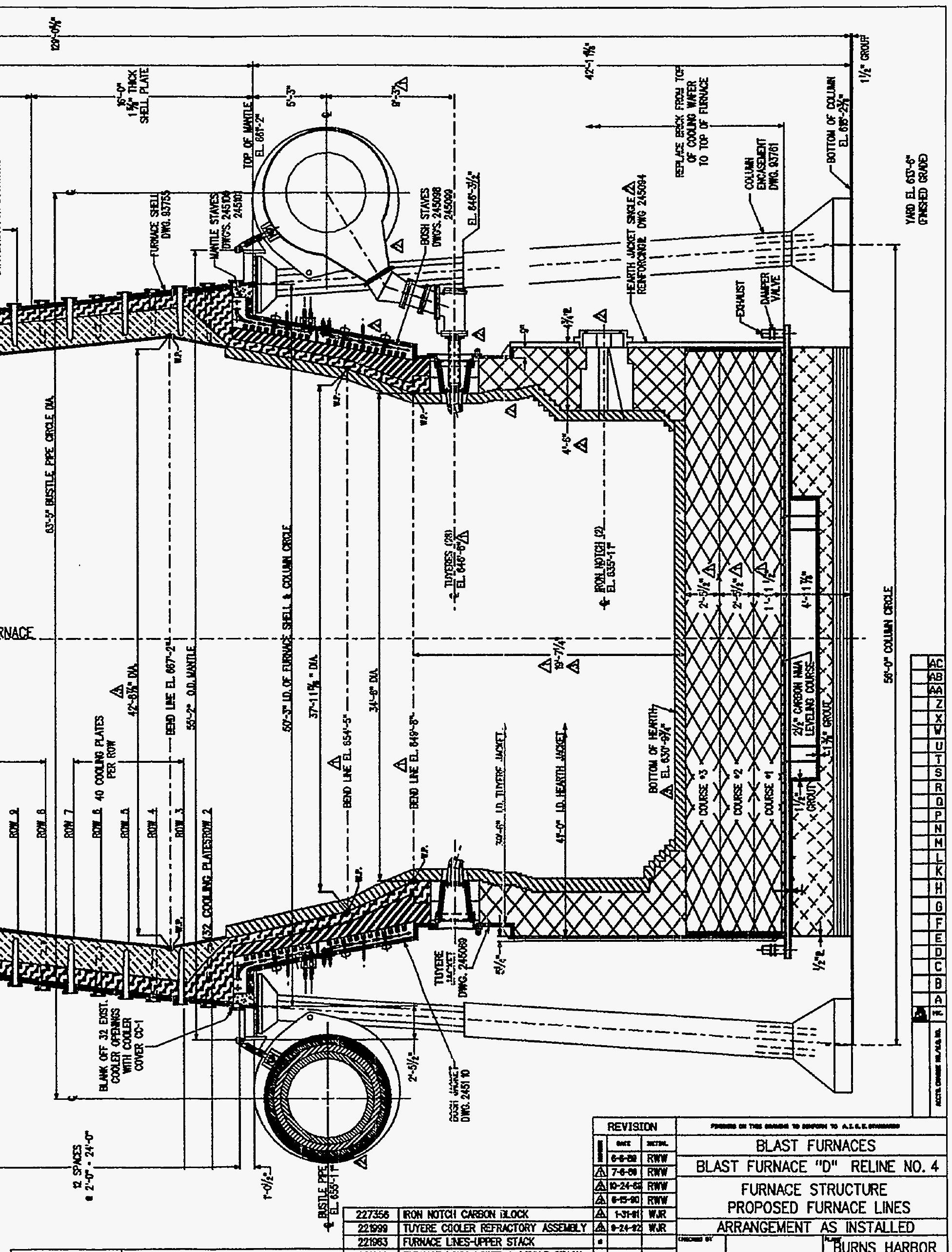




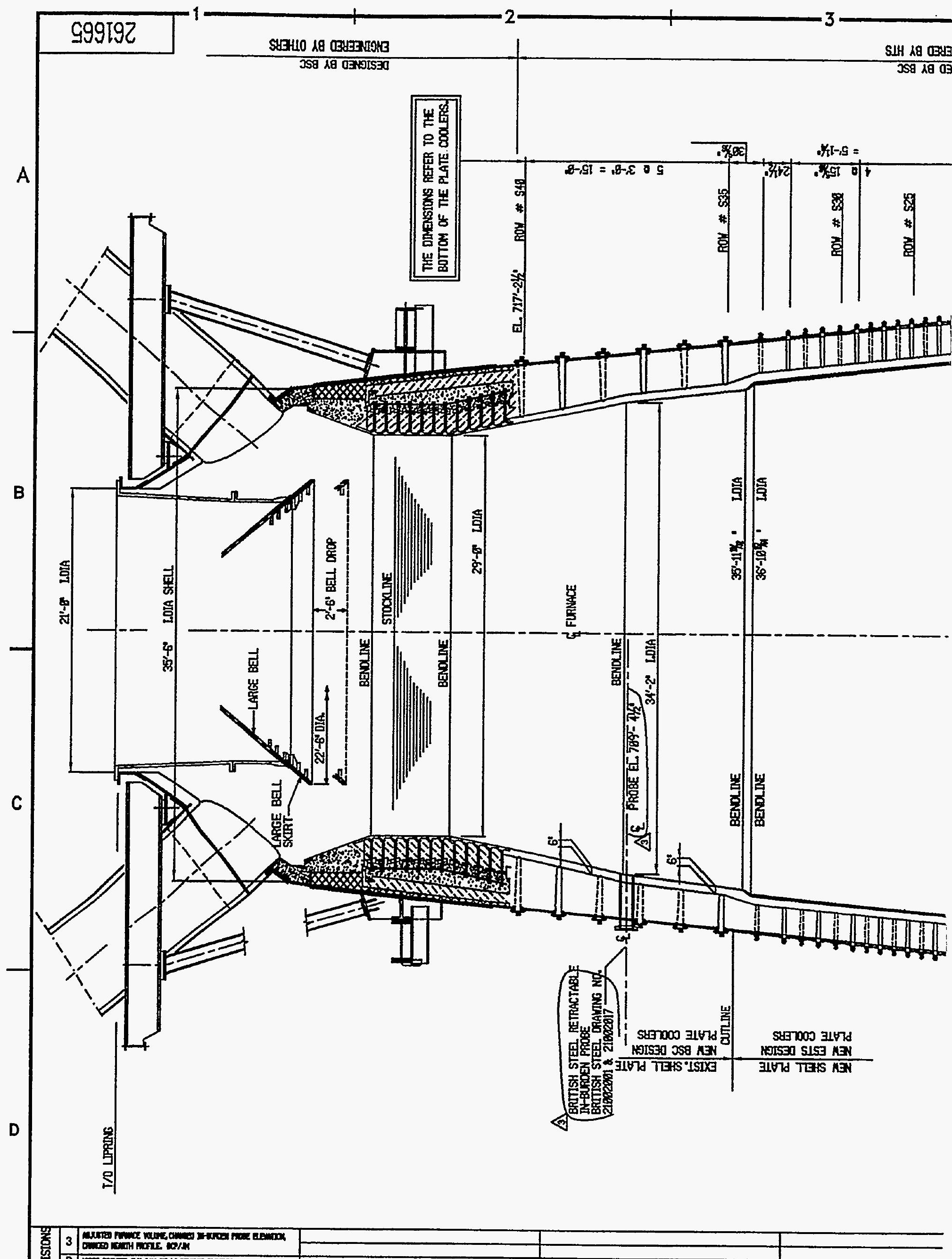




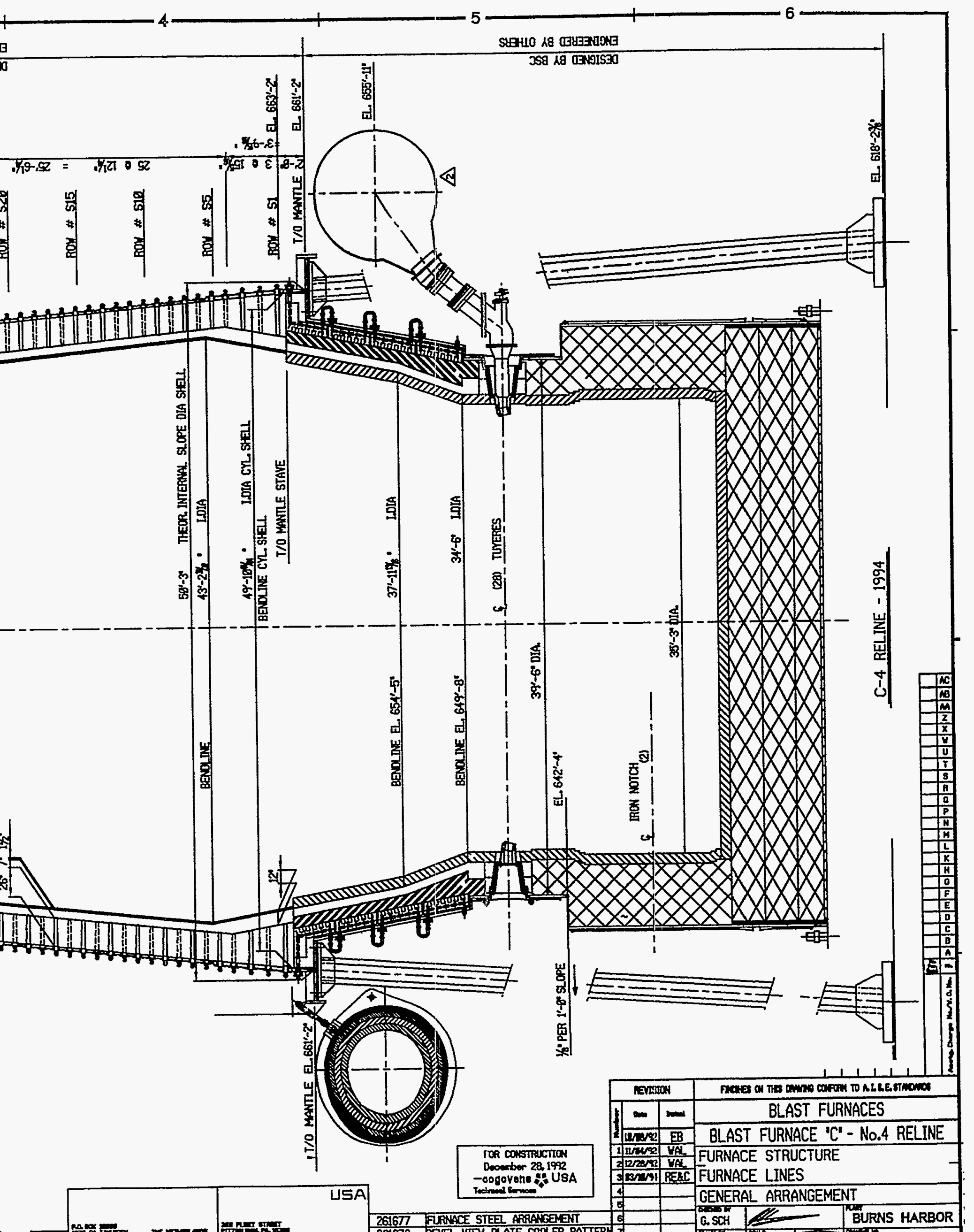




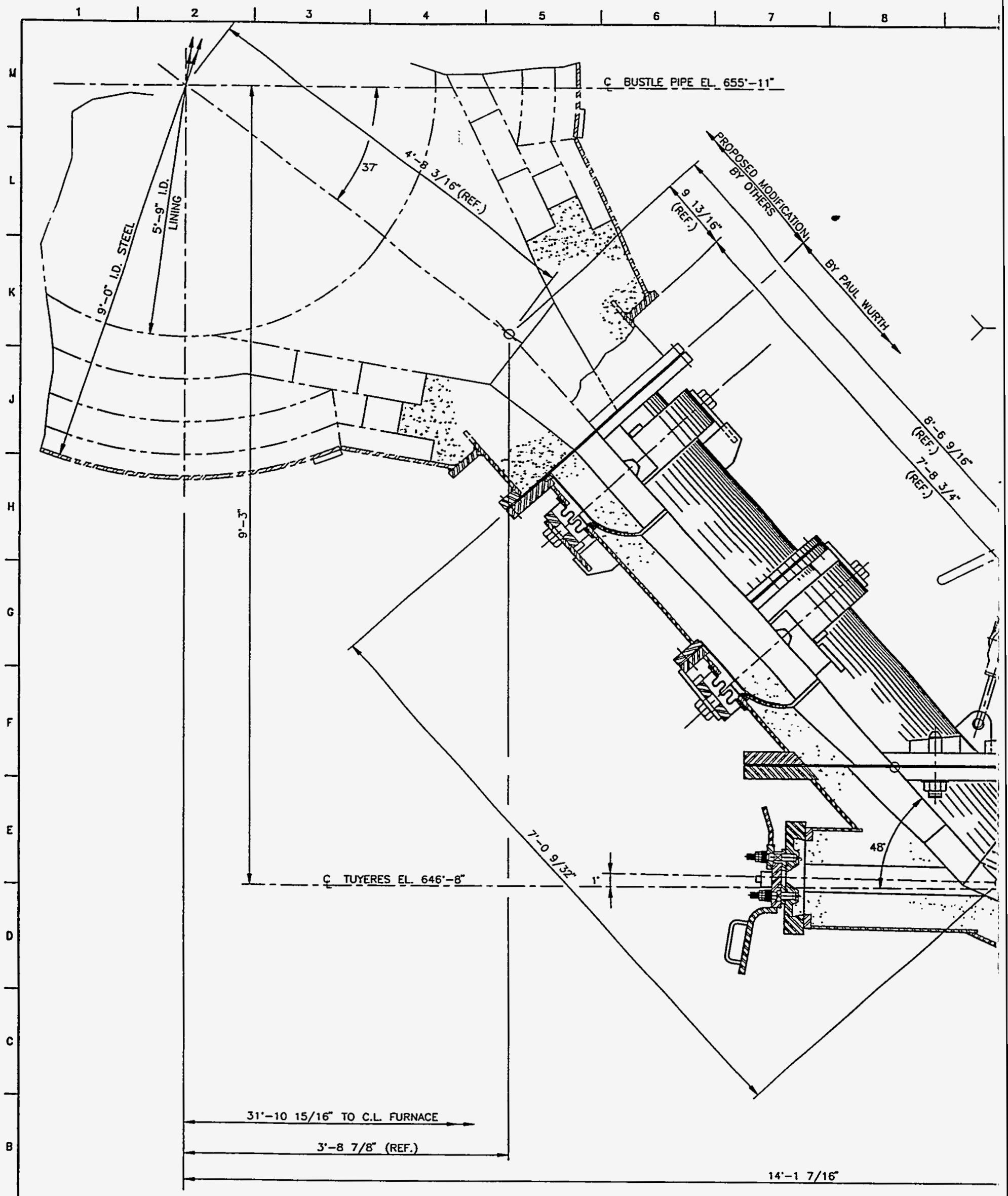




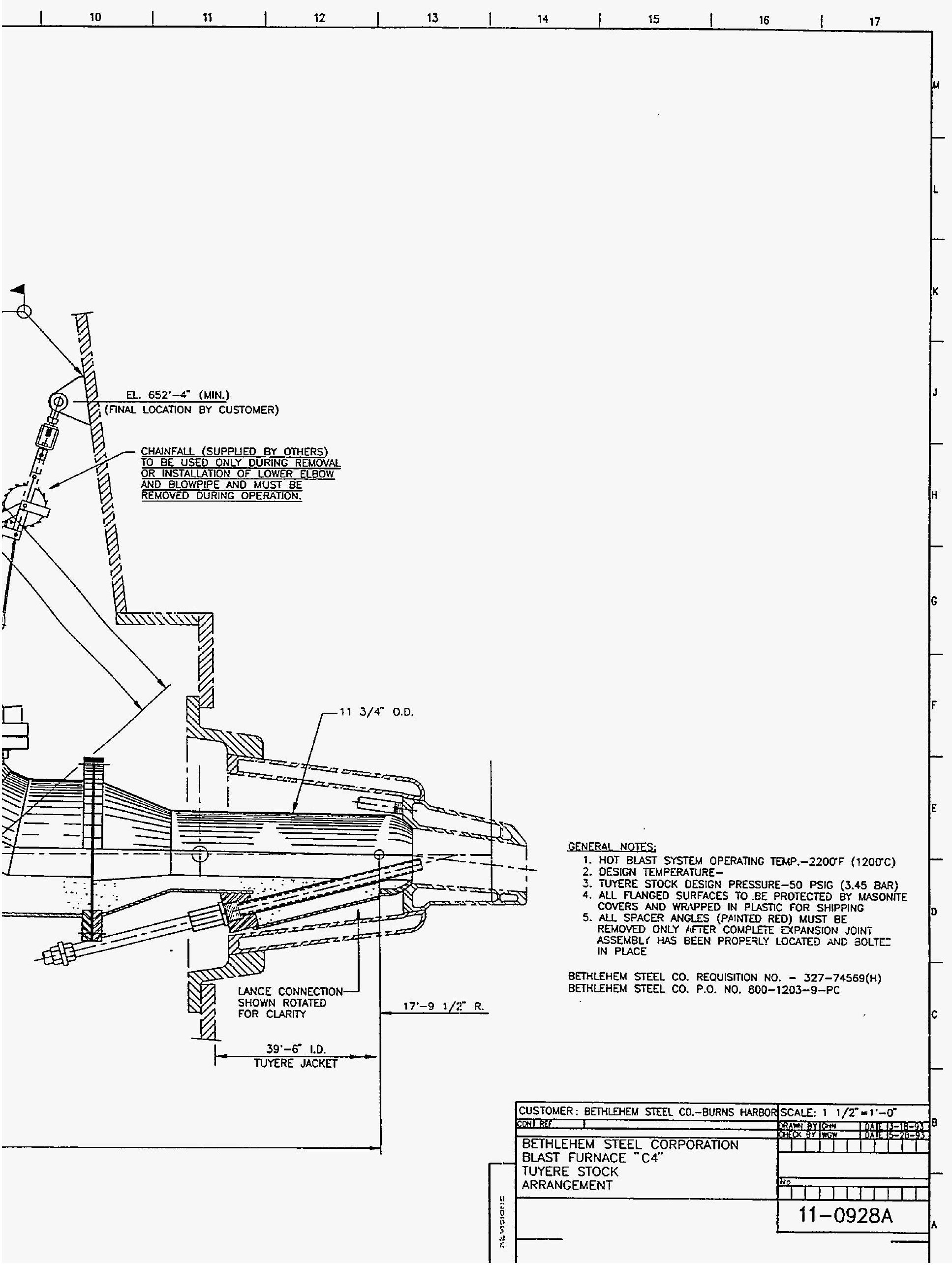




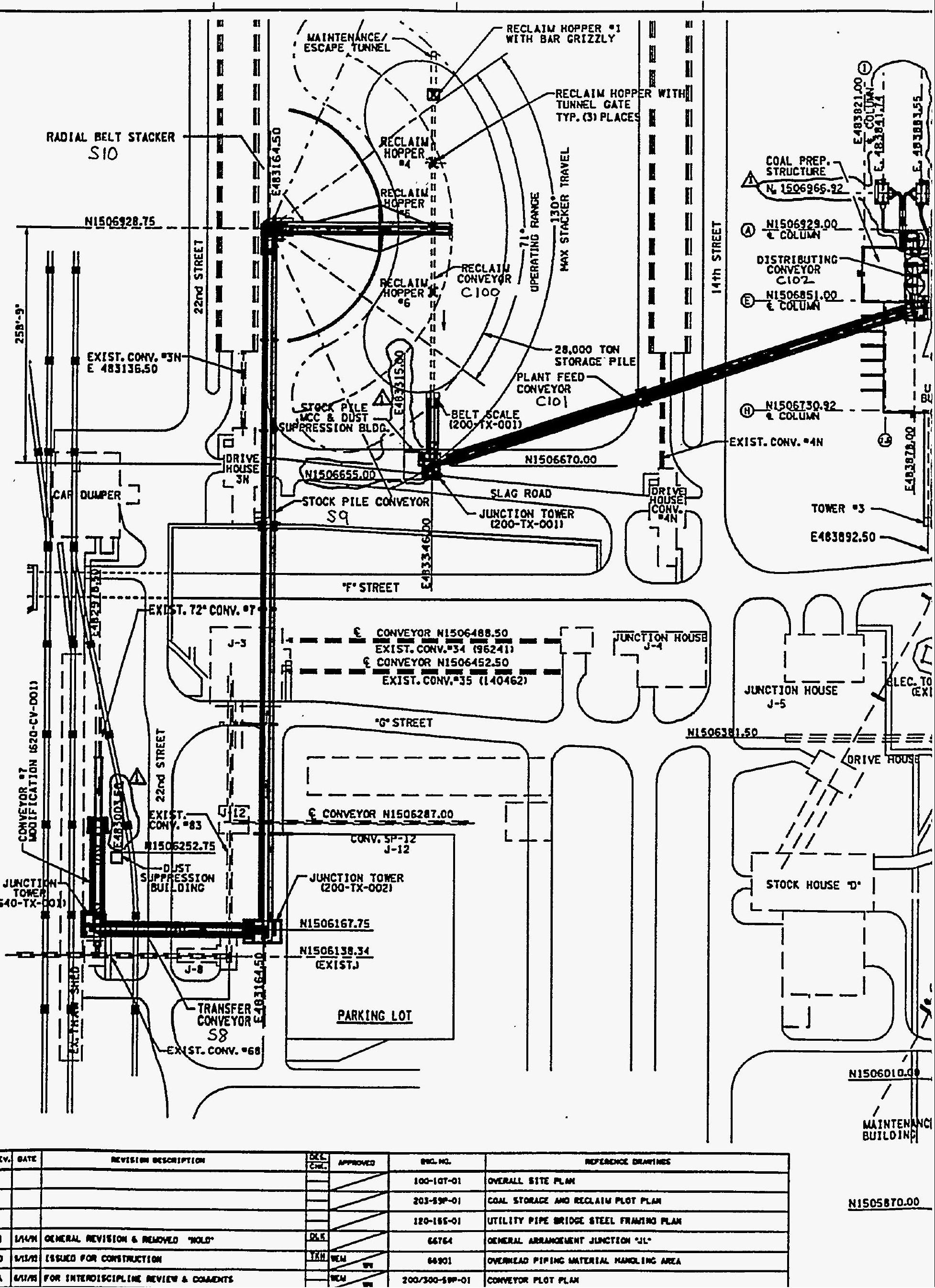




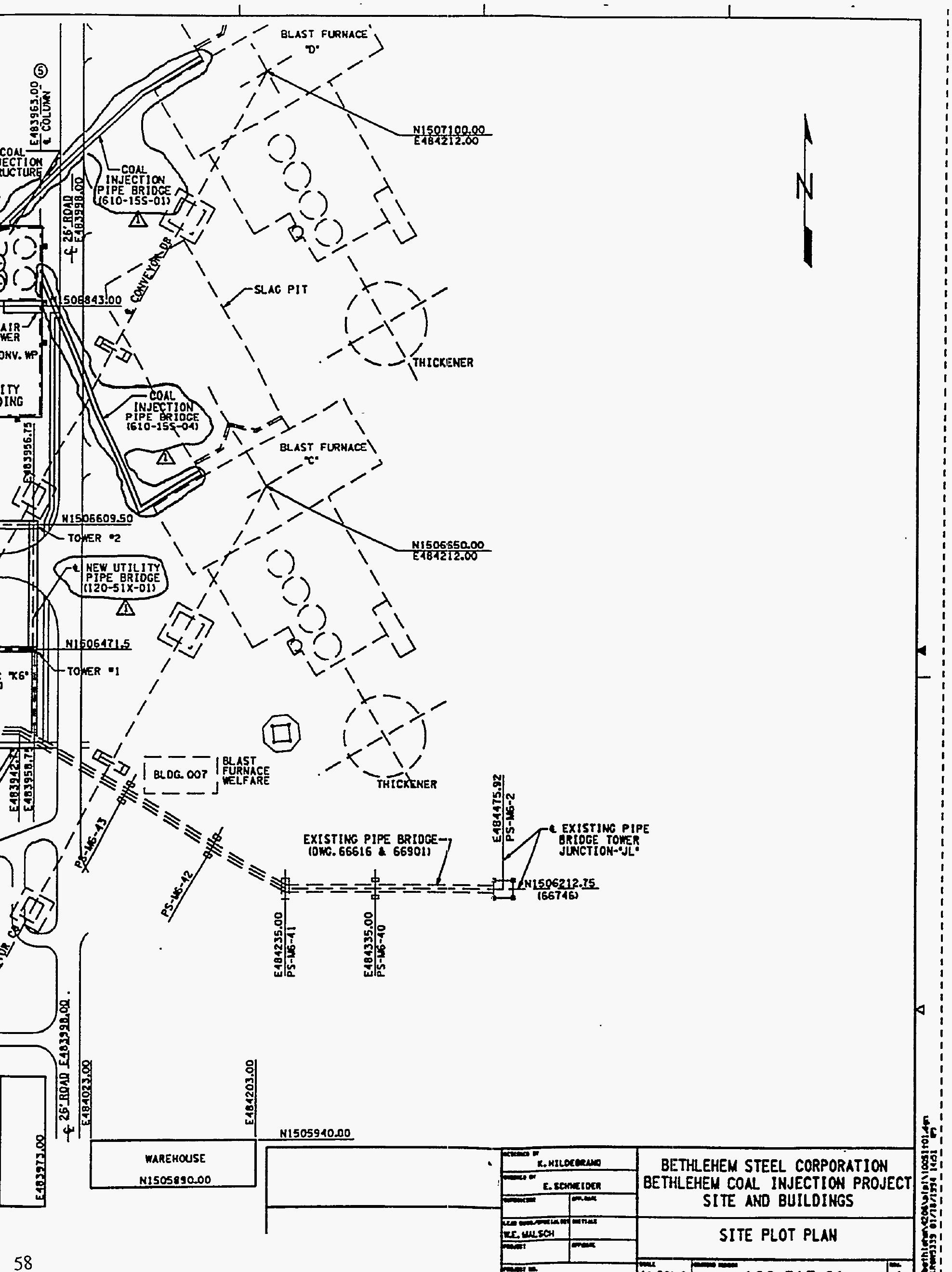




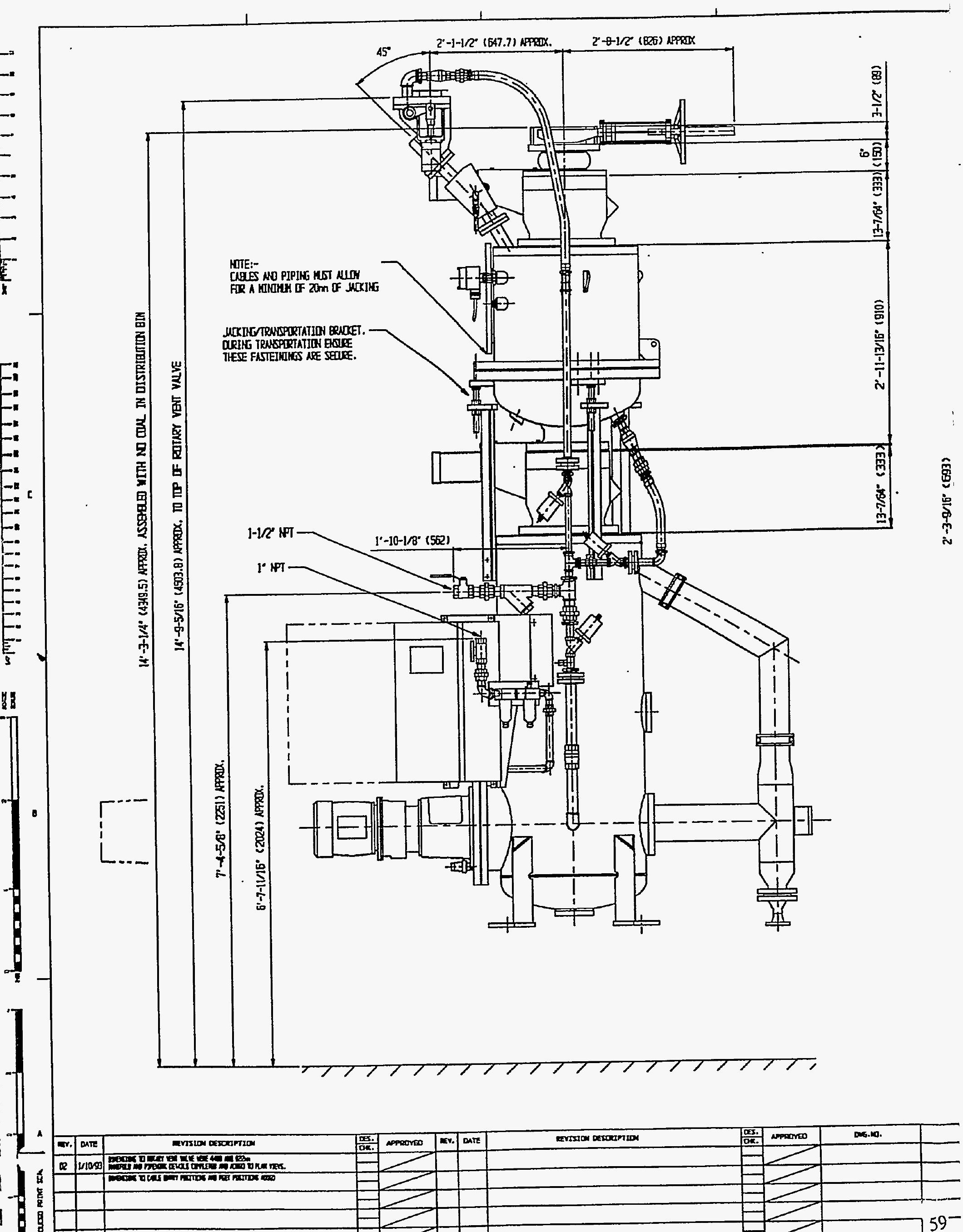




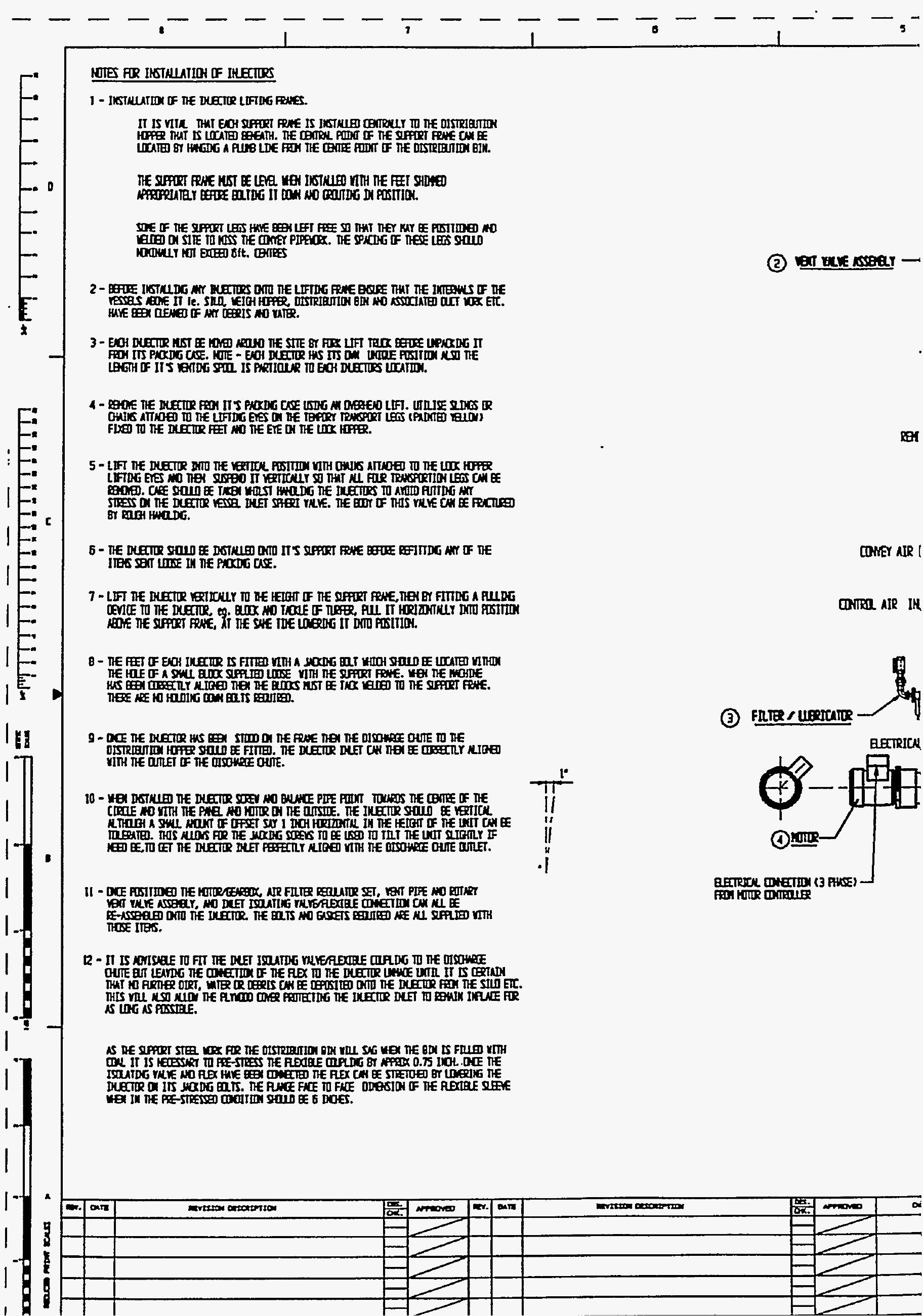




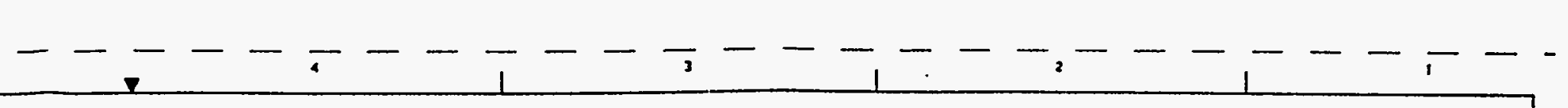

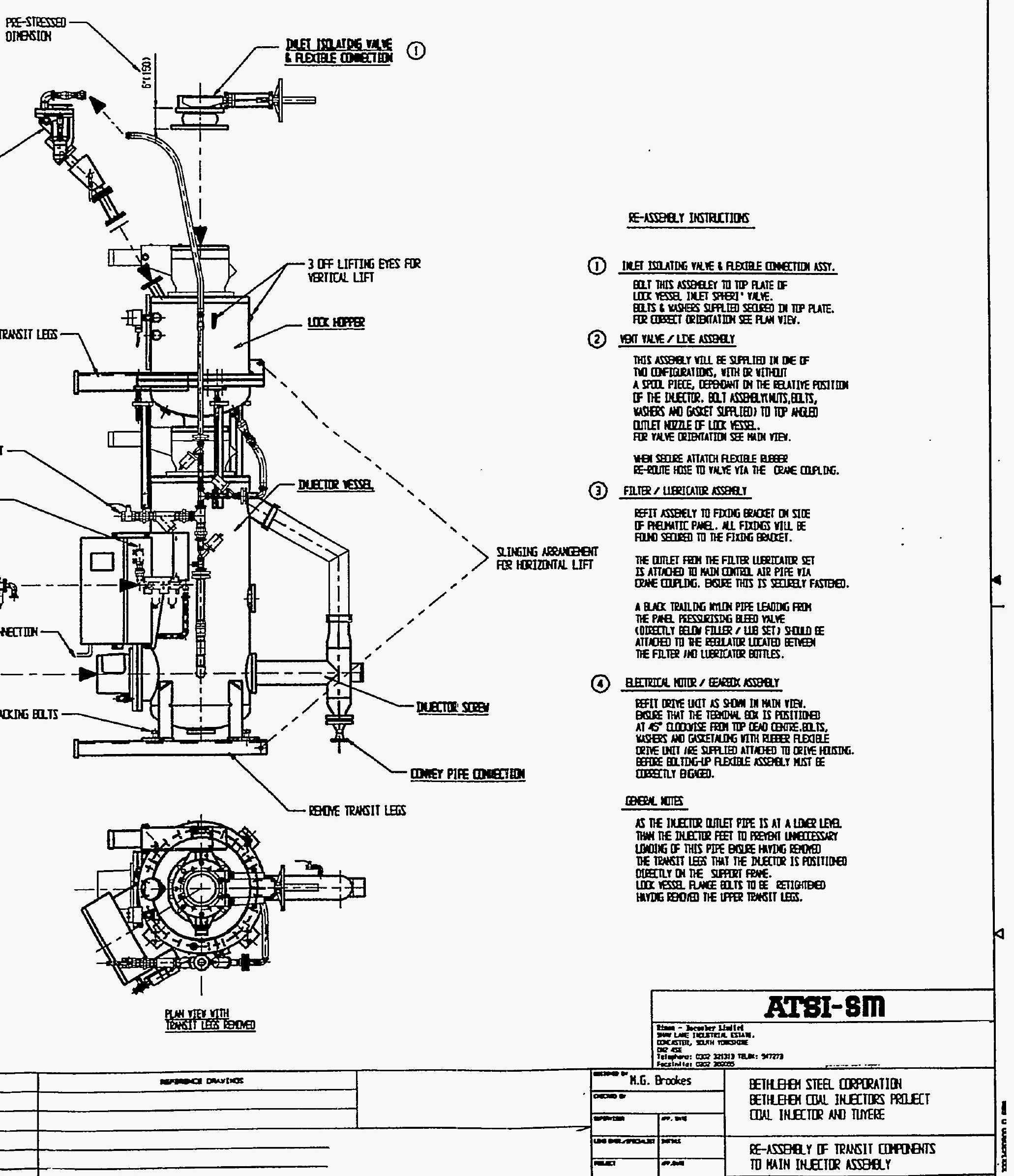




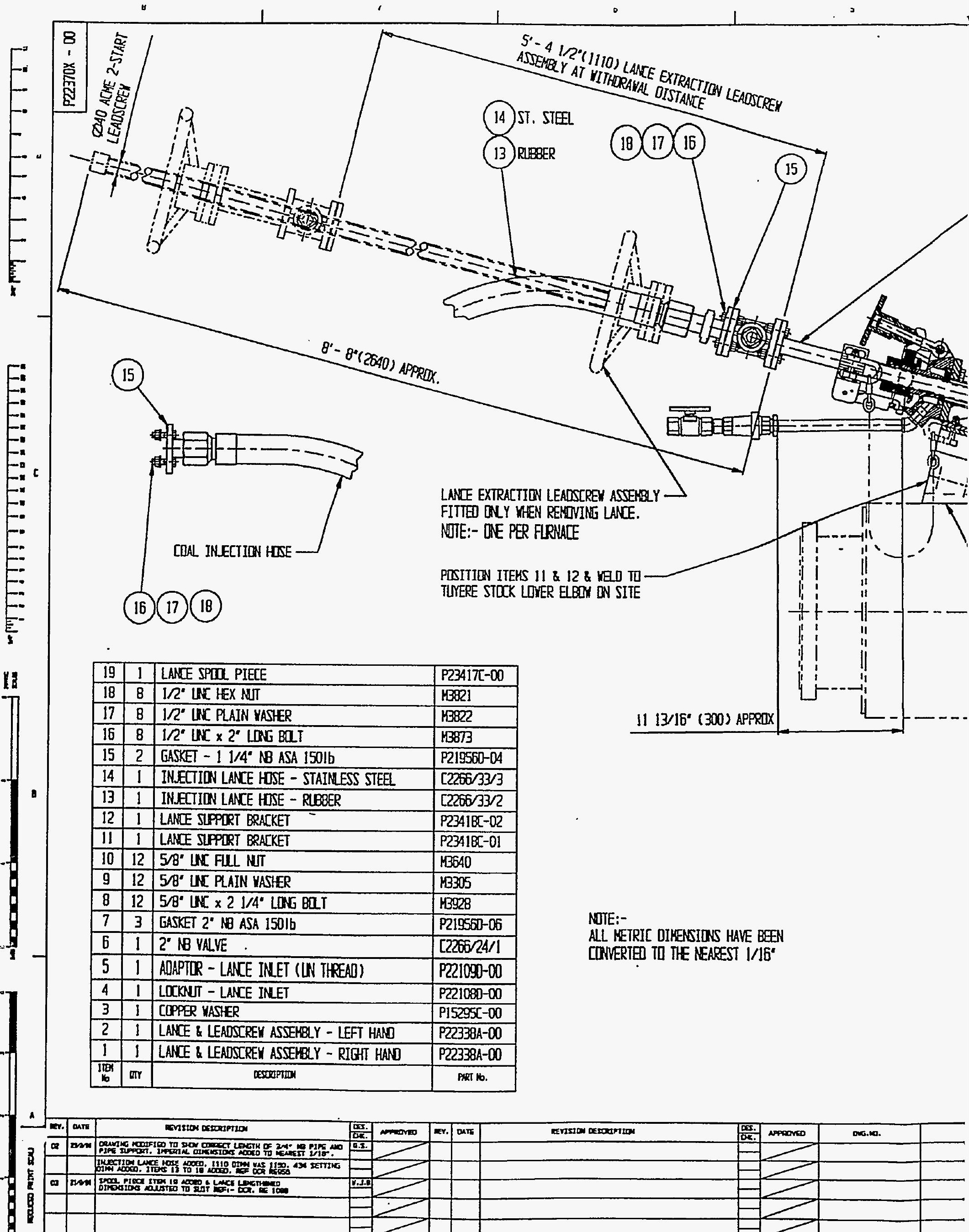




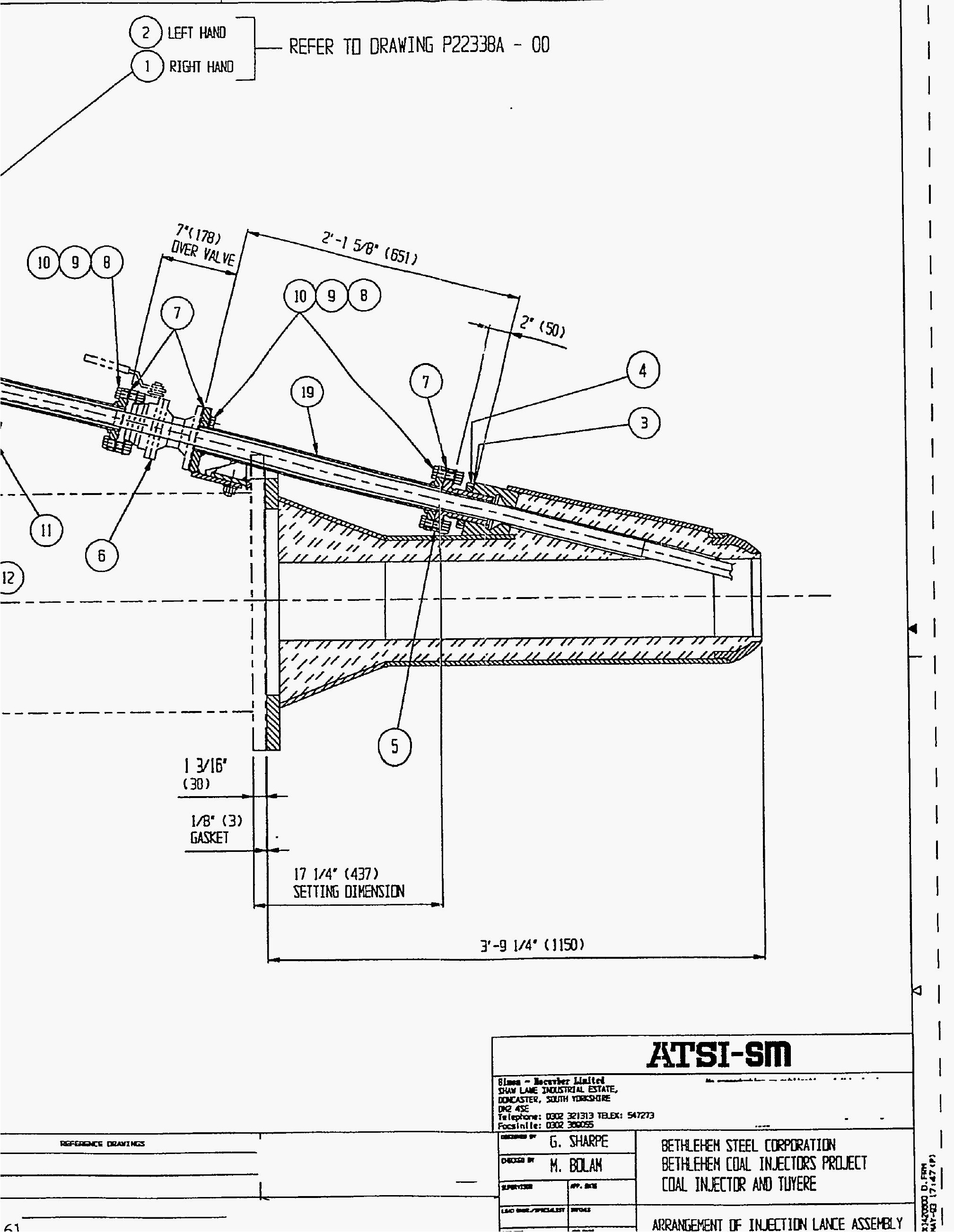




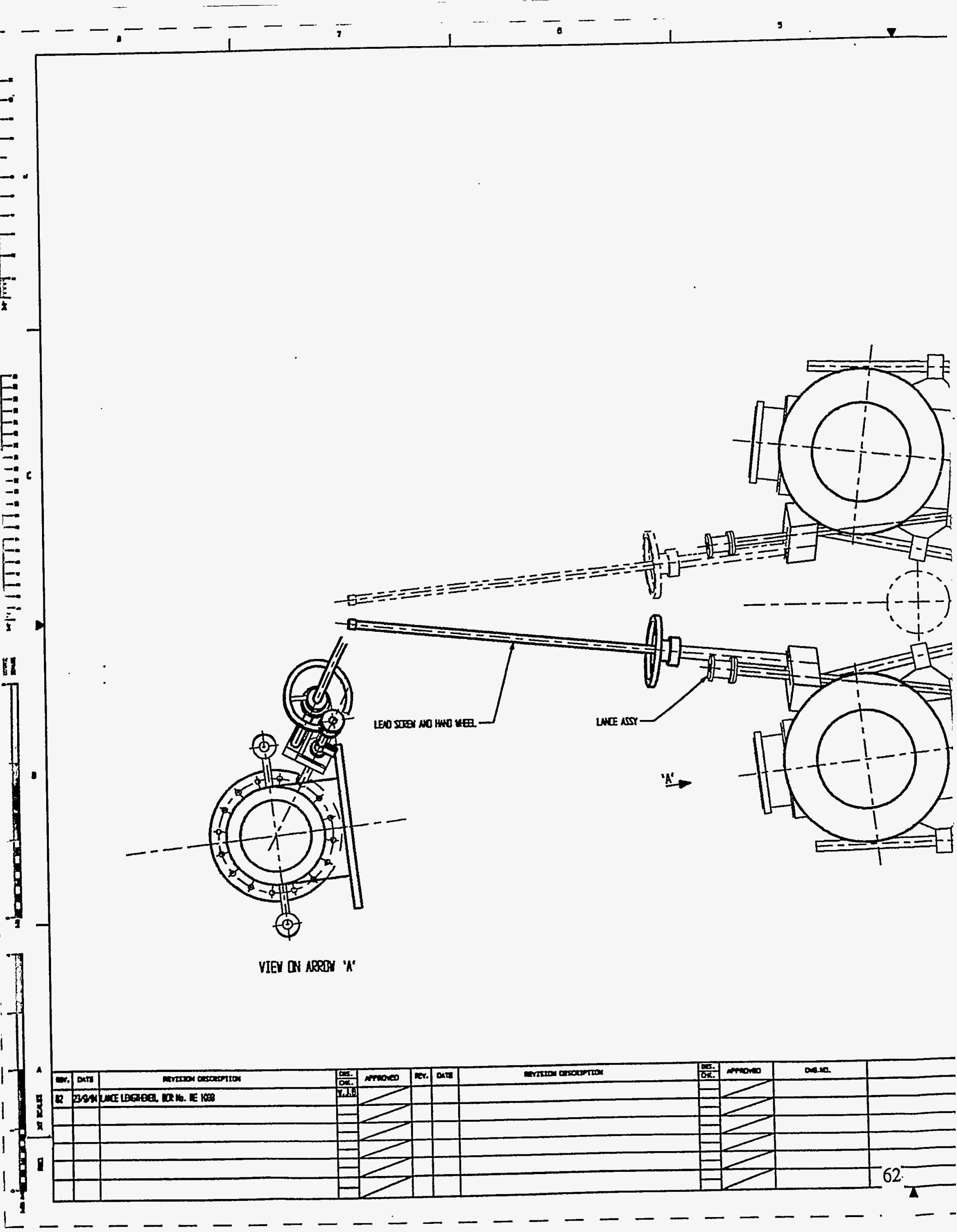




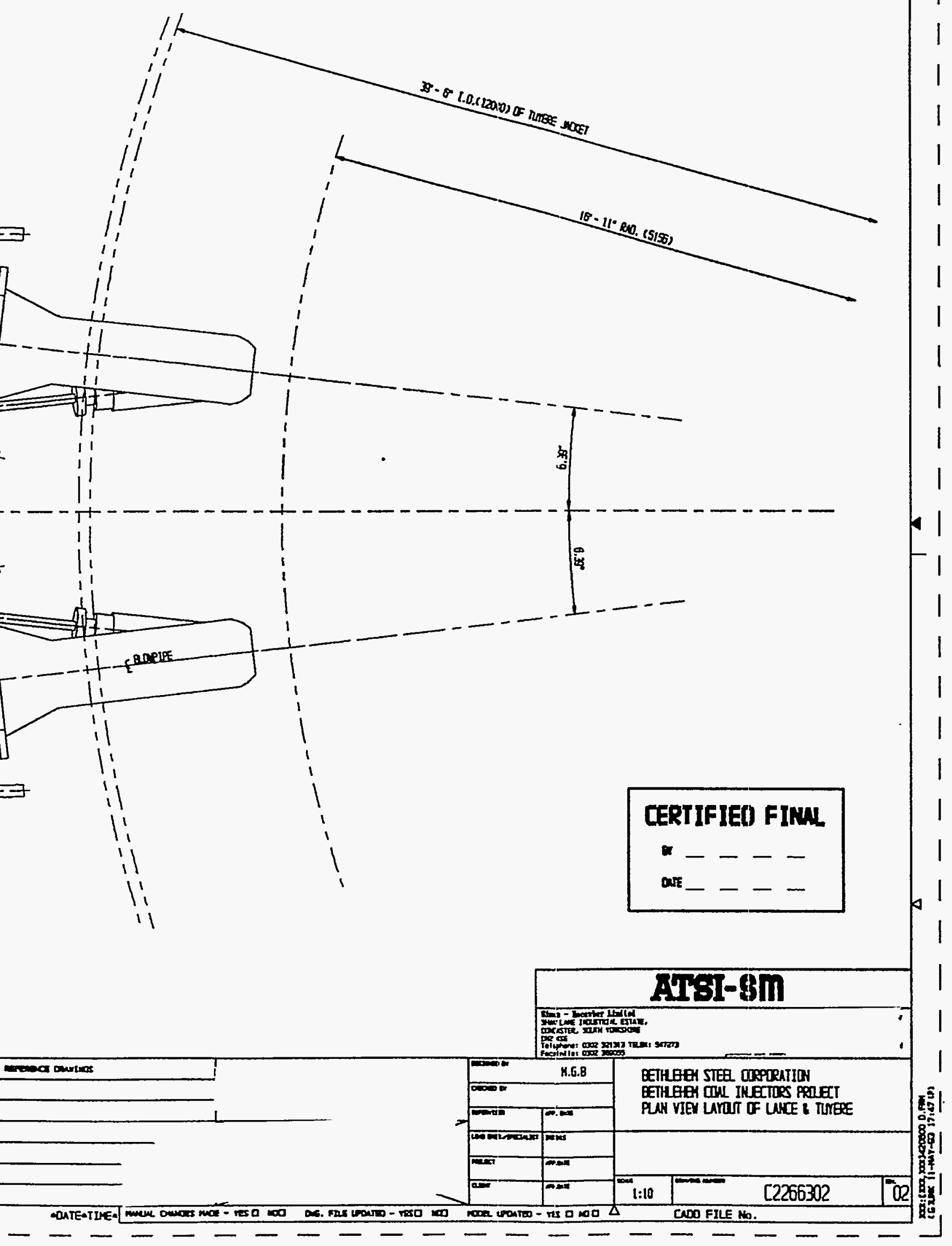




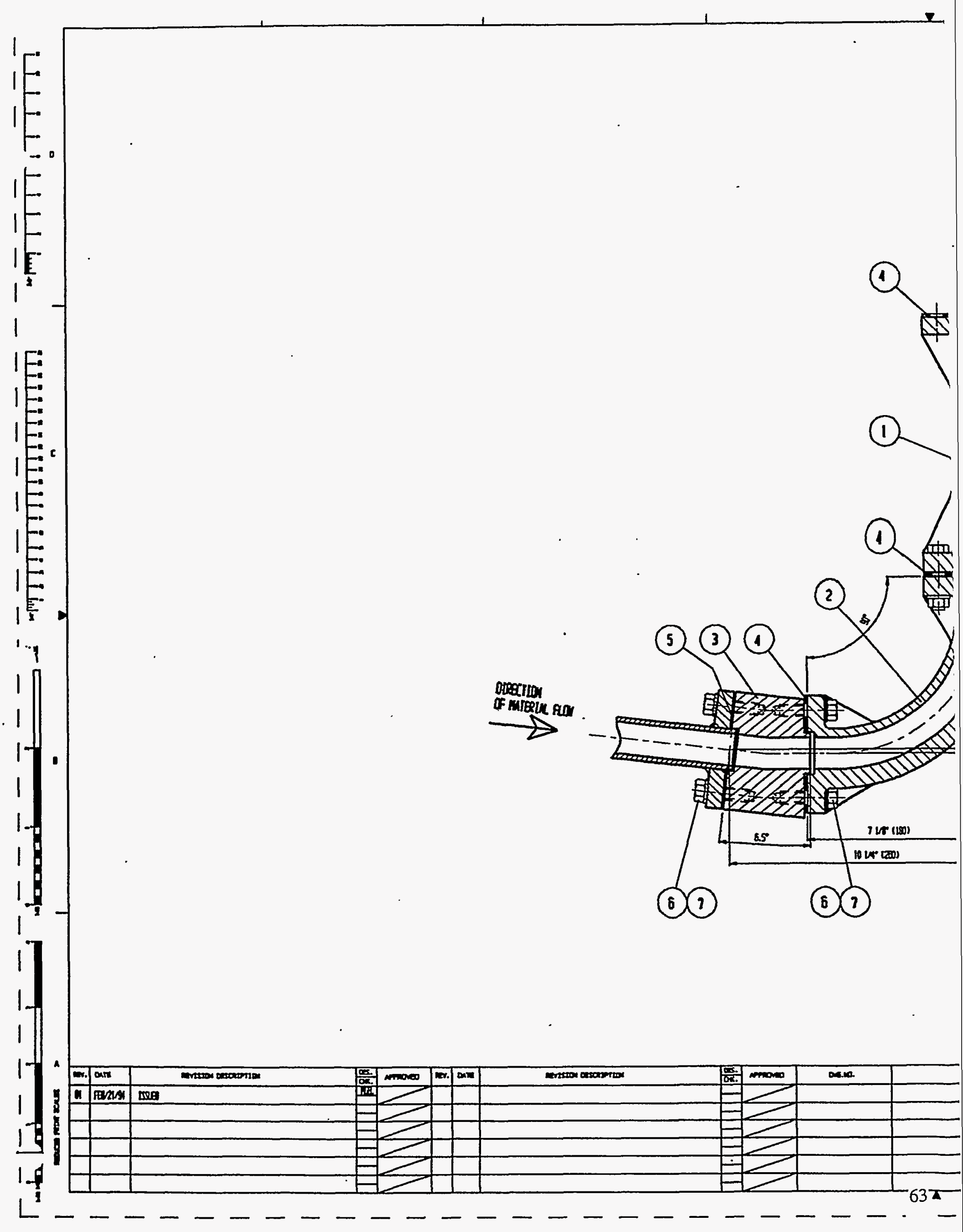




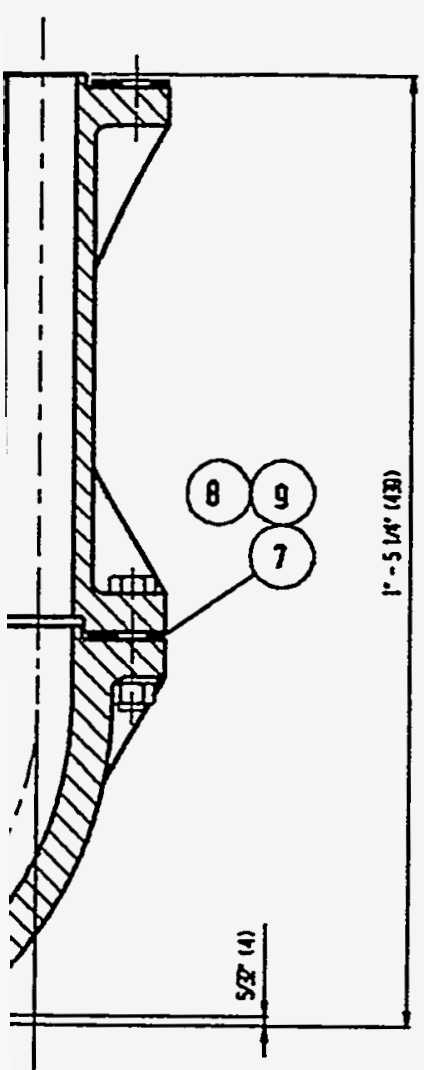

\begin{tabular}{|c|c|c|c|}
\hline 田 & 8 & 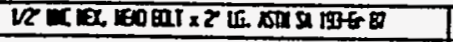 & \\
\hline 由 & 8 & Ve arcon angaga & \\
\hline 0 & 5 & VR STERAI wa & \\
\hline 66 & 8 & 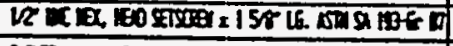 & \\
\hline Б5 & 1 & 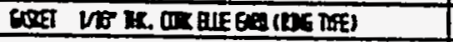 & \\
\hline B & 3 & 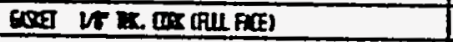 & \\
\hline B & 1 & $65^{\circ}-\mathrm{m} \times \mathrm{gII}$ & P2023 0 \\
\hline $\mathbf{Q}$ & 1 & 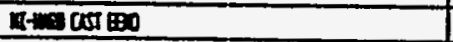 & P2008 -11 \\
\hline fif & I & $8 \div 20075000$ & $\operatorname{ran} \theta$ \\
\hline II: & H. & Bring & inn \\
\hline
\end{tabular}

AIE] $-8 m$

ing

cocosition

fertinter

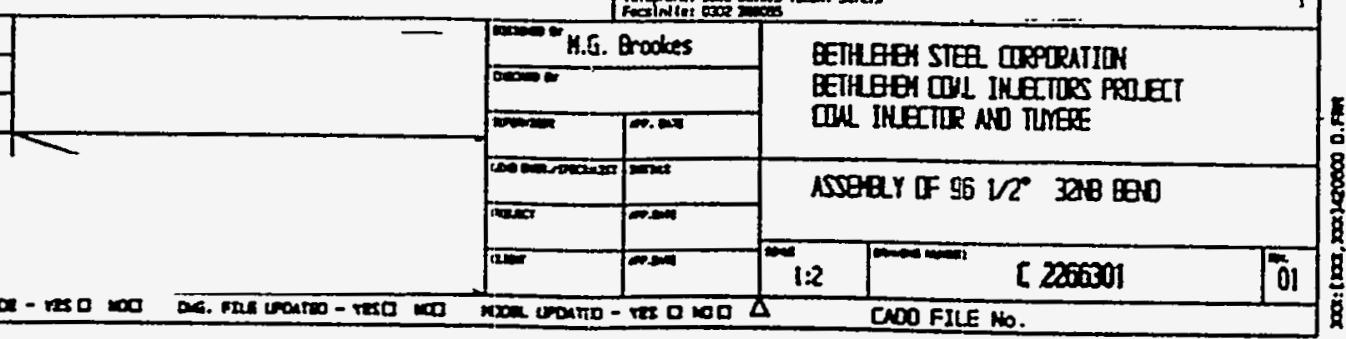

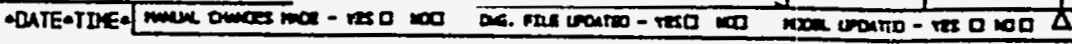




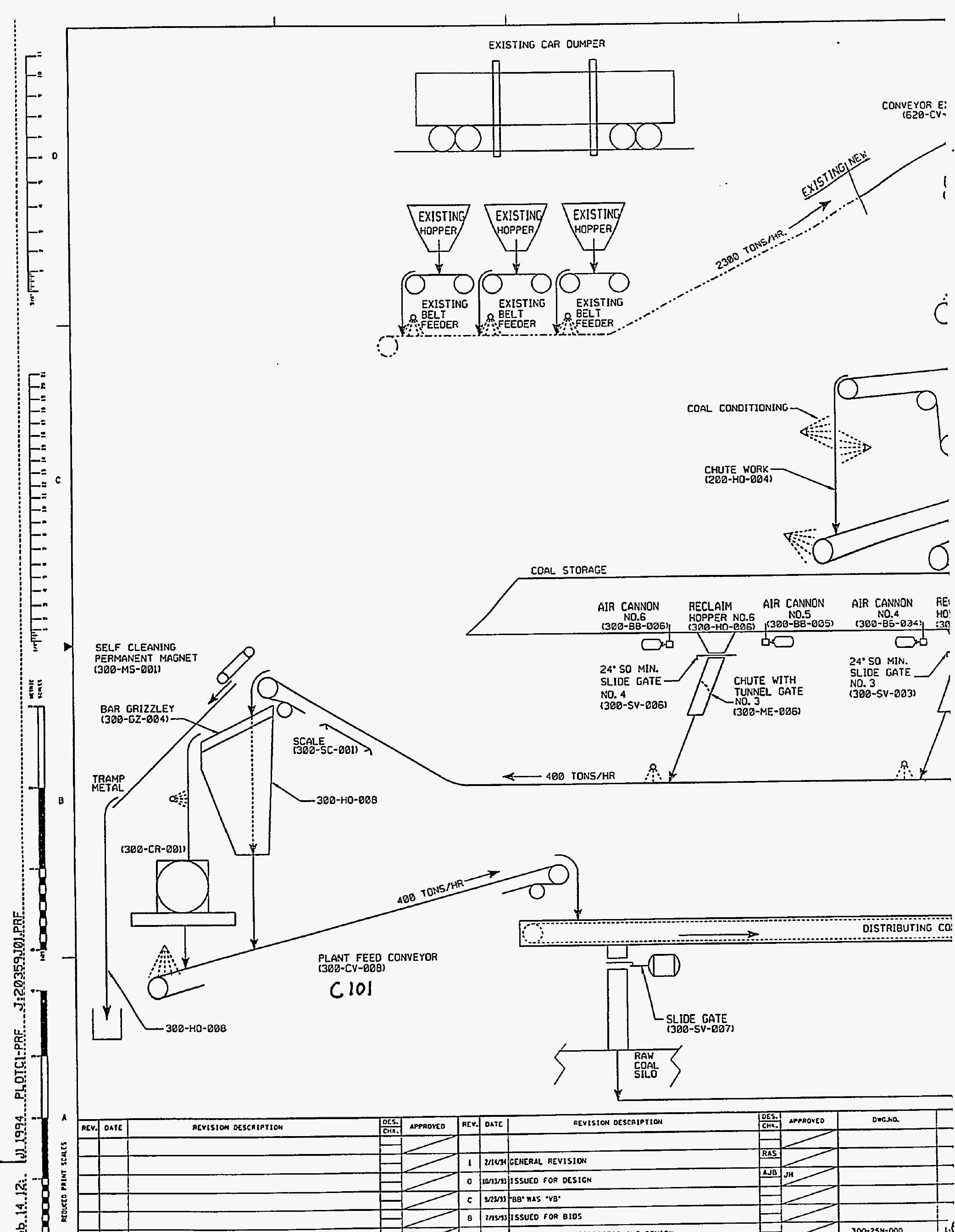




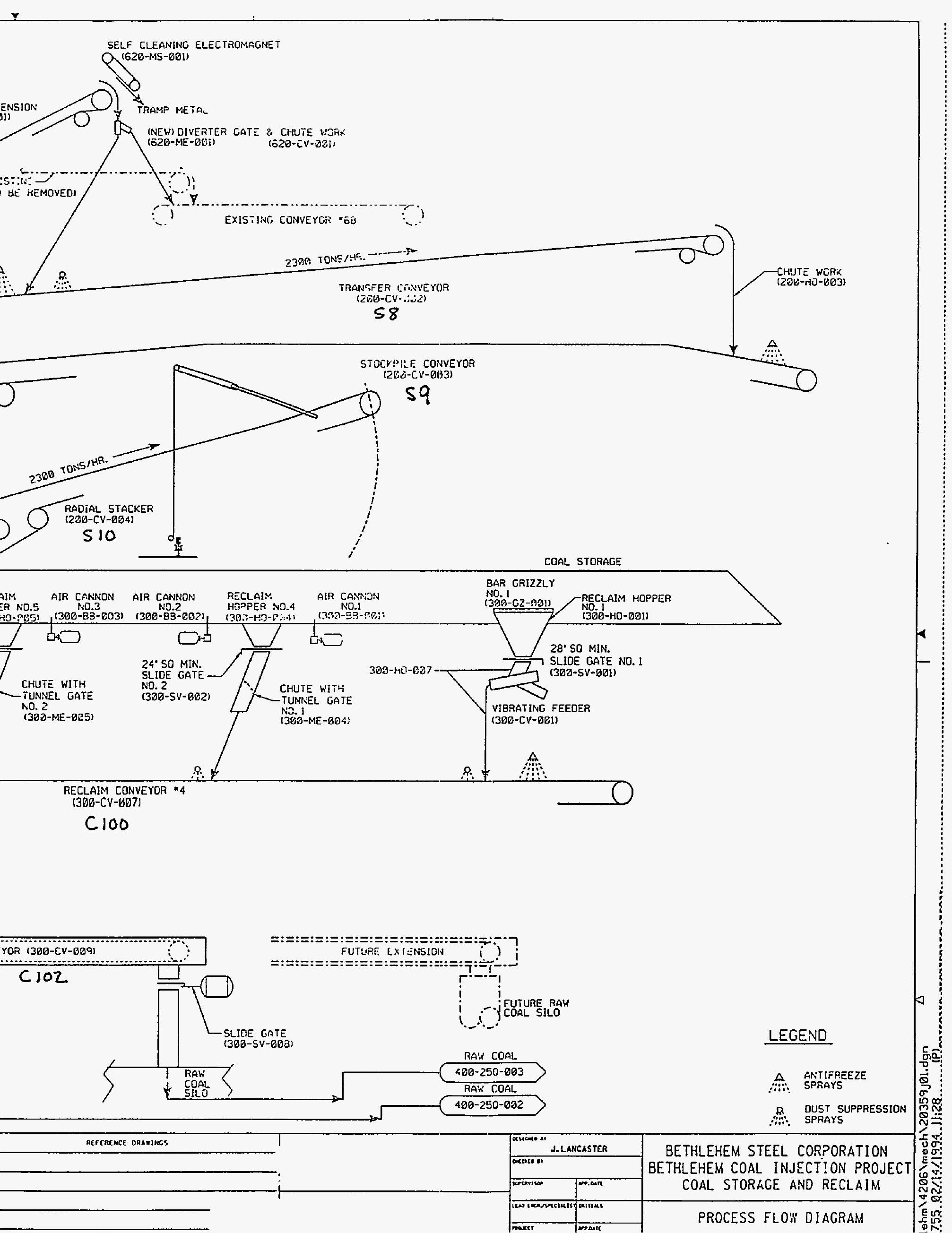




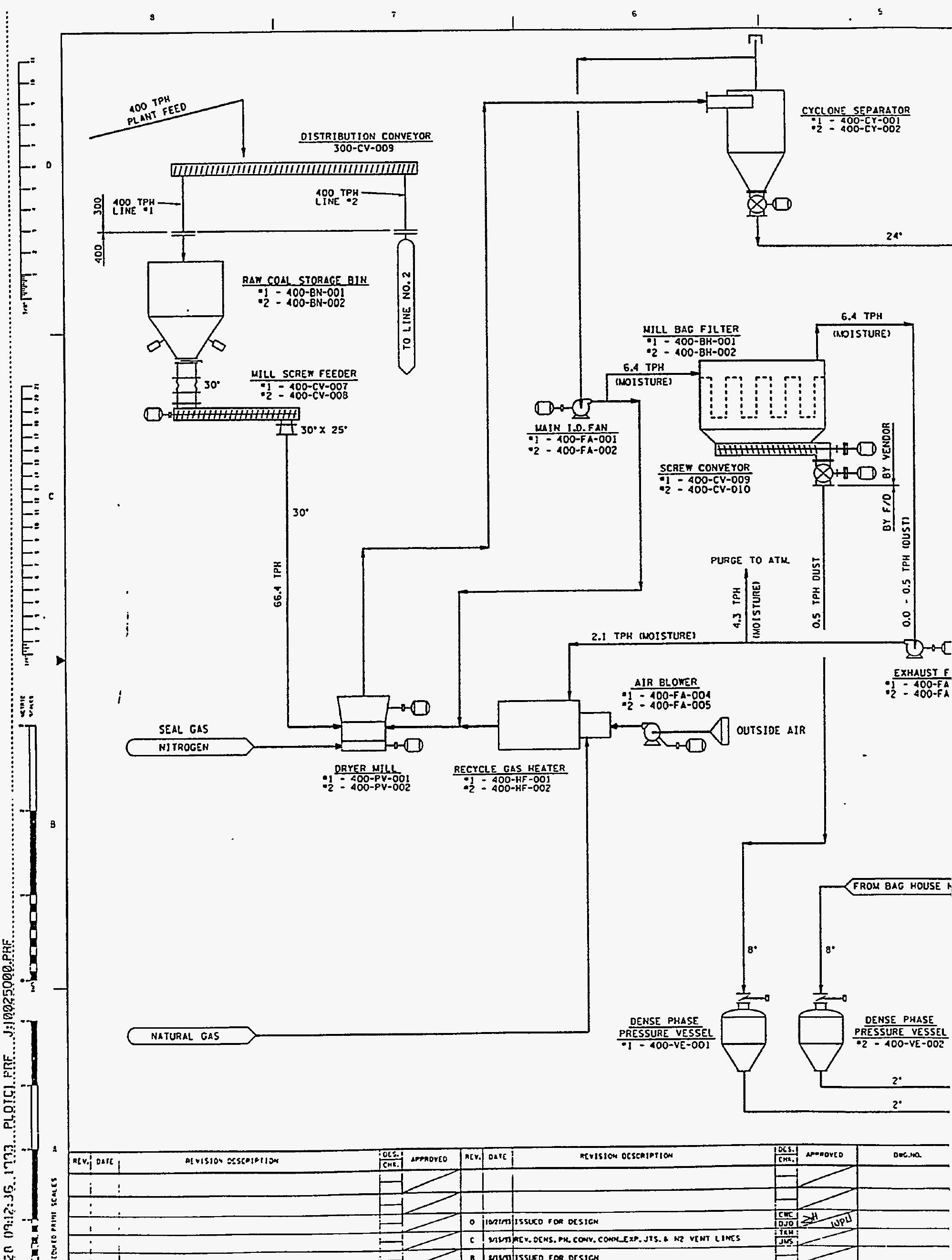




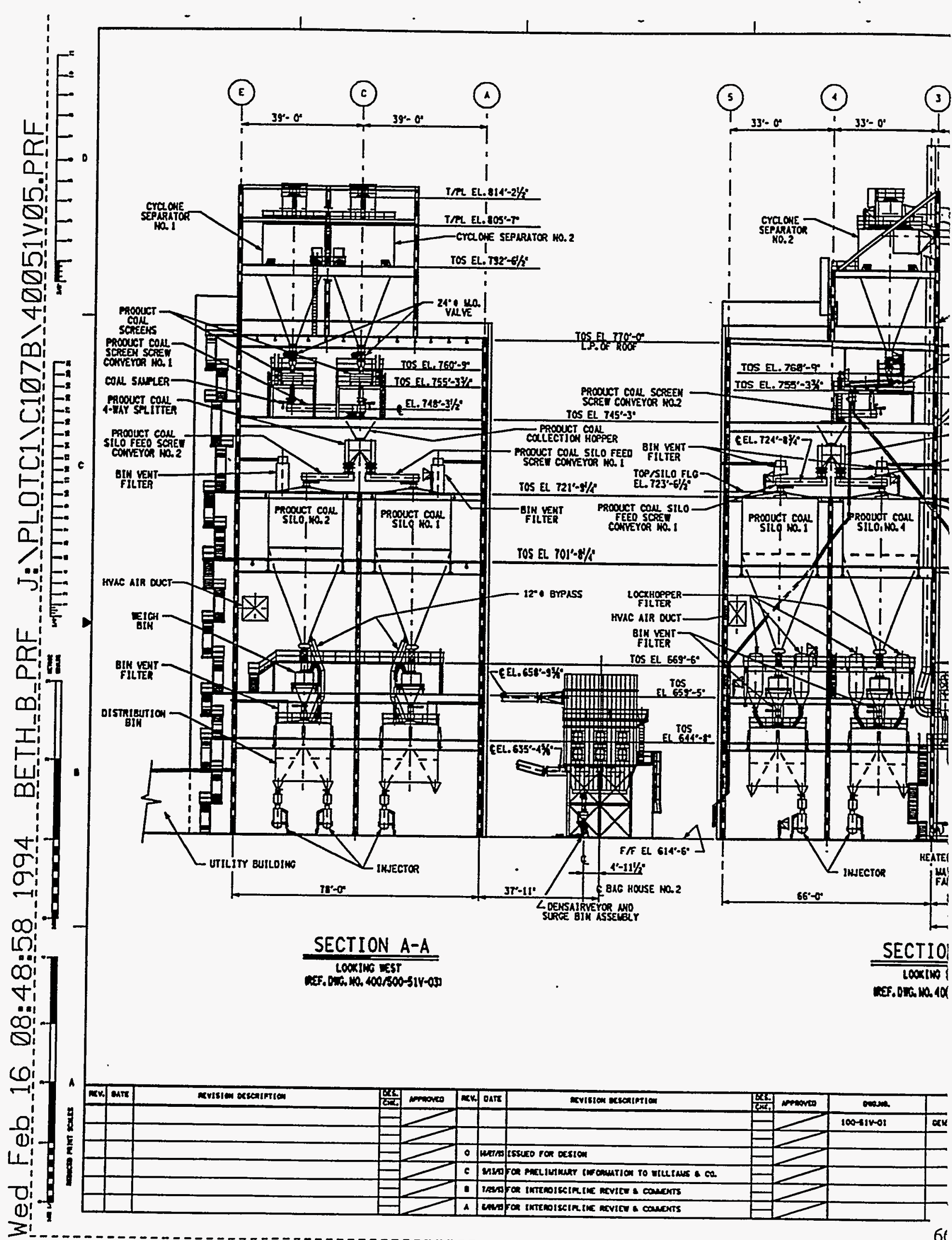




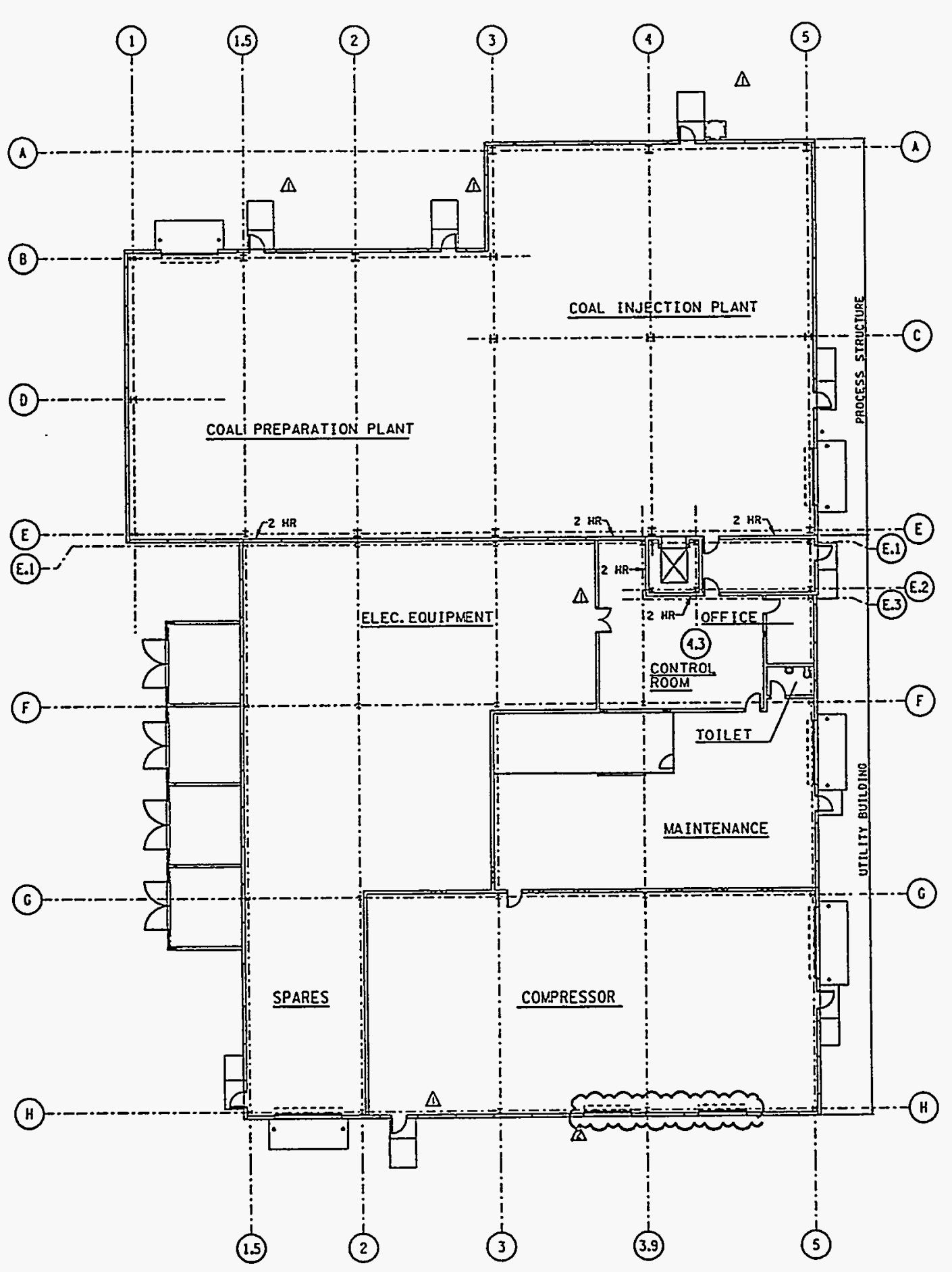

(3)

(3.9) 


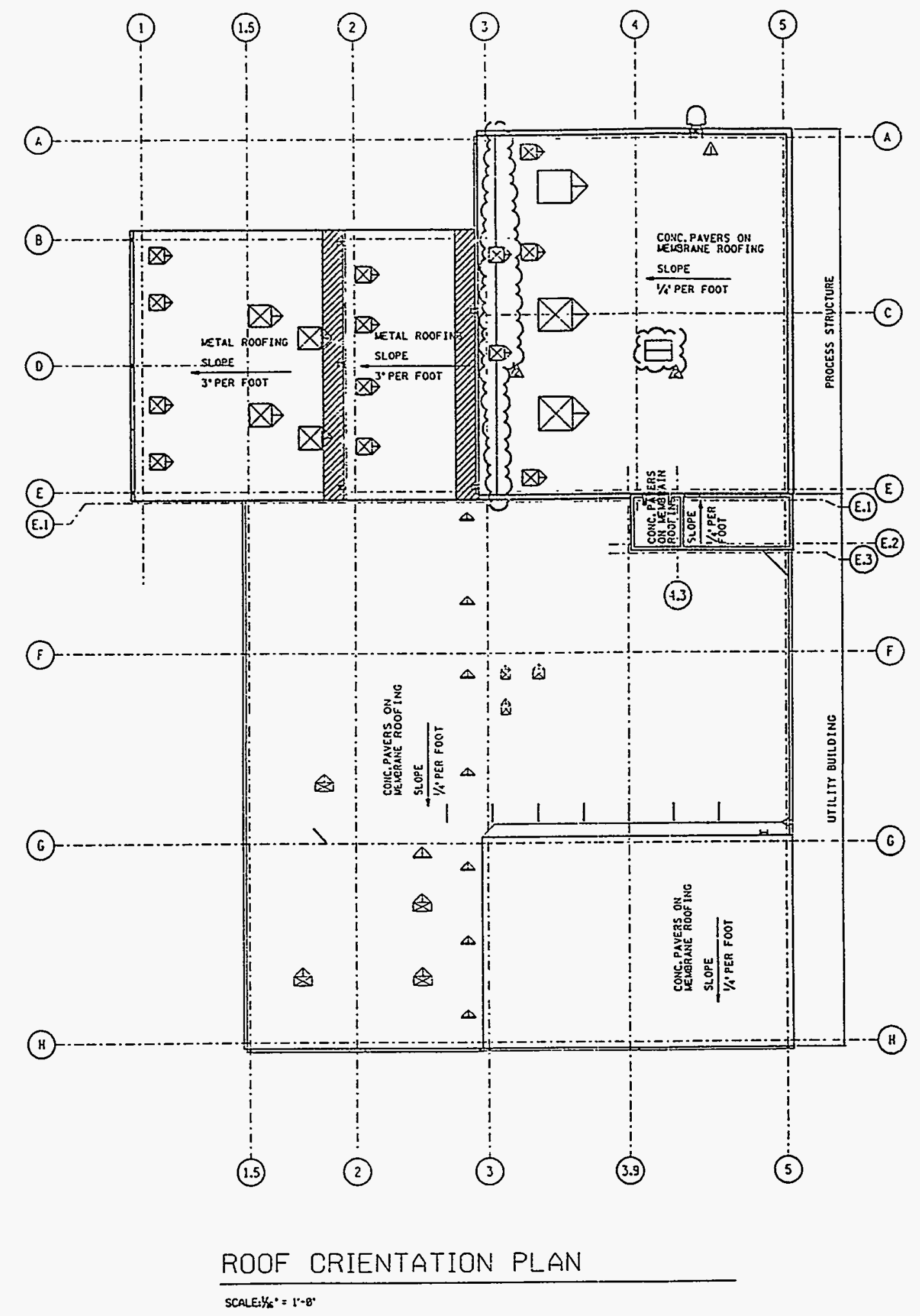

$N^{N}$

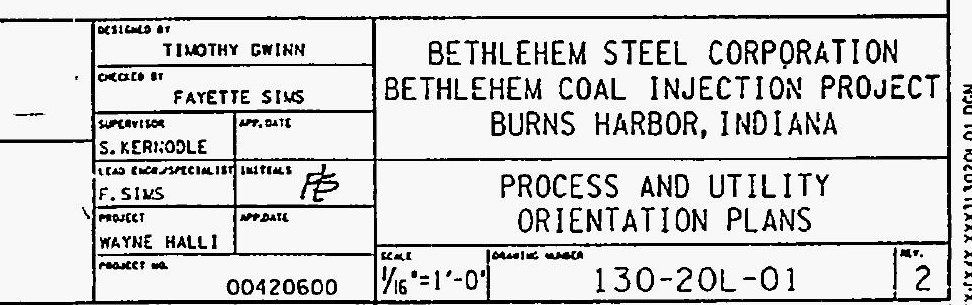




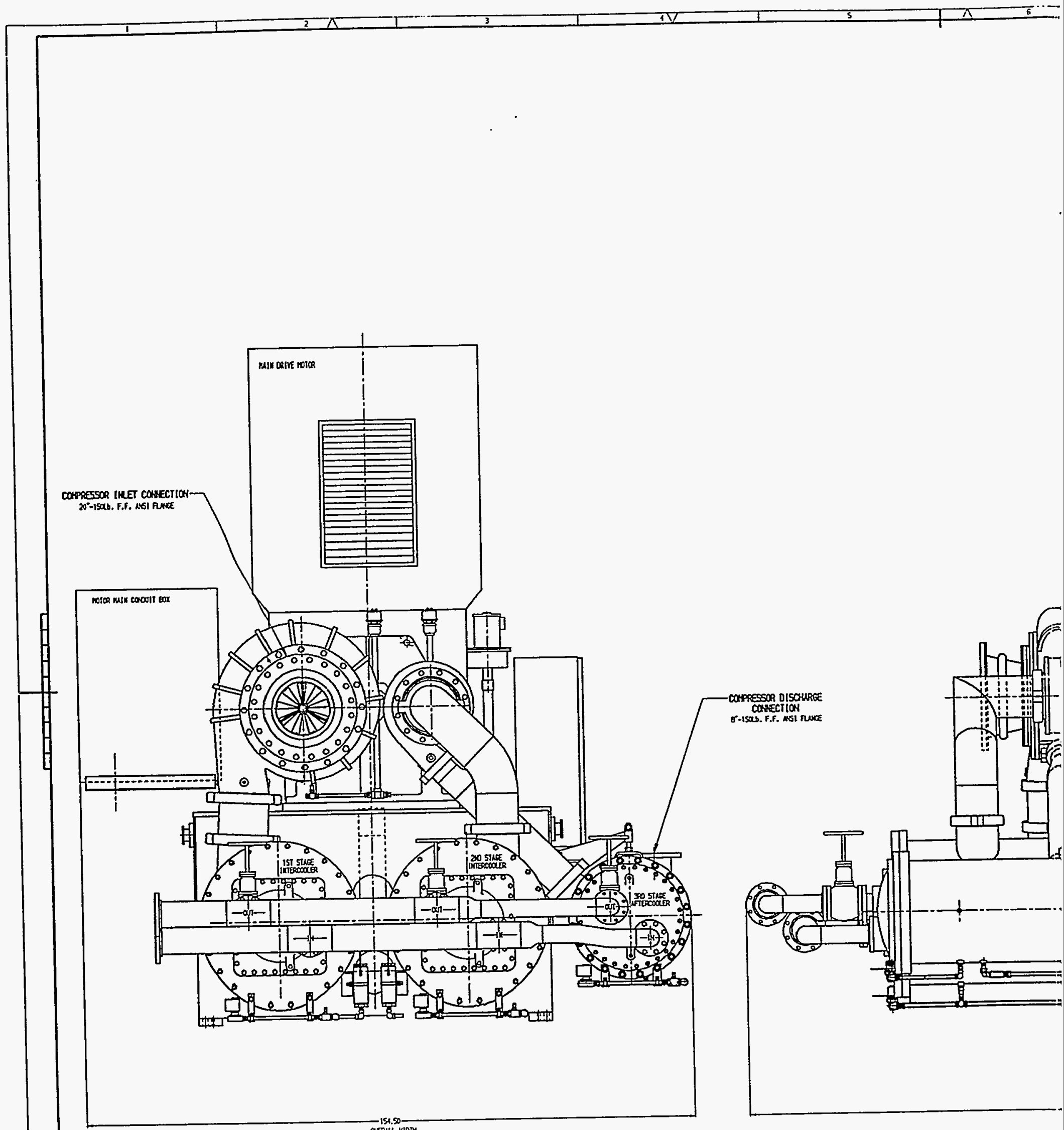




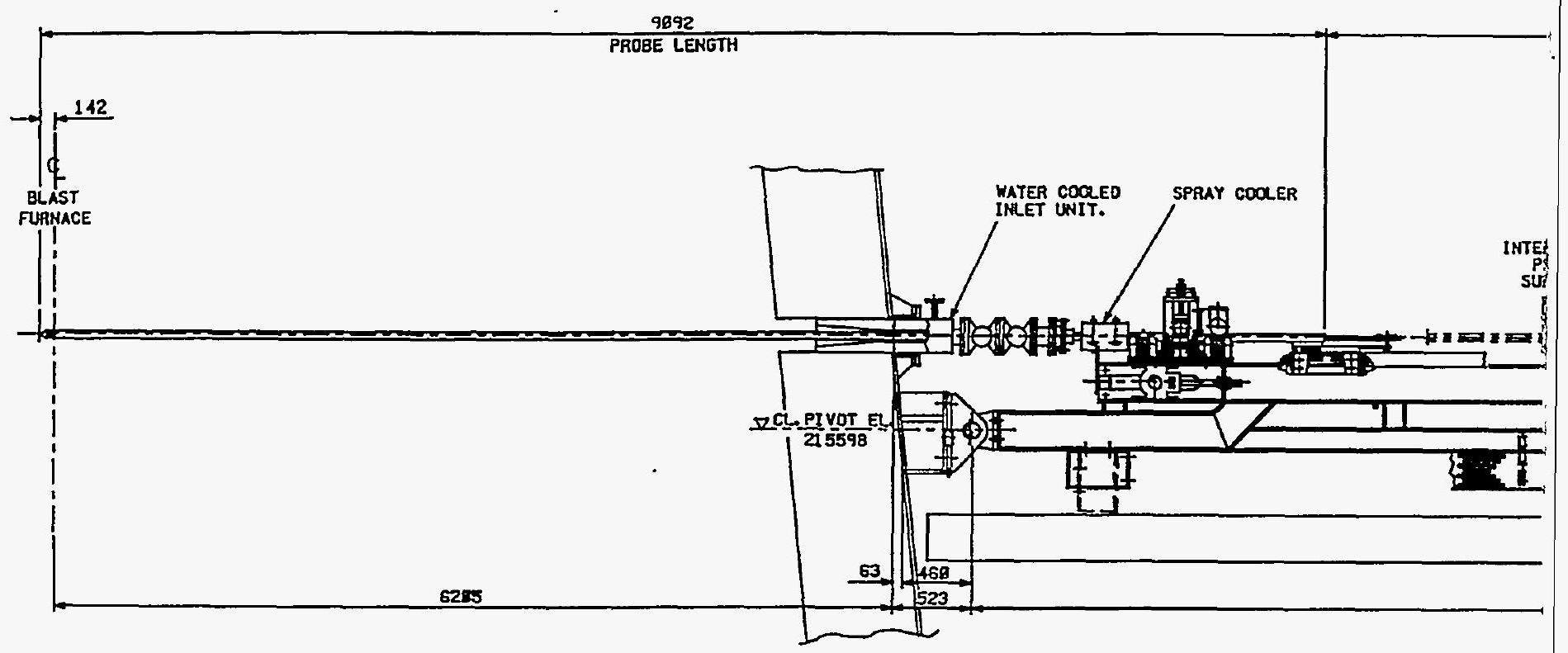

ELEVATION

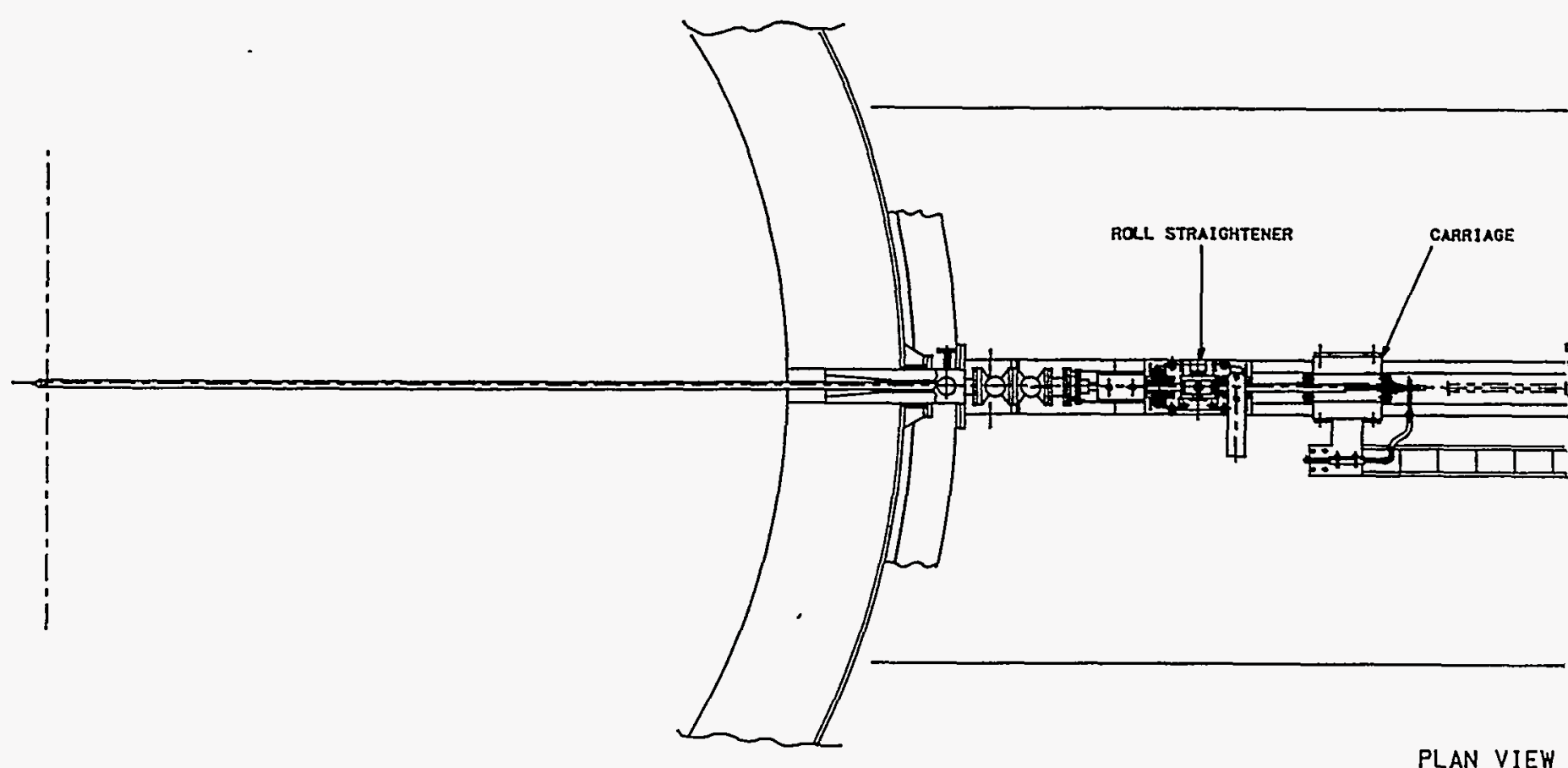

PLAN VIEW 
7325

MOAMAL TRAVEL
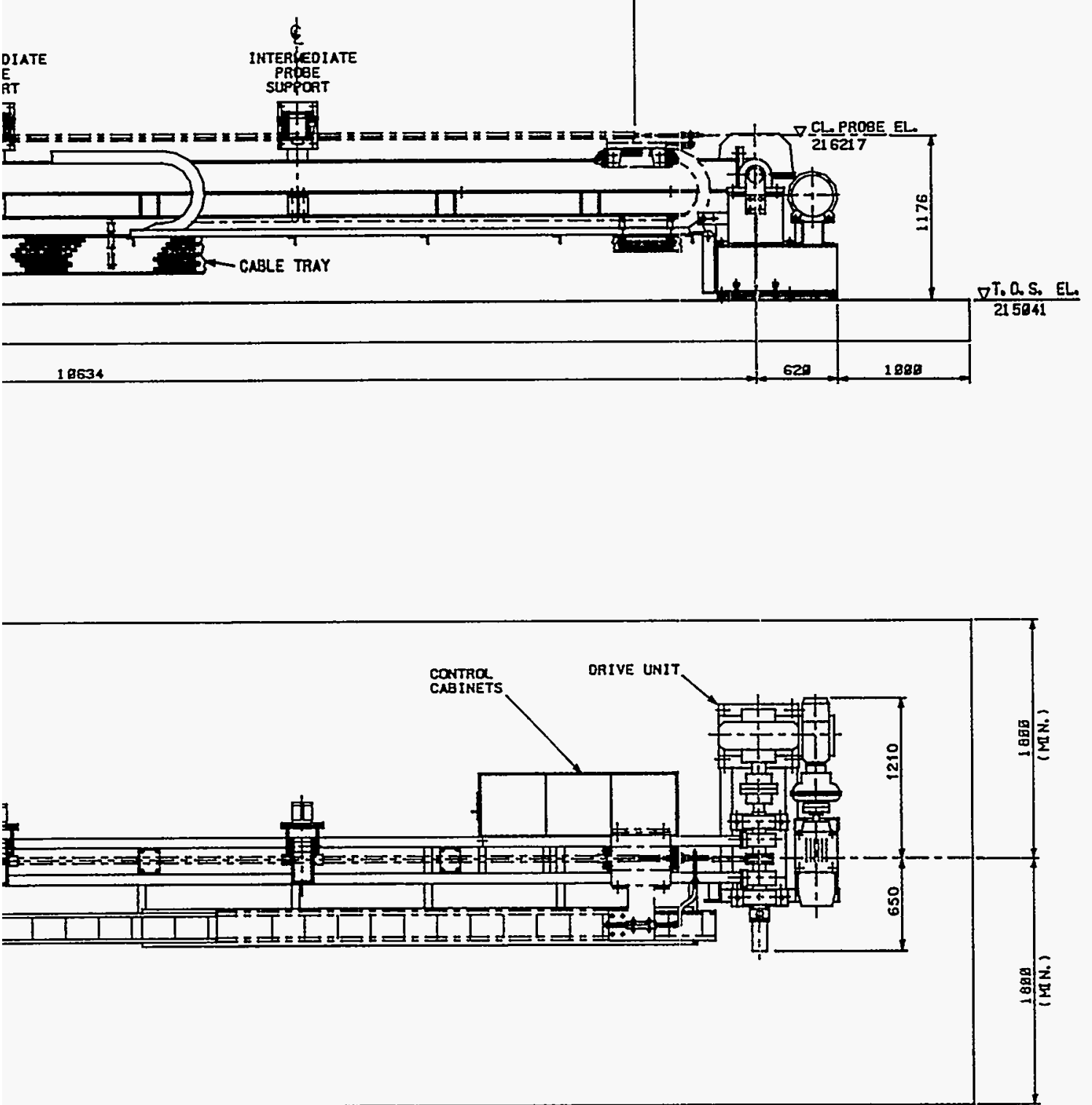

. 